Portland State University

PDXScholar

Fall 1-25-2019

\title{
The Role of Teacher Autonomy Support Across the Transition to Middle School: its Components, Reach, and Developmental Effects
}

Julia Sara Dancis

Portland State University

Follow this and additional works at: https://pdxscholar.library.pdx.edu/open_access_etds

Part of the Developmental Psychology Commons, and the Educational Psychology Commons Let us know how access to this document benefits you.

Recommended Citation

Dancis, Julia Sara, "The Role of Teacher Autonomy Support Across the Transition to Middle School: its Components, Reach, and Developmental Effects" (2019). Dissertations and Theses. Paper 4727.

https://doi.org/10.15760/etd.6611

This Thesis is brought to you for free and open access. It has been accepted for inclusion in Dissertations and Theses by an authorized administrator of PDXScholar. Please contact us if we can make this document more accessible: pdxscholar@pdx.edu. 
The Role of Teacher Autonomy Support Across the Transition to Middle School:

Its Components, Reach, and Developmental Effects

by

Julia Sara Dancis

A thesis submitted in partial fulfillment of the requirements for the degree of

\section{Master of Science}

in

Psychology

Thesis Committee:

Ellen Skinner, Chair

Thomas Kindermann

Andrew Mashburn

Portland State University

2018 


\begin{abstract}
Building upon self-determination theory (Deci \& Ryan, 1985; 2000), this study sought to ascertain the reach of teacher autonomy support beyond its well-documented impact on student autonomy and engagement to include student competence and relatedness, as well as to parse apart specific teacher behaviors that comprise autonomy support (i.e., respect, choice, relevance, coercion) and their unique influences on the multiple motivational outcomes, surrounding the transition to middle school. These questions were examined using information from 224 fifth graders, 339 sixth graders, and 345 seventh graders attending elementary and middle schools in a predominantly Caucasian working and middle class school district.

Regression analyses, predicting change in student motivation over time, revealed that students' experiences of their teachers' autonomy support in the fall predicted changes in student competence, relatedness, and engagement from fall to spring. Although teacher autonomy support was positively connected to student autonomy in correlational analyses, it did not predict changes in student autonomy from fall to spring. Unique effect analyses regressing each of these motivational outcomes on all four components of teacher autonomy-support revealed that respect, relevance, and coercion were unique predictors of each outcome concurrently, but that choice only made a unique contribution to autonomy and relatedness.
\end{abstract}

Developmental patterns extracted from multiple regression analyses in all three grade samples indicate that respect is most predictive of fifth grade student motivation, respect and coercion are most salient for sixth grade motivation, and respect, coercion 
and relevance together are most central to seventh grade students. MANOVA analyses of mean levels showed the expected patterns of differences, namely: compared to fifth graders, sixth graders reported lower levels of teacher autonomy support (and every component) and seventh graders showed even lower levels still. Further, students reported lower levels of all four motivational outcomes with the same pattern as autonomy support differences. MANCOVA analyses examined whether grade differences in teacher autonomy support could account for this pattern of grade differences in motivational outcomes. When analyses controlled for levels of teacher autonomy support, mean levels of relatedness were no longer significantly different across grades. Although still significant, MANCOVA analyses for autonomy, competence, and engagement showed much smaller $F$-values when teacher autonomysupport was entered into the model.

Together, these findings illustrate that teacher autonomy support does predict student competence and relatedness, in addition to autonomy and engagement. Additionally, it highlights the importance of several components of teacher autonomy support, especially for middle school students. Finally, it points to the need for further investigation on how teacher autonomy support, as an organizational construct and as separated by its components, impacts key motivational outcomes for students in different grades surrounding the middle school transition. Implications for researchers and educational practitioners are discussed. 


\section{Acknowledgements}

It is with sincere gratitude that I acknowledge my thesis chair, Dr. Ellen Skinner, for the tremendous mentorship she has given me throughout this process. Ellen, thank you for your high expectations for my output that stretched me to be a better researcher, writer, and thinker. Thank you to my other thesis committee members-Dr. Thomas Kindermann and Dr. Andrew Mashburn—for reading this very long document and for providing me encouraging words and probing questions throughout the thesis process. I would also like to thank my cohort and lab mates for their continued support over the past three years. In particular, Jaiya, thank you for always offering another perspective, strategy, or pathway forward through this arduous endeavor. I am deeply indebted to my parents and sibling — making you all proud is one of my biggest motivators. Finally, I'd like to mention my partner, Neal, for those homemade lattes that powered some very deep thinking. 


\section{Table of Contents}

ABSTRACT

ACKNOWLEDGEMENTS

iii

LIST OF TABLES

vi

LIST OF FIGURES

$x$

CHAPTER I: PROBLEM STATEMENT

CHAPTER II: LITERATURE REVIEW

Self-Determination Theory

Academic Engagement

Transition to Middle School

Autonomy Support

CHAPTER III: THE CURRENT STUDY

Expanded Motivational Outcomes

Components of Autonomy Support

Developmental Differences

55

Research Questions and Hypotheses

CHAPTER IV: RESEARCH DESIGN AND METHODS

Participants

Design And Procedure

Measures

CHAPTER V: RESULTS

Initial Analyses

Descriptive Statistics and Measurement Properties

Research Question 1: Effects of Teacher Autonomy Support on Changes in Students' Motivational Outcomes, Overall and Differentially by Grade Level.

RQ1a.

RQ1b. 
Research Question 2: Individual Effects of Each of the Components of Teacher Autonomy Support on Students' Motivational Outcomes, Overall and Differentially by Grade Level.

RQ2a.

RQ2b.

Research Question 3: Unique Effects of The Components of Teacher Autonomy Support on Students' Motivational Outcomes (and Changes in Their Motivational Outcomes), Overall and for Each Grade Level.

RQ3a.a.

RQ3a.b.

Research Question 4: Normative Grade Differences in Teacher Autonomy Support and

Students' Motivational Outcomes.

RQ4a.

RQ4b.

Research Question 5: Buffering Effects of Autonomy Support on Student Motivation during the Middle School Transition. 


\section{List of Tables}

Table 2.1 Summary of Studies Illustrating Academic Benefits of Autonomy Support 26

Table 3.1 Autonomy Support Measures using Respect Component 42

Table 3.2 Autonomy Support Measures using Choice Component, in Chronological Order

Table 3.3 Autonomy Support Measures using Relevance Component, in Chronological Order

Table 3.4 Autonomy Support Measures using Coercion Component, in Chronological Order

Table 5.1 Summary of Descriptive Statistics for each Construct 70

Table 5.2 Inter-Correlations among Constructs in Fall and Spring 71

Table 5.3 Intra-Correlations among Autonomy Support Components in Fall and Spring 72

Table 5.4 t-test Results Comparing Males and Females on Motivational Outcomes in Fall and Spring 73

Table 5.5 Alpha Levels of Scales by Grade $\quad 79$

Table 5.6 Descriptive Statistics, including Mean Levels and Standard Deviations, by Grade

Table 5.7 Inter-Correlations among Constructs in Fall and Spring, for Fifth, Sixth, and Seventh Grade Students

Table 5.8 Individual Effects of Four Components of Teachers' Provision of Autonomy Support in Fall on Changes in Student Autonomy from Fall to Spring

Table 5.9 Individual Effects of Four Components of Teachers' Provision of Autonomy

Support in Fall on Changes in Student Competence from Fall to Spring

Table 5.10 Individual Effects of Four Components of Teachers' Provision of Autonomy Support in Fall on Changes in Student Relatedness from Fall to Spring

Table 5.11 Individual Effects of Four Components of Teachers' Provision of Autonomy Support in Fall on Changes in Student Relatedness from Fall to Spring 92

Table 5.12 Alpha Levels of Fall Autonomy Support Scales by Grade

Table 5.13 Unique Effects of Four Components of Teachers' Provision of Autonomy Support in Fall on changes in Student Autonomy from Fall to Spring, Differentially by Grade

Table 5.14 Unique Effects of Four Components of Teachers' Provision of Autonomy Support in Fall on changes in Student Competence from Fall to Spring, Differentially by Grade 
Table 5.15 Unique Effects of Four Components of Teachers' Provision of Autonomy Support in Fall on changes in Student Relatedness from Fall to Spring, Differentially by Grade

Table 5.16 Unique Effects of Four Components of Teachers' Provision of Autonomy Support in Fall on changes in Student Engagement from Fall to Spring, Differentially by Grade

Table 5.17 Unique Effects of Four Components of Teachers' Provision of Autonomy Support in Fall on Student Autonomy in Fall 103

Table 5.18 Unique Effects of Four Components of Teachers' Provision of Autonomy Support in Fall on Student Competence in Fall 103

Table 5.19 Unique Effects of Four Components of Teachers' Provision of Autonomy Support in Fall on Student Relatedness in Fall 103

Table 5.20 Unique Effects of Four Components of Teachers' Provision of Autonomy Support in Fall on Student Engagement in Fall

Table 5.21 Unique Effects of Four Components of Teachers' Provision of Autonomy Support in Fall on Changes in Student Autonomy from Fall to Spring

Table 5.22 Unique Effects of Four Components of Teachers' Provision of Autonomy Support in Fall on Changes in Student Competence from Fall to Spring

Table 5.23 Unique Effects of Four Components of Teachers' Provision of Autonomy Support in Fall on Changes in Student Relatedness from Fall to Spring 106

Table 5.24 Unique Effects of Four Components of Teachers' Provision of Autonomy Support in Fall on Changes in Student Engagement from Fall to Spring

Table 5.25 Unique Effects of Four Components of Teachers' Provision of Autonomy

Support in Fall on Fifth Grade Student Autonomy in Fall 108

Table 5.26 Unique Effects of Four Components of Teachers' Provision of Autonomy Support in Fall on Sixth Grade Student Autonomy in Fall

Table 5.27 Unique Effects of Four Components of Teachers' Provision of Autonomy Support in Fall on Seventh Grade Student Autonomy in Fall

Table 5.28 Unique Effects of Four Components of Teachers' Provision of Autonomy Support in Fall on Fifth Grade Student Competence in Fall

Table 5.29 Unique Effects of Four Components of Teachers' Provision of Autonomy Support in Fall on Sixth Grade Student Competence in Fall

Table 5.30 Unique Effects of Four Components of Teachers' Provision of Autonomy Support in Fall on Seventh Grade Student Competence in Fall

Table 5.31 Unique Effects of Four Components of Teachers' Provision of Autonomy Support in Fall on Fifth Grade Student Relatedness in Fall 
Table 5.32 Unique Effects of Four Components of Teachers' Provision of Autonomy Support in Fall on Sixth Grade Student Relatedness in Fall

Table 5.33 Unique Effects of Four Components of Teachers' Provision of Autonomy

Support in Fall on Seventh Grade Student Relatedness in Fall

Table 5.34 Unique Effects of Four Components of Teachers' Provision of Autonomy

Support in Fall on Fifth Grade Student Engagement in Fall

Table 5.35 Unique Effects of Four Components of Teachers' Provision of Autonomy Support in Fall on Sixth Grade Student Engagement in Fall

Table 5.36 Unique Effects of Four Components of Teachers' Provision of Autonomy

Support in Fall on Seventh Grade Student Engagement in Fall

Table 5.37 Unique Effects of Four Components of Teachers' Provision of Autonomy

Support in Fall on Changes in Fifth Grade Student Autonomy from Fall to Spring 113

Table 5.38 Unique Effects of Four Components of Teachers' Provision of Autonomy

Support in Fall on Changes in Sixth Grade Student Autonomy from Fall to Spring 114

Table 5.39 Unique Effects of Four Components of Teachers' Provision of Autonomy

Support in Fall on Changes in Seventh Grade Student Autonomy from Fall to Spring

Table 5.40 Unique Effects of Four Components of Teachers' Provision of Autonomy

Support in Fall on Changes in Fifth Grade Student Competence from Fall to Spring

Table 5.41 Unique Effects of Four Components of Teachers' Provision of Autonomy

Support in Fall on Changes in Sixth Grade Student Competence from Fall to Spring

Table 5.42 Unique Effects of Four Components of Teachers' Provision of Autonomy

Support in Fall on Changes in Seventh Grade Student Competence from Fall to Spring

Table 5.43 Unique Effects of Four Components of Teachers' Provision of Autonomy

Support in Fall on Changes in Fifth Grade Student Relatedness from Fall to Spring 117

Table 5.44 Unique Effects of Four Components of Teachers' Provision of Autonomy

Support in Fall on Changes in Sixth Grade Student Relatedness from Fall to Spring

Table 5.45 Unique Effects of Four Components of Teachers' Provision of Autonomy

Support in Fall on Changes in Seventh Grade Student Relatedness from Fall to Spring

Table 5.46 Unique Effects of Four Components of Teachers' Provision of Autonomy

Support in Fall on Changes in Fifth Grade Student Engagement from Fall to Spring 
Table 5.47 Unique Effects of Four Components of Teachers' Provision of Autonomy Support in Fall on Changes in Sixth Grade Student Engagement from Fall to Spring

Table 5.48 Unique Effects of Four Components of Teachers' Provision of Autonomy Support in Fall on Changes in Seventh Grade Student Engagement from Fall to Spring

Table 5.49 Teachers' Provision of Autonomy Support and Components in fall Across Fifth, Sixth, and Seventh Grades

Table 5.50 Student Motivational Outcomes Across Fifth, Sixth, and Seventh Grades

Table 5.51 Student Motivational Outcomes Across Fifth, Sixth, and Seventh Grades Controlling for Autonomy Support

Table 5.52 Student Motivational Outcomes Across Fifth, Sixth, and Seventh Grades for Students with High, Moderate, and Low Levels of Teacher Autonomy Support 


\section{List of Figures}

Figure 3.1. The Conceptual Model

Figure 5.1. Teacher autonomy support in fall as a predictor of student autonomy in spring, controlling for student autonomy in fall.

Figure 5.2. Teacher autonomy support in fall as a predictor of student competence in spring, controlling for student competence in fall. 75

Figure 5.3. Standardized betas of teacher autonomy support in fall as a predictor of student relatedness in spring, controlling for student relatedness in fall. 76

Figure 5.4. Teacher autonomy support in fall as a predictor of student engagement in spring, controlling for student engagement in fall.

Figure 5.5. Testing grade differences in the effects of teacher autonomy support as a predictor of changes in students' autonomy, by including an interaction term for the cross-product of autonomy support and grade level

Figure 5.6. Testing grade differences in the effects of teacher autonomy support as a predictor of changes in students' competence, by including an interaction term for the cross-product of autonomy support and grade level

Figure 5.7. Testing grade differences in the effects of teacher autonomy support as a predictor of changes in students' relatedness, by including an interaction term for the cross-product of autonomy support and grade level 84

Figure 5.8. Standardized betas of teacher autonomy support in fall as a predictor of student relatedness in Spring, controlling for student relatedness in fall for fifth grade students.

Figure 5.9. Standardized betas of teacher autonomy support in fall as a predictor of student relatedness in Spring, controlling for student relatedness in fall for sixth grade students.

Figure 5.10. Standardized betas of teacher autonomy support in fall as a predictor of student relatedness in spring, controlling for student relatedness in fall for seventh grade students.

Figure 5.11. Testing grade differences in the effects of teacher autonomy support as a predictor of changes in students' engagement, by including an interaction term for the cross-product of autonomy support and grade level

Figure 5.12. Standardized betas of teacher autonomy support in fall as a predictor of student engagement in spring, controlling for student engagement in fall for sixth grade students. 
Figure 5.13. Mean Levels of Teacher Autonomy Support and Components in Fifth, Sixth, and Seventh Grades

Figure 5.14. Mean Levels of Student Motivational Outcomes in Fifth, Sixth, and Seventh Grades 125

Figure 5.15. Mean Levels of Student Autonomy in Fifth, Sixth, and Seventh Grades for Students with Low, Moderate, and High Teacher Autonomy Support 132

Figure 5.16. Mean Levels of Student Competence in Fifth, Sixth, and Seventh Grades for Students with Low, Moderate, and High Teacher Autonomy Support 132

Figure 5.17. Mean Levels of Student Relatedness in Fifth, Sixth, and Seventh Grades for Students with Low, Moderate, and High Teacher Autonomy Support 133

Figure 5.18. Mean Levels of Student Engagement in Fifth, Sixth, and Seventh Grades for Students with Low, Moderate, and High Teacher Autonomy Support 133 


\section{Chapter I: Problem Statement}

Research suggests that student motivation is shaped by a variety of factors, ranging from student-centered characteristics, such as their perceptions about school, to classroom- and school-level characteristics, such as curricula and school budget. Chief among the factors that influence student motivation are student-teacher relationships. Research has shown that the quality of students' relationships with their teachers shapes their intrinsic motivation, self-efficacy, belongingness, and engagement with learning activities (Brophy, 1986; Martin \& Dowson, 2009; Pianta, Hamre, \& Allen, 2012; Wentzel 2010). As a result of these findings, researchers have become interested in identifying the specific characteristics of student-teacher relationships that might enhance student motivation (Wentzel, 2009). In recent decades, many of these factors have coalesced into a conceptualization of motivation called Self-Determination Theory (SDT), which highlights three basic needs students experience: relatedness, competence, and autonomy (Connell \& Wellborn, 1991; Deci \& Ryan, 2000). When these needs are met, SDT posits, students' academic motivation is optimized. Teachers can support students' need for relatedness through involvement, competence through the provision of structure, and autonomy through agentic learning experiences, or autonomy support (Connell \& Wellborn, 1991; Deci \& Ryan, 2000).

These supports are key throughout students' academic careers, but may be especially important during the adaptation to middle school. During this transition, adolescents experience biological, cognitive, and social-emotional changes (Roeser, Eccles, \& Sameroff, 2000), as they simultaneously navigate a plethora of school 
upheavals, such as different school buildings, increased class sizes, more distant studentteacher relationships, and more controlling classroom climates (Anderman \& Mueller, 2010; Eccles et al., 1993; Roeser, Eccles, \& Sameroff, 2000). Not surprisingly, this time is also marked by considerable declines in academic motivation and school attendance (Eccles \& Midgley, 1989), expectations of academic success (Anderman \& Mueller, 2010), and increases in misconduct (Simmons \& Blyth, 1987). Fortunately, these negative changes are not universal; some students maintain their motivation and engagement over this transition (Ryan \& Deci, 2016). In fact, some studies suggest that, if teachers provide motivational buffers for students, through their use of involvement, structure, and autonomy support, the declines following a school transition may be reduced, or even disappear. However, the very buffer that can protect students from this array of negative outcomes, student-teacher relationships, that is, also seems to show declines (according to both students and teachers) at the onset of middle school. Therefore, this motivationally vulnerable moment seems especially important as a potential turning point in students' academic careers.

Past research suggests that of the motivational supports that students receive, autonomy support may be in particularly short supply. It shows the lowest mean levels, as compared with involvement and structure (Reeve et al., 2004) and although all three supports (involvement, structure, and autonomy support) from teachers tend to decline in middle school, autonomy support seems to experience the steepest declines (Reeve et al., 2004). These findings do not bode well for students entering middle school, as it appears that the need for autonomy becomes even more salient for students reaching adolescence 
(Cobb, 1998; Feldman \& Quartman, 1988; Hill \& Holmbeck, 1986; Steinberg \& Silverberg, 1986). As such, discovering ways to foster autonomy-supportive instruction for students during the transition to middle school takes on added importance.

A great deal of research has found that in addition to increased motivation, classrooms that support student autonomy provide multiple other positive effects (Reeve, 2006; Reeve, Jang, Carrell, Jeon, \& Barch, 2004), including greater perceived student competence (Deci et al., 1981), enhanced creativity (Koestner, Ryan, Bernieri, \& Holt, 1984), increased conceptual understanding (Benware \& Deci, 1984), positive emotionality (Patrick, Skinner, \& Connell, 1993), better academic performance (Boggiano, Flink, Shields, Seelbach, \& Barrett, 1993), and lower dropout rates (Vallerance, Fortier, \& Guay, 1997). As research on autonomy support continues, more attention has been given to identifying construct components, in order to better locate classroom targets for improvement (Assor \& Kaplan, 2001; Reeve et al., 2006; Skinner \& Belmont, 1993). Breaking down autonomy support can offer actionable information to educators on how to optimize their students' experiences, through authentic learning activities, in practical and developmentally appropriate ways. As the essential elements of autonomy support are identified, researchers may be able to determine how each component functions uniquely. It is possible that one or more of them are more important than the others at different times. Locating these gaps will guide teachers toward the most immediate needs of their students, namely, motivational buffers that are most likely to be missing at certain developmental stages. By examining autonomy support through its 
components, researchers can help teachers stabilize student motivation across a normatively precarious school transition.

Ultimately, we are most interested in whether protecting autonomy support through the transition will, in turn, also protect student motivation. It is with this new understanding of autonomy support that we can better assess what students need during the transition to middle school. Examining both the components of autonomy support, as well as its relations with motivational outcomes across transitional years will help teachers develop strategies for optimizing student motivation. Thus, the purpose of the current study is to identify the components of autonomy support and to evaluate their unique contributions to students' motivational outcomes across the middle school transition. 


\section{Chapter II: Literature Review}

Researchers emphasize the important roles that motivation and engagement play in student achievement, retention, and learning (Appleton, Christenson, \& Furlong, 2008; Connell \& Wellborn, 1991; Janosz, Archambault, Morizot, \& Pagani, 2008; Ullah \& Wilson, 2007). Given the amount of instructional time students spend with their teachers, it is no surprise that teachers make major contributions to their students' academic engagement. Teachers foster student engagement through curricula, instructional methods, and emotional climate (Brophy, 1986). Permeating methods and climate is the way in which teachers relate to and interact with their students. Research tells us that the nature of students' relationships with their teachers has lasting academic effects (Brophy, 1986; Martin \& Dowson, 2009; Pianta, Hamre, \& Allen, 2012; Wentzel 2016). Specifically, well-documented teacher practices that bolster student achievement include providing emotional support, clear communication and expectations, help and advice, and emotionally and physically safe environments (for review, Wentzel, 2016).

\section{Self-Determination Theory}

One theory that has pulled together multiple ways in which teachers can promote student motivation is self-determination theory (SDT; Deci \& Ryan, 1985; Deci \& Ryan, 2000; Reeve, 2002). The underlying assumption of SDT is that humans are naturally curious and will interact with an enterprise, like school, to the extent that it meets their needs. Thus, schools that are able to meet certain innate motivational needs will cultivate high levels of motivated and engaged students. Three key motivational needs have been 
identified by researchers as fundamental to optimizing students' natural inclination toward curiosity and enthusiastic attention: relatedness, competence, and autonomy (for review, see Ryan \& Deci, 2016). Conversely, when these three motivational needs are not satisfied, students respond with diminished academic motivation, stunted development, and poor performance (Deci, Vallerand, Pelletier, \& Ryan, 1991). An overview of students' experiences with these motivational needs, including benefits found in the research of meeting these needs and ways teachers can support these needs follow.

Sense of Relatedness. Relating to others and forming strong interpersonal bonds seems to be universally sought out (Baumeister \& Leary, 1995). Researchers have found that school is no exception and have given attention to classroom contexts that make students feel connected, included, and safe. Fostering relatedness for students means reaching underneath math and science curricula and cushioning them with climates that cultivate inclusion and belonging. Decades of research support the notion that students with a strong sense of classroom and school belonging also experience numerous academic benefits (for review, Osterman 2000), including: high importance of school work, expectations of success, and persistence to graduate (Goodenow \& Grady, 1993); school enjoyment and positivity (Roeser, Midgley, \& Urdan, 1996); academic motivation and engagement (Roeser, Eccles, \& Sameroff, 1998; Furrer \& Skinner, 2003, respectively); and academic achievement (Roeser, Eccles, \& Sameroff, 1998). Conversely, the absence of sense of relatedness, or feeling neglect, is related to lower grades, behavior problems, and school dropout (for review, Osterman, 2000). 
According to SDT, teachers can cultivate relatedness amongst their students through involvement (Wentzel, 2016). Involvement can be expressed by prioritizing individual relationships with students, demonstrating authentic interest in students' emotional well-being, and by providing emotional support. The resulting feelings of belonging are thought to increase student adoption of classroom norms and teacher values, the desire to positively contribute to class functioning, and academic engagement, achievement, and persistence (Wentzel, 2016).

Perceived Competence. The second motivational need identified by SDT is the intrinsic desire to effectively navigate through one's environment, to master new tasks, and to conquer challenges. In school, this equates to accomplishing assignments, performing well on exams, and generally feeling capable of academic success. Students who see themselves as competent exhibit higher levels of academic motivation (Roeser, Eccles, \& Sameroff, 1998); emotional and behavioral engagement (Patrick, Skinner, \& Connell, 1993; Skinner, Wellborn, \& Connell 1990; Skinner, Zimmer-Gembeck, \& Connell, 1998); prosocial behavior (Bandura, Barbaranelli, Caprara, \& Pastorelli, 1996); and academic achievement (Marsh, 1990; Roeser, Eccles, \& Sameroff, 1998; for review, Stipek \& Weisz, 1981).

SDT suggests that teachers can encourage students' perceptions of competence by providing structure. By clearly communicating behavioral and academic expectations and consistently enforcing those expectations, students can anticipate how their behavior and work will be evaluated. These consistent patterns inform students how to succeed (Wang \& Eccles, 2013). Conversely, when teachers create classroom environments marked by 
chaos, namely ones in which expectations are constantly changing and in which rewards and punishments seem arbitrary, the potential for students' competence is undermined (Skinner, Zimmer-Gembeck, \& Connell, 1998).

Autonomy Orientation. Third, the need for autonomy is defined as the need for genuine and agentic interactions with one's environment (Connell \& Wellborn, 1991). Autonomy, in particular, is related to intrinsic motivation, which is the natural desire to engage in inherently fun and interesting activities (Ryan \& Deci, 2016). Autonomous students exhibit enhanced creativity (Koestner, Ryan, Bernieri, \& Holt, 1984); increased conceptual understanding (Benware \& Deci, 1984); more positive emotionality (Patrick, Skinner, \& Connell, 1993); higher academic motivation (Roeser, Eccles, \& Sameroff, 1998); better academic performance (Boggiano, Flink, Shields, Seelbach, \& Barrett, 1993; Roeser, Eccles, \& Sameroff, 1998); and lower dropout rates (Vallerance, Fortier, \& Guay, 1997).

National standards, benchmarks, and common core curricula make this motivational need particularly challenging to meet in the school context. Additionally, attending to each student's unique academic pursuit may not be possible for teachers in large classrooms. Despite these dilemmas, several strategies are thought to support students' autonomy. A few autonomy-supportive practices include: introducing choice whenever possible, limiting classroom rules and clearly stating why those rules exist, keeping the content relevant to students' experiences, and giving respect to students' needs (Connell, 1990; Patrick, Skinner, \& Connell, 1993; Skinner \& Belmont, 1993; Skinner \& Wellborn, 1994). Threats to a student's sense of autonomy in the classroom 
include punishment, competitive rather than cooperative activities, extrinsic reinforcements, and seemingly arbitrary rules (Reeve \& Jang., 2006; Skinner \& Wellborn, 1994). Together, these threats are known as coercion, and not only undermine students' feelings of autonomy, but also, in turn, threaten student motivation and engagement.

\section{Academic Engagement}

Students who experience themselves as competent, autonomous, and connected members of the classroom are more likely to show heightened levels of academic engagement. Here, academic engagement is defined as active and enthusiastic involvement in learning, which has behavioral and emotional components (For review, Fredricks, Blumenfeld, \& Paris, 2004; Skinner, Kindermann, Connell, \& Wellborn, 2009). Behavioral engagement refers to active participation in academic work such as, positive conduct, adherence to classroom norms, effort, attention, and question-asking (for review, Fredricks, Blumenfeld, \& Paris, 2004). Emotional engagement is less visible and includes academic interest, enthusiasm, and enjoyment in learning activities. Taken together, researchers and educators alike put great value on finding ways to foster engagement.

Several decades of research suggest that, in addition to its intrinsic value, engagement is key for students' academic success, including performance, retention, and graduation (For review, Fredricks, Blumenfeld, \& Paris, 2004). The increased demands on students to meet national educational standards, in many cases, put student 
engagement in jeopardy. As such, teachers are tasked with the challenge of maintaining student engagement, in spite of this added pressure. Fortunately, researchers find that students' academic engagement is not fixed. So, with proper intervention, students who exhibit low levels of engagement at one point in time can and do foster it at another. For example, a targeted intervention aimed at enhancing student engagement through mentoring, called Check \& Connect, has been linked to academic success (for review, Reschly \& Christenson, 2012). Middle school students who have participated in Check \& Connect have higher rates of enrollment, shorter high school graduation timelines, increased homework completion, more interest in school, better relationships with peers, greater persistence of challenging academic tasks, and heightened teacher respect as compared to middle school students who have not participated in Check \& Connect (for review, Reschly \& Christenson, 2012). These and other findings (e.g., Guthrie, Wigfield, \& You, 2012; Ladd \& Dinella, 2009; Lam, Wong, Yang, Liu, 2012) suggest that engagement is a malleable process, shaped by the school environment. Thus, interventions like Check \& Connect, targeted at increasing engagement, have strong implications for optimizing academic success (Birch \& Ladd, 1997; for review, Reschly \& Christenson, 2012).

Conclusion. As was illustrated through self-determination theory and student engagement findings, motivating students is vital for academic success. As such, developmental moments when student motivation is compromised may be particularly important to identify. The next section reviews the literature on a period in which 
researchers see declines in the satisfaction of motivational needs and academic engagement.

\section{Transition to Middle School}

Although engagement is an important predictor of students' performance and functioning across their entire educational career, it shows marked declines over school transitions (Anderman \& Mueller, 2010; Gottfried, Fleming, \& Gottfried, 2001; Harter, 1981; Roeser, Eccles, \& Sameroff, 2000; Sosic-Vasic, Keis, Lau, Spitzer, \& Streb, 2015; for review, Mahatmya, Lohman, Matjasko, \& Feldman Farb, 2012). For example, Wylie and Hodgen's (2012) longitudinal study followed over 500 students from the end of elementary school through middle school (ages 10 to 16) and found that overall engagement significantly declined over the transition to middle school. However, many students with higher levels engagement in elementary school sustained a comparatively high level of engagement through the end of middle school. Students with lower initial levels of engagement, on the other hand, reported more variable levels of engagement subsequently. These findings suggest that overall, students experience declines in engagement, but that these declines are not inevitable.

Researchers have created a framework, called stage-environment fit theory, to explain the overall decline in student engagement over the transition to middle school (Eccles \& Midgley, 1989). This framework is based on the recognition that, at the same time students experience marked changes in the organization of schooling, they also undergo significant changes of their own (Anderman \& Mueller, 2010; Wentzel, Muenks, 
McNeish, \& Russell, 2016). Stage-environment fit theory points to the misalignment between students' needs during this developmental period (i.e., stage) and the learning context that middle school affords them (i.e., environment). Thus, students' academic downturn can be best understood by examining the interaction between adolescent needs and the middle school context.

Development During Early Adolescence. Adolescence, the time of puberty, is marked by biological, cognitive, and social-emotional changes that occur roughly between 10 to 14 years of age (Anderman \& Mueller, 2010; Roeser, Eccles, \& Sameroff, 2000). Researchers find that many adolescents experience declines in general functioning. For example, Simmons and colleagues (Simmons, Rosenberg, \& Rosenberg, 1973; Simmons \& Blyth, 1987) found that early adolescents experience increased selfconsciousness, more depressed affect, reduced participation in extracurricular activities, and a host of other issues associated with identity development, peer relationships, and academic achievement. Specific declines in adolescent motivation have also been cataloged in this research (e.g., Gottfried, Fleming, \& Gottfried, 2001; Harter, 1981). Harter (1981) found declines in challenge-seeking, curiosity-expression, and independent task-mastery. Gottfried, Fleming, and Gottfried (2001) documented reductions in intrinsic motivation for math, science, and reading, but not for social studies. Consistent with stage-environment fit theory, these authors argue that these decreases are neither inevitable nor universal, but rather a function of changes in educational practices.

Despites these declines in academic and general functioning, adolescents also experience improvements in cognition, including increased sophistication and complexity 
of decision-making abilities as compared to younger children (Lewis, 1981). These newfound abilities are paired with the desire to exercise decision-making skills, and so adolescents often seek out (and insist on) opportunities for choice more than younger children. Researchers also find that adolescence is marked by a hatching independence from family and an increased need for positive and productive relationships with teachers and peers (Anderman \& Mueller, 2010; Damon \& Hart, 1982; Selman, 1980). Fulfilling this increased need for autonomy, along with other nascent concerns, is dependent upon what the middle school environment affords.

Context Changes. When adolescents attend middle schools (comprising of sixth to eighth grade), they also experience changes to the school environment. For those students, entering sixth grade means entering a new building with new administrators, new teachers, and new staff. Additionally, the structure of middle school often differs greatly from elementary school. Whereas elementary school students stay with one teacher for the majority of the day (with the exception of lunch and weekly electives), middle school students are taught by four to eight teachers each day. This structure allows teachers to specialize in particular subjects, but as a result, student-teacher interactions are reduced to about forty-five minutes a day. This reduced student-teacher interaction, paired with the larger class sizes of middle school, decreases a teacher's ability to foster personal relationships with any given student. Both student- and teacherreports illustrate this decline in the quality of student-teacher relationships from elementary to middle school (Atkinson \& Atkinson, 1977; Eccles \& Midgely, 1989; Feldlaufer, Midgley, \& Eccles, 1988). In addition to added teachers, the changing student 
ecology may stunt the formation of solid friendships. Researchers have found that close peer networks and friend groups enhance school belonging (Wentzel, Muenks, McNeish, \& Russell, 2016; Osterman, 2000), while the change in peer composition in middle school may put student motivation and engagement even more in jeopardy.

Conclusion. There exists a disconnect between the aforementioned developmental and environmental changes associated with the middle school transition. At a time when students want more freedom and choice, they actually receive less in middle school than they did in elementary school (e.g., Brophy \& Evertson, 1976; Feldlaufer, Midgley, \& Eccles, 1988). Many middle school teachers rely on more coercive, rather than autonomy-supportive motivating strategies, which suppress students' intrinsic motivation (Harter, 1981). Although adolescents are able to perform more abstract reasoning, they are often given more trivial, and less cognitivelydemanding work. Just as they find themselves craving social bonds with peers and teachers, the limited social structures of middle school diminish this possibility. As a result, the typical middle school context thwarts motivation and engagement, and may be particularly harmful for early adolescents, given the other vulnerabilities of their developmental stage.

Fortunately, understanding the developmental mismatch helps diagnose potential underlying causes of declines in student motivation and engagement across the transition. As is documented in many research studies, bolstering middle school classrooms with teachers who provide high levels of attentive involvement, consistent and clear structure, and plenty of opportunities for agentic identity development (autonomy support), can 
buffer many students from sharp motivational declines (e.g., Roeser, Eccles, \& Sameroff, 2000; for review, Ryan \& Deci, 2016). Researchers suggest that it is the waning of teacher involvement, structure, and autonomy support that likely contributes to the downward spiral, and so it follows that by using these motivational styles, teachers may see significant improvements in students' engagement, achievement, and persistence over the middle school transition and beyond.

\section{Autonomy Support}

Numerous studies have found that, although all three motivational supports decrease during the middle school transition, this drop is much steeper for autonomy support than for structure and involvement (Reeve, et al., 2004; for review, Stroet, Opdenakker, \& Minnaert, 2013). These greater losses of autonomy support, as compared to structure and involvement, are amplified by lower initial levels (Tucker, Zayco, Herman, Reinke, Trujillo, Carraway, 2002). In addition to the provision of lower levels of autonomy support as compared to other supports, research suggests that student desire for autonomy is amplified during adolescence (Eccles \& Midgely, 1989). More than any other developmental period, adolescents are especially concerned with identity development, expression, and freedom—hallmarks of autonomy (Simmons \& Blyth, 1987). Literature on adolescent motivation suggests that boosting autonomy-supportive instruction for middle schoolers is particularly important.

Teachers support student autonomy by encouraging the pursuit of educational paths best suited for each student and giving them the space to pursue those unique paths 
(Assor \& Kaplan, 2001; Deci \& Ryan 1987; Reeve, 2006). Along with yielding increased autonomy orientation in students, researchers have found that supporting students' autonomy also benefits their academics in other ways. The following section outlines almost a dozen cross-sectional and longitudinal studies that link teacher provision of autonomy support to positive academic outcomes for students entering middle school. The majority of this work has been studied correlationally, but the few experimental studies on autonomy support will also be discussed.

Cross-Sectional Studies. Four studies examined the concomitant correlates of autonomy support in middle school. [1] Deci, Nezlek, and Sheinman (1981) examined the relation between teacher-rated autonomy support and students' perceptions of classroom climate, student intrinsic motivation, and perceived competence (cognitive, social, physical, and general). Teachers $(\mathrm{n}=35)$ were surveyed on their motivating styles via the Problems in Schools Questionnaire, which was created for this study. This questionnaire included eight school-related problem scenarios and four possible solutions to each problem. The solutions ranged from highly controlling to highly autonomous in nature and teachers were asked to rate the appropriateness of each potential solution on a one-to-seven scale. A composite score between -18 and +18 was created by weighing the highly controlling items by -2 , the moderately controlling items by -1 , the moderately autonomous items by +1 , and the highly autonomous items by +2 and then summing the scores. Students $(n=610$, grades 4,5 , and 6) completed deCharm's (1976) Classroom questionnaire in the fall and spring of one year. This questionnaire measured the extent to 
which students felt that their classroom climate supported their own intrinsic motivation. An adapted version of Harter's (1982) intrinsic versus extrinsic orientation scale measured student intrinsic motivation, and perceived competence was assessed in three specific domains: cognitive competence, social competence, and physical competence, as well as general self-worth.

Results showed that students of teachers with autonomous motivating styles rated their classrooms as being more autonomy-supportive, had higher levels of intrinsic motivation, and higher levels of general perceived competence. Results on cognitive, social, and physical perceptions of competence were less conclusive. Teachers' motivating styles were significantly associated with students' perceived cognitive competence in both fall and spring, and marginally with students' perceived social competence in fall, but not spring. Students' perceptions of their physical competence were not significantly related to teachers' motivating styles in either fall or spring.

[2] Sosic-Vasic, Keis, Lau, Spitzer, and Streb (2015) studied the connection between teacher-rated autonomy support, student intrinsic motivation, and executive functioning among elementary school students $(n=50$, grades 3 and 4$)$ and junior high school students $(\mathrm{n}=158$, grades 5 and 6$)$. Teachers reported on their autonomy support using a German translation of Deci et al.,'s (1981) Problems in Schools Questionnaire. Additionally, students completed computer-based executive function tests, as well as a questionnaire regarding their academic self-regulation. Results from multilevel modeling indicated that students of teachers who rated themselves as highly autonomy-supportive showed higher intrinsic motivation and executive functioning. Conversely, students of 
teachers who rated themselves as highly controlling showed higher external regulation styles.

[3] Ryan and Grolnick (1986) studied student perceptions of their teachers' autonomy support as it related to student perceived competence and control. Fourth through sixth grade students $(\mathrm{n}=140)$ completed deCharms' (1976) Origin Climate Questionnaire. Additionally, the students answered questions pertaining to their perceived competence and perceived control. Here, perceived competence related to students' self-worth (general) and perceptions of their academic ability (cognitive). The measurement of perceived control assessed the extent to which students found themselves to be in control of academic outcomes. Regression analyses revealed that the origin climate significantly predicted the students' self-report variables. Students who found their classroom environment to be autonomy-supportive also felt competent and in control of their academic outcomes.

In the second phase of this study, students were asked to write stories about pictures of classroom scenes. Stories were rated on their creativity, technical goodness, and effort. Additionally, raters coded the story for the extent to which the student in the picture was given volitional control; the extent to which the teacher in the picture was autonomy-supportive or coercive; and the amount of aggression expressed in the story. ANOVA analyses revealed that students who rated their classroom climate as high in origin wrote stories with higher volitional control and depicted their teachers as being more autonomy-supportive. These students also produced more creative stories and obtained marginally higher scores on technical goodness. The amount of aggression 
expressed and the effort put in by students did not significantly differ by origin climate rating. Thus, this study illustrates how students' perceptions of classroom climate, including autonomy support, are related to higher perceived competence, control, and creativity.

[4] Tucker, Zayco, Herman, Reinke, Trujillo, Carraway, and colleagues (2002) examined the role of teacher autonomy support in student autonomy, competence, relatedness, and engagement. One-hundred-seventeen students in first through twelfth grade were surveyed on teacher supports, namely autonomy support, structure, and involvement (adapted from RAPS-S; Institute for Research and Reform in Education, 1998), as well as the four motivational outcomes. Correlational analyses revealed that perception of teacher autonomy support was significantly and positively related to student autonomy, competence, relatedness, and engagement. However, in a multiple regression analysis using structure, involvement, and autonomy support to predict engagement, when controlling for grade level, only involvement significantly uniquely predicted engagement; autonomy support and structure did not. These results suggest that autonomy support does relate to all four motivational outcomes, but that the nature of these relations may be impacted by other motivational supports.

Longitudinal Studies. Three studies investigated the academic benefits of teacher autonomy support over time. [1] In a large longitudinal study of middle schoolers, Way, Reddy, and Rhodes (2007) followed 1,451 students from sixth to eighth grade and obtained student perceptions of opportunities for autonomy and student self-esteem, depressive symptoms, and behavior problems. Opportunities for autonomy was measured 
using a five-item subscale of the Perceived School Climate Scale (Center for Prevention Research and Development, 1993), and pertained to student decision-making. Crossdomain modeling, which incorporates growth curve modeling and covariance structure analysis, revealed that students' perception of opportunities for autonomy declined from sixth to eighth grade. Additionally, initial levels of teacher autonomy opportunities predicted change in student behavior problems over the three years. This finding exhibits temporal precedence needed to infer causality. Further, the decline in teacher autonomy opportunities positively related to the increases in adolescent behavior problems and depression and negatively related to increases in student self-esteem.

The combined cross-domain model depicted by the researchers only included significant paths, to which none of the outcome intercepts (initial levels of behavior problems, self-esteem, and depression) showed paths to the teacher autonomy opportunities slope (change in opportunities for autonomy). One can infer from this pictorial omission that the influence of teacher autonomy support on adolescent behavior problems, depression, and self-esteem is unidirectional, rather than bidirectional, in nature. These findings underscore the impact of autonomy support on students' wellbeing.

[2] Yu, Li, Wang, and Zhang (2016) surveyed Chinese seventh and eighth grade students $(\mathrm{n}=236)$ on student-perceived teacher provisions of autonomy support, feelings of autonomy, competence, relatedness, academic engagement, depression, and anxiety. Perceived autonomy support was measured using Jia et al.'s (2009) five-item measure. Structural equation modeling analyses showed that teacher autonomy support in the fall 
of seventh grade predicted higher levels of student autonomy, competence, and relatedness over the school year, which predicted higher student engagement from the spring of seventh grade to the fall of eighth grade, which in turn predicted lower anxiety and depression from the fall of eighth grade to the spring of eighth grade. This study illustrates the potential causal influence of autonomy support on autonomy, competence, relatedness, and engagement by predicting behavior over three school years.

[3] Vallerand, Fortier, and Guay (1997) used autonomy support to predict an important motivational outcome, namely, dropout. The researchers began by surveying ninth grade students on their perceptions of autonomy support from their teachers, school administrators, and parents adapted from Pelletier's (1992) Perceived Interpersonal Style Scale. Students were also asked about their own perceived competence, autonomy, academic motivation, and intentions to dropout of high school. The following year, the researchers obtained dropout information from the Ministry of Education and confirmed that information with each school.

The results of structural equation modeling of ninth grade data coincided largely with their psychological model, namely, students who experienced lower levels of autonomy support from their parents, teachers, and school administrators also experienced lower levels of autonomy. Similarly, students who perceived lower levels of autonomy support from their parents and teachers experienced lower levels of competence, as well. The students with lower perceived competence and autonomy also experienced less academic motivation. This motivation predicted intentions to persist or dropout, which ultimately predicted persistence or dropout behavior the following year. 
Experimental Studies. Four additional studies consider the role of autonomy support using experimental designs. [1] deCharms' (1976) quasi-experimental field study, examining the extent to which classrooms support students' intrinsic motivation, was the basis for several of the above studies because of its important measure. Over the course of three years, 48 fifth, sixth, and seventh grade teachers underwent a five-day residential training workshop and monthly meetings to strengthen their utilization of the origin-pawn concept. This concept refers to self-determination of one's own goals, as well as realistic expectations and execution of those goals, which has been translated as a sense of autonomy. Each year, students $(n=1,200)$ and teachers were surveyed on several dimensions of student achievement, punctuality, and attendance. As was revealed through ANCOVA analyses (covarying out IQ), students of teachers who underwent this autonomy-supportive training were found to have increased punctuality, attendance, intrinsic motivation, and academic achievement, as compared to students from the control conditions, whose teachers did not receive any training. Training effects were found to be the strongest for sixth students, as compared to seventh grade students.

[2] Grolnick and Ryan (1987) built upon their correlational study of autonomysupportive motivational styles by experimentally examining the impact of coercion on students' self-regulation, interest and enjoyment, feelings of pressure, and learning in the lab. In their study, 91 fifth grade students were given a reading task, with either coercive, autonomy-supportive, or no directions for the task. In the coercive directions, students were informed that their work would be graded, whereas the autonomy-supportive directions focused on learning outcomes. Students were surveyed on all outcome 
variables immediately after the task, and were tested again on their proficiency in the material one week later. Students in the autonomy-supportive and no-directions conditions reported experiencing significantly less pressure than students in the coercivedirections condition. Additionally, students in the autonomy-supportive condition showed higher levels of intrinsic regulation, interest and enjoyment, conceptual learning at the time, and greater rote recall one-week later (although immediate rote recall was not significantly different).

[3] Chatzisarantis and Hagger (2009) examined the potential of autonomysupportive instruction on student intrinsic motivation, behavioral intentions, and behavior in ten middle school physical education classrooms. Their cluster randomized design consisted of a five-week autonomy-supportive intervention for physical education teachers and a ten-week evaluation spanning and following the intervention. The teachers in the treatment condition were trained to enhance autonomy support by providing positive feedback to students, presenting rationales for activities, and acknowledging difficulties associated with physical education. Additionally, these teachers were trained to do so using non-controlling language, with the goal of increasing students' feelings of choice and reducing feelings of coercion. Teachers in the control condition were taught to provide positive feedback and present rationales. However, they were not given instruction on acknowledging difficulties, nor were they educated about how to communicate with their students in a non-controlling way.

Students reported on their teachers' provision of autonomy support using a scale adapted from the Learning Climate Questionnaire (Williams, Saizow, Ros, \& Deci, 
1997), which tapped into the amount of choice provided to students, the degree to which students felt that their teachers understood their feelings and perspectives, and the confidence conveyed. Students were also surveyed on their motivational orientations (i.e., intrinsic, identified, introjected, and external motivation), from Ryan and Connell's 1989 scale, which was adapted for physical education. Finally, students were asked about their behavioral intentions to exercise, as well as their subsequent exercise behaviors. Path analyses, using comparison maximum likelihood models, revealed that students with teachers in the experimental condition (i.e., autonomy-supportive) reported higher levels of autonomous motivation, intention to exercise and more participation in physical activities as compared to students of teachers in the control condition. Students' autonomous motivation and physical activity in the follow-up, which were measured more than once, showed significant increases from baseline in the experimental condition. Contrastingly, students in the control condition did not experience these changes. Additionally, students' autonomous motivation mediated the relation between teacher autonomy support and student behavioral intentions.

[4] Reeve, Jang, Carrell, Jeon, and Barch (2004) examined the impacts of high school teachers' provision of autonomy support, structure, and involvement on student engagement. Baseline observations of teacher autonomy support, structure, and involvement and student engagement were measured in an experimental group and a waitlist control. Teachers in the experimental group were then given a one-hour training on how to support their students' autonomy. In subsequent weeks, teachers in both groups were again rated on their provision of motivational supports and student 
engagement. Midway through the study, the delayed-treatment control group was also given the training and a final observation occurred.

Reeve and colleagues (2004) found, through ANCOVA analyses (covarying out baseline autonomy support measures) that teachers who had received information on how to be autonomy-supportive after the first observation and before the second showed significantly more autonomy-supportive behaviors at the second observation than teachers who had not been exposed to it yet. Paired-samples $t$ tests revealed that teachers in the waitlist control group exhibited significantly more autonomy support to their students in the third observation than they did in the second observation. Further, hierarchical regressions showed that increased teacher autonomy support predicted higher levels of observed student engagement. Additionally, although increases occurred in the amount of autonomy support provided, no changes were found in the amount of structure and involvement given to students, suggesting that changes in engagement were solely caused by increases in autonomy support. 
Table 2.1

Summary of Studies Illustrating Academic Benefits of Autonomy Support

\begin{tabular}{|c|c|c|c|c|}
\hline Author (year) & Sample & $\begin{array}{c}\text { Methods \& } \\
\text { Analyses }\end{array}$ & $\begin{array}{c}\text { Autonomy } \\
\text { Support Measure }\end{array}$ & Benefits \\
\hline \multicolumn{5}{|c|}{ Correlational Single Time Point } \\
\hline $\begin{array}{l}\text { Deci, Nezlek, } \\
\text { \& Sheinman } \\
(1981)\end{array}$ & $\begin{array}{l}35 \text { teachers } \\
\text { and } 610 \\
4 \text { th- } 6 \text { th } \\
\text { grade } \\
\text { students }\end{array}$ & $\begin{array}{l}\text { Student-report } \\
\text { and teacher- } \\
\text { report }\end{array}$ & $\begin{array}{l}\text { Deci, Schwartz, } \\
\text { Sheinman, \& } \\
\text { Ryan (1981) } \\
\text { Problems in } \\
\text { Schools } \\
\text { Questionnaire } \\
\text { (TR) } \\
\text { deCharms' (1976) } \\
\text { Origin Climate } \\
\text { Questionnaire } \\
\text { (SR) }\end{array}$ & $\begin{array}{l}\text { + Intrinsic Motivation } \\
\text { + General } \\
\text { Competence } \\
\text { + Cognitive Comp. } \\
\text { + Social Comp. } \\
\text { (marginal sig.) } \\
\text { n.s. Physical Comp. }\end{array}$ \\
\hline $\begin{array}{l}\text { Ryan \& } \\
\text { Grolnick } \\
(1986)\end{array}$ & $\begin{array}{l}1404 \text { th-6th } \\
\text { grade } \\
\text { students } \\
\text { (ages not } \\
\text { given) }\end{array}$ & $\begin{array}{l}\text { Student-report } \\
\text { and student } \\
\text { stories written } \\
\text { about } \\
\text { classroom } \\
\text { scenes }\end{array}$ & $\begin{array}{l}\text { deCharms' (1976) } \\
\text { OCQ } \\
\text { Volitional Control } \\
\text { of Story }\end{array}$ & $\begin{array}{l}+ \text { Mastery Motivation } \\
+ \text { Competence } \\
+ \text { Perceived Self- } \\
\text { Worth }\end{array}$ \\
\hline $\begin{array}{l}\text { Sosic-Vasic, } \\
\text { Keis, Lau, } \\
\text { Spitzer, \& } \\
\text { Streb (2015) }\end{array}$ & $\begin{array}{l}208 \text { German } \\
\text { students } \\
\text { (Grades } 3 \& \\
4, \mathrm{n}=50 ; \\
\text { Grades } 5 \& \\
6, \mathrm{n}=158 ; \\
\text { age } 8-14 \text { ) } \\
\text { and } 150 \\
\text { teachers }\end{array}$ & $\begin{array}{l}\text { Teachers } \\
\text { surveyed; } \\
\text { Students } \\
\text { surveyed and } \\
\text { tested; } \\
\text { Multilevel } \\
\text { modeling }\end{array}$ & $\begin{array}{l}\text { German adapted } \\
\text { Problems in } \\
\text { Schools } \\
\text { Questionnaire } \\
\text { (Martinek, 2007 } \\
\text { adapted from Deci } \\
\text { et al., 1981) }\end{array}$ & $\begin{array}{l}\text { + Intrinsic Motivation } \\
\text { - External Regulation } \\
+ \text { Executive } \\
\text { functioning }\end{array}$ \\
\hline $\begin{array}{l}\text { Tucker, Zayco, } \\
\text { Herman, } \\
\text { Reinke, } \\
\text { Trujillo, } \\
\text { Carraway, \& } \\
\text { Ivery (2002) }\end{array}$ & $\begin{array}{l}117 \text { African } \\
\text { American } \\
\text { students } \\
\text { grades } 1-12\end{array}$ & $\begin{array}{l}\text { Student- } \\
\text { surveys; } \\
\text { correlational } \\
\text { and HLM } \\
\text { analyses }\end{array}$ & $\begin{array}{l}\text { Perceived Teacher } \\
\text { Context (adapted } \\
\text { from RAPS-S; } \\
\text { Institute for } \\
\text { Research and } \\
\text { Reform in } \\
\text { Education, 1998) }\end{array}$ & $\begin{array}{l}\text { Correlations: } \\
\text { + Autonomy } \\
\text { + Competence } \\
\text { + Relatedness } \\
\text { + Engagement } \\
\text { HLM: } \\
\text { n.s. All outcomes } \\
\text { when Teacher } \\
\text { Involvement entered } \\
\text { into model }\end{array}$ \\
\hline
\end{tabular}


Table 2.1 Continued

Correlational Longitudinal

\begin{tabular}{|c|c|c|c|c|}
\hline $\begin{array}{l}\text { Way, Reddy, } \\
\text { \& Rhodes } \\
(2007)\end{array}$ & $\begin{array}{l}14516 \text { th- } \\
8 \text { th grade } \\
\text { students } \\
\text { (ages not } \\
\text { given) }\end{array}$ & $\begin{array}{l}\text { Students } \\
\text { surveyed over } \\
3 \text { years; SEM } \\
\text { analyses }\end{array}$ & $\begin{array}{l}\text { Opportunities for } \\
\text { Autonomy } \\
\text { Subscale in } \\
\text { Perceived School } \\
\text { Climate Scale } \\
\text { (CPRD, 1993) }\end{array}$ & $\begin{array}{l}\text { - Adolescent } \\
\text { depression + Student } \\
\text { self-esteem } \\
\text { - Behavior Problems }\end{array}$ \\
\hline $\begin{array}{l}\text { Vallerand, } \\
\text { Fortier, \& } \\
\text { Guay (1997) }\end{array}$ & $\begin{array}{l}4,5379- \\
\text { 10th grade } \\
\text { Canadian } \\
\text { students } \\
\text { (mean age } \\
14.97 \text { ) }\end{array}$ & $\begin{array}{l}\text { Students } \\
\text { surveyed; } \\
\text { Tracked } \\
\text { dropout rates }\end{array}$ & $\begin{array}{l}\text { Parent, Teacher, } \\
\text { and } \\
\text { Administration } \\
\text { Autonomy } \\
\text { Support (adapted } \\
\text { from Perceived } \\
\text { Interpersonal } \\
\text { Style Scale; } \\
\text { Pelletier, 1992) }\end{array}$ & $\begin{array}{l}\text { + Autonomy } \\
+ \text { Competence } \\
\text { + Academic } \\
\text { Motivation } \\
\text { - Dropout rates }\end{array}$ \\
\hline $\begin{array}{l}\text { Yu, Li, Wang, } \\
\text { \& Zhang } \\
(2016)\end{array}$ & $\begin{array}{l}236 \text { Chinese } \\
7 \text { th and } 8 \text { th } \\
\text { graders }(11- \\
17 \text { years } \\
\text { old; mean } \\
14.34)\end{array}$ & $\begin{array}{l}\text { Students } \\
\text { surveyed fall } \\
\text { and spring of } \\
7 \text { th and } 8 \text { th } \\
\text { grade; SEM } \\
\text { analyses }\end{array}$ & $\begin{array}{l}\text { Jia's et al. (2009) } \\
\text { five-item } \\
\text { Autonomy } \\
\text { Support } \\
\text { measure }\end{array}$ & $\begin{array}{l}+ \text { Student autonomy } \\
\text { in spring of } 7 \text { th grade, } \\
+ \text { Student } \\
\text { engagement in fall of } \\
8 \text { th grade, }\end{array}$ \\
\hline $\begin{array}{l}\text { deCharms } \\
\text { (1976) }\end{array}$ & $\begin{array}{l}1755 \text { th, } \\
6 \text { th, and } 7 \text { th } \\
\text { graders }\end{array}$ & $\begin{array}{l}\text { Students and } \\
\text { teachers } \\
\text { surveyed over } \\
3 \text { years; } \\
\text { ANOVA \& } \\
\text { ANCOVA }\end{array}$ & $\begin{array}{l}\text { Intrinsic } \\
\text { Motivational } \\
\text { Support }\end{array}$ & $\begin{array}{l}\text { + Intrinsic Motivation } \\
+ \text { Academic } \\
\text { Achievement }\end{array}$ \\
\hline
\end{tabular}

$\underline{\text { Experimental Designs }}$

\begin{tabular}{|c|c|c|c|c|}
\hline $\begin{array}{l}\text { Chatzisarantis } \\
\text { \& Hagger } \\
(2009)\end{array}$ & $\begin{array}{l}215 \text { middle } \\
\text { school } \\
\text { students, } \\
\text { ages } 14-16, \\
\text { from } 10 \\
\text { schools in } \\
\text { the UK }\end{array}$ & $\begin{array}{l}\text { Cluster- } \\
\text { randomized } \\
\text { design of five- } \\
\text { week } \\
\text { autonomy- } \\
\text { supportive } \\
\text { intervention } \\
\text { for physical } \\
\text { education } \\
\text { teachers; } \\
\text { students } \\
\text { surveyed }\end{array}$ & $\begin{array}{l}\text { Learning Climate } \\
\text { Questionnaire } \\
\text { (Williams, } \\
\text { Saizow, Ross, \& } \\
\text { Deci, 1997) } \\
\text { adapted for } \\
\text { physical education }\end{array}$ & $\begin{array}{l}\text { +Autonomous } \\
\text { Motivation } \\
+ \text { Intention to } \\
\text { exercise } \\
+ \text { Physical Activity } \\
\text { Participation }\end{array}$ \\
\hline
\end{tabular}


Table 2.1 Continued

\begin{tabular}{|c|c|c|c|c|}
\hline $\begin{array}{l}\text { Grolnick \& } \\
\text { Ryan (1987) }\end{array}$ & $\begin{array}{l}915 \text { th } \\
\text { graders } \\
\text { (ages not } \\
\text { given) }\end{array}$ & $\begin{array}{l}\text { Manipulated } \\
\text { directed } \\
\text { learning } \\
\text { conditions; } \\
\text { student } \\
\text { surveys }\end{array}$ & $\begin{array}{l}\text { Coercive versus } \\
\text { non-coercive } \\
\text { Directions for } \\
\text { Activity }\end{array}$ & $\begin{array}{l}\text { + Intrinsic Regulation } \\
+ \text { Interest/Enjoyment } \\
\text { - Pressure } \\
+ \text { Conceptual } \\
\text { Learning } \\
+ \text { Rote Longitudinal } \\
\text { Recall }\end{array}$ \\
\hline $\begin{array}{l}\text { Reeve, Jang, } \\
\text { Carrell, Jeon, } \\
\text { \& Barch } \\
(2004)\end{array}$ & $\begin{array}{l}20 \text { high } \\
\text { school } \\
\text { teachers }\end{array}$ & $\begin{array}{l}\text { Taught AS } \\
\text { teaching } \\
\text { strategies and } \\
\text { compared to } \\
\text { control }\end{array}$ & $\begin{array}{l}\text { Rated } 4 \\
\text { motivating } \\
\text { behaviors on 7- } \\
\text { point scale } \\
\text { ranging from } \\
\text { controlling to AS } \\
\text { behavior }\end{array}$ & + Engagement \\
\hline
\end{tabular}

Summary. This section limned the extant research on the benefits of providing autonomy support in the classroom, as supported by concurrent, longitudinal, and experimental studies. The four cross-sectional studies showed positive, significant concurrent relations between teacher autonomy support and student motivational outcomes. Two of the longitudinal studies demonstrated that autonomy support predicted change over time in many of the same motivational outcomes. The longitudinal nature of these two studies established a causal precedence for autonomy support on motivational outcomes. The third longitudinal study illustrated the potential predictive power of teacher autonomy support not only on student attitudes, but also on behavior. Finally, findings from the four experimental studies demonstrated the causal role of autonomy support on motivational variables, thus weakening alternative explanations of influence. These eleven studies presented student-report, teacher-report, and observational evidence from more than 8,800 students in first through twelfth grade and 205 teachers, spanning 
five countries (i.e., the United States, Canada, the United Kingdom, Germany, and China) on the positive impact of autonomy support on student motivation and well-being.

These studies also provide evidence relevant to the goals of the current study. Ten of the eleven studies examined the four key motivational outcomes, namely, autonomy, competence, relatedness, and engagement. Eight studies demonstrated that higher levels of teacher autonomy support (6 student-report and 2 teacher-report) predicted higher levels of student autonomy (also called, intrinsic motivation, autonomous motivation, and intrinsic regulation). Four studies examined the association between autonomy support and student perceived competence, as measured by feelings of academic ability ( 2 studies), feelings of control over academic outcomes (1 study), or both (1 study). Of the three studies that defined competence in terms of perceived ability, all found significant and positive relations with teacher autonomy support. Of the two studies that measured control, one found only a marginal positive relation with autonomy support and the other found positive significant correlations, but non-significant unique effects in regressions controlling for involvement and structure. These findings on perceived competence outcomes suggest that further differentiation of constructs (i.e., perceived ability versus perceived control) and follow-up analyses may be useful to better pin down the relation between teacher autonomy support and student perceived competence. Only one study assessed the connection between autonomy support and students' sense of relatedness and this study revealed a positive correlation between autonomy support and relatedness, but a non-significant relation between the two in a regression analysis including involvement as a predictor, suggesting that involvement accounted for most of the 
variance between autonomy support and involvement. Four studies looked at the influence of autonomy support on student engagement, three of which found positive and significant relations between teacher autonomy support and student engagement. One study found positive and significant correlations, but non-significant regression results, when involvement was included in the model.

Taken together, the studies found a suite of other autonomy support benefits related to academic motivation, including: increased mastery motivation, executive functioning, self-esteem, class participation, conceptual learning, academic achievement, and decreased external regulation, depression, behavior problems, and dropout. The range of methods, including, student- and teacher-reported surveys, achievement data, other records, and behavioral observation, suggest that teacher autonomy support not only shapes students' perceptions of themselves and their schools, but also predicts behavior that may have long-lasting effects on students into adulthood (e.g., grades and graduation).

Critiques. Although almost a dozen studies document the scholastic benefits of autonomy support, the current literature is surprisingly limited in its utility for teachers. Because teachers are positioned to provide autonomy support to students--and thus are the target users of this research--they can be seen as the critical resource for enhancing student motivation and achievement. Hence, the paucity of actionable information for teachers slows the application of motivational supports for students, which, in turn, deters researchers' development of precise constructs and models. As such, this deficit of 
accessible knowledge inhibits both theoretical and practical advancement. In particular, three areas can be identified that would be chiefly useful for researchers and educators.

First, several studies of autonomy support examine its impact on student autonomy and engagement, but fewer have investigated its influence on the other three motivational outcomes (i.e., competence, relatedness, and engagement). As is readily documented, perceived student competence can be cultivated via teacher provision of structure (Skinner, Zimmer-Gembeck, \& Connell, 1998) and student sense of relatedness can be fostered by via increased teacher involvement (e.g., Deci \& Ryan, 2000). A few studies suggest that competence and relatedness may also be nurtured through teacher autonomy support, but more research is needed to assess this potential contribution. The limited research to date on how autonomy support affects other motivational needs may prevent teachers from discovering the true reach of this motivational support. Without this knowledge, the incentive for teachers to provide increased levels of autonomy support in a highly restrictive school context may be undercut (Reeve, 2009).

Second, the conceptualizations of autonomy support used in extant research are neither consistent across studies nor clear, in many instances. For example, several studies operationalize autonomy support as amount of choice teachers provide, whereas others focus on freedom versus coercion. Because researchers use a range of indicators to define autonomy support, it is unclear what exactly is predicting these academic benefits. Without clarifying specific strategies that support students' autonomy, teachers may be ill-equipped to implement autonomy-supportive practices into their instruction. 
Third, none of the extant studies assessed whether the effects of autonomy support on the four motivational outcomes differed depending on students' age or gradelevel. Without applying a developmental framework to the research, researchers cannot discern whether autonomy support differentially affects student motivation across grades. Consequently, teachers may lack the information that need to determine whether researchers' recommendations are pertinent to the grades they teach. The incomplete exploration of these three critical research areas hinders the progress potential of researchers and teachers alike to bolster autonomy support in the classroom, and, in turn, impedes the motivational-support for middle school students. 


\section{Chapter III: The Current Study}

The purpose of the proposed study is to further our understanding of teacher provision of autonomy support and to examine the role it plays in shaping the development of students' motivation during the transition to middle school. More specifically, this study aims to first extend the reach of teacher autonomy support by introducing its potential influence on student perceived competence and relatedness, in addition to student autonomy and engagement. Second, this study aims to examine the differential importance of four components of autonomy support on these expanded motivational outcomes. Third, this study aims to bring a developmental framework to bear-considering not only age-graded trends in the components of teacher autonomy support and student motivation, and but also in their connections across fifth, sixth, and seventh grades. The following sections summarize empirical studies and theoretical explanations that provide a rationale for each of these aims. This chapter ends with the corresponding research questions and hypotheses.

\section{Expanded Motivational Outcomes}

Robust findings in the literature provide support for the connections between teacher provision of autonomy support, student autonomy, and student academic engagement (Assor \& Kaplan, 2001; Benware \& Deci, 1984; Deci \& Ryan, 1987;

Connell \& Wellborn, 1991; Patrick, Skinner, \& Connell, 1993; Reeve et al., 2004; Skinner \& Belmont, 1993; Vallerand, Fortier, \& Guay, 1997; for review, Stroet, Opdenakker, \& Minnaert, 2013). This study proposes that in addition to students' 
autonomy and academic engagement, autonomy support may also predict students' perceived competence and relatedness, two motivational indicators that are also conceptually related to student motivation, but have not yet been widely studied.

Perceived competence. Three of the studies listed above provide evidence suggesting that autonomy support may predict student perceived competence. Selfdetermination theory states that for students to feel competent in their academics, they need proper classroom structure that consistently informs them how to succeed. Structure may not be enough, however. In a study by Jang, Reeve, and Deci (2010), researchers assessed the complementary nature of structure and autonomy support on students' engagement and found that although structure and autonomy support are distinct, there is a significant and moderate correlation between the two constructs $(r=.60)$. The researchers did not measure the potential impact of autonomy support on perceived competence, but did find that only autonomy support was a unique predictor of students' self-reported engagement. Although one could interpret this finding in many ways, one possibility is that teachers must provide clear expectations for students in an autonomysupportive, rather than coercive way, if they wish to cultivate student perceived competence, which is readily linked to academic engagement. Perhaps supporting students' need for autonomy also impacts the way in which instructions are given to students, such that students know what is expected of them and further feel that their teachers trust them to carry out the instruction successfully. In another study examining self-regulated learning, researchers found that teachers' provision of structure was only associated with more self-regulated learning when it was coupled with either moderate or 
high levels of autonomy support (Sierens, Vansteenkiste, Goossens, Soenens, \& Dochy, 2009). This finding attests to the possible contribution autonomy support makes in supporting students' perceived competence. Thus, the few studies that have already demonstrated positive relations between autonomy support and perceived competence, and the few studies that show links between teacher autonomy support and teacher structure (or competence-support) provide impetus for examining the potential contributions of autonomy support to student perceived competence.

Relatedness. Although, to date, research within the SDT framework has not tested the potential impact of teacher provision of autonomy support on students' sense of relatedness in the classroom, at least eleven studies in the social relationships literature have suggested that autonomy support, in addition to involvement, may contribute to feelings of relatedness in other domains (for review, Deci \& Ryan, 2014). Relationship Motivation Theory (RMT) posits that high quality relationships are a function not only of relatedness-support (i.e., involvement), but also of autonomy support and competencesupport (i.e., structure) (Deci \& Ryan, 2014). For example, La Guardia, Ryan, Couchman, and Deci (2000) examined within-person variability in attachments across relational partners and found evidence for RMT. More specifically, even when controlling for relatedness satisfaction, both autonomy satisfaction and competence satisfaction from relational partners remained significant predictors of attachment security in those close relationships. It is important to note, however, that the contribution of autonomy satisfaction to attachment security was much stronger than that of competence satisfaction. In one experimental study, Niemiec and Deci (2014) primed 
either autonomous or controlled motivation in participant-dyads who did not know each other. After the dyads engaged in a sharing task, the participants in the autonomous condition felt higher satisfaction with their new dyad, more positive affect, more relatedness need satisfaction, and greater well-being than pairs in the controlling condition. These examples demonstrate that providing autonomy support in relationships enhances those relationships.

It is plausible then that higher levels of autonomy support in student-teacher relationships likely enhance students' sense of relatedness in the classroom. Although it may not be intuitively clear why supporting a student's autonomy might also support their feelings of relatedness, research has intimated that when students are provided opportunities to feel autonomous they feel "psychologically free" to satisfy their other basic needs, such as relatedness and competence (Deci \& Ryan, 2014). Evidence for this idea can also be seen in examining situations in which involvement alone does not lead to feelings of relatedness. Deci and Ryan (2014) reviewed several studies on Parental Conditional Regard (PCR), which refers to increased expression of parental warmth and involvement with their children when their children do what parents want them to do. This is considered tacitly coercive because the extra warmth acts as a reinforcer for children to do what the parents want in order to forestall withdrawal of attention, affection, and approval. Several studies show that PCR can lead to negative effects on children's well-being, as well as the child-parent relationship. Thus, parental involvement, when coercive, may not facilitate feelings of relatedness. 
Previously conceptualized as three distinct motivational pathways to student motivation, the above evidence suggests that autonomy support may be a more general support to multiple motivational needs. The current model, as can be seen in Figure 3.1, proposes that autonomy support acts as an additional force nurturing relatedness and perceived competence.

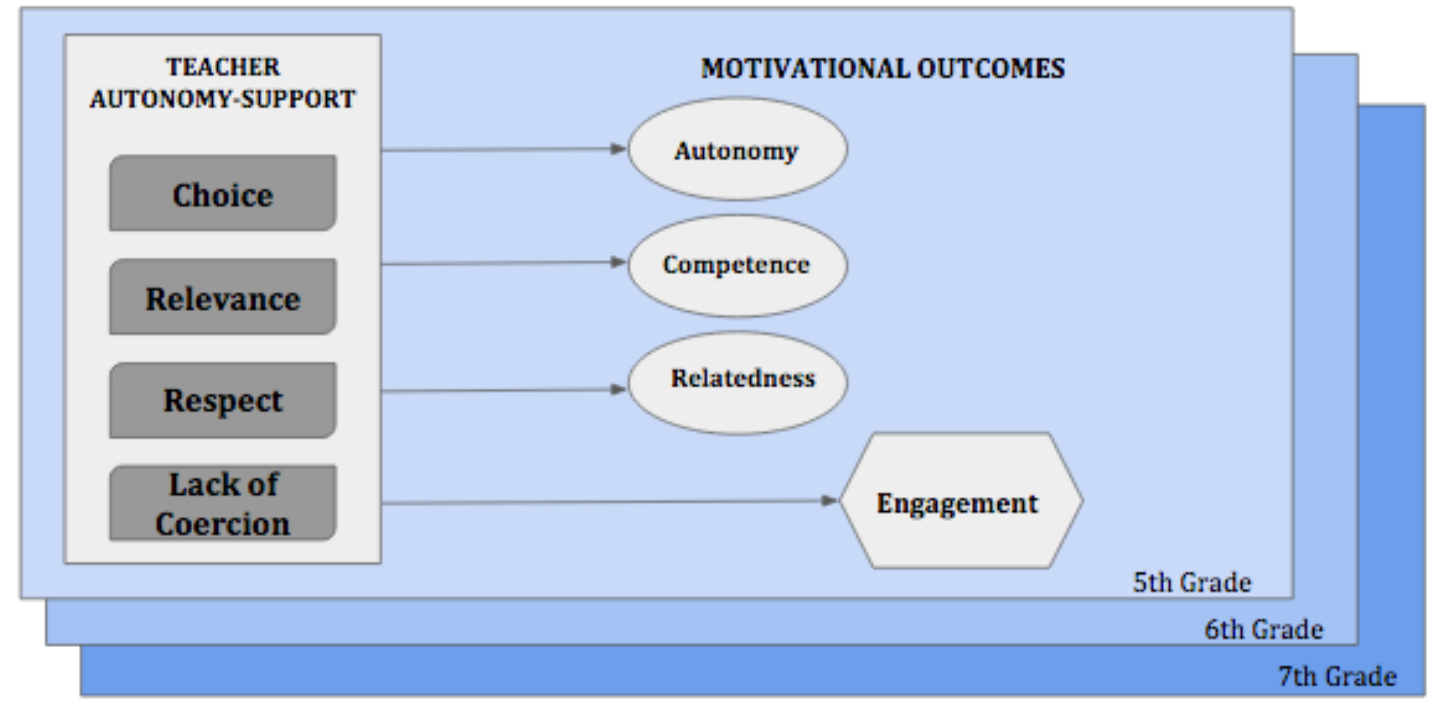

Figure 3.1. The Conceptual Model

\section{Components of Autonomy Support}

This study was also designed in part to contribute to a more differentiated and comprehensive understanding of autonomy support itself. Tables 3-6 contain the fifteen different measures (nine student-report, three teacher-report, and three teacher observations) that have been utilized to assess teacher autonomy support to date. Although each scale generally taps the construct of autonomy support, many differences among the assessments are apparent. About one-third of measures operationalize autonomy support as an omnibus aggregate, whereas the remaining measures 
differentiate autonomy support into multiple subscales or components. Of the nine scales that do define autonomy support as multi-dimensional, some break the construct down into as few as two different components and others into as many as seven. Together, researchers have used 15 different labels to identify the components that make up teacher autonomy support, many of which seem to overlap partially or completely. As can be seen, current measures of teacher autonomy support (and their underlying conceptualizations) seem in general to show significant overlap, but they lack consensus about the specifics of autonomy support, that is, about its essential elements.

However, it is possible that efforts to begin distinguishing the components of autonomy support could serve theoretical, empirical, and practical purposes for the field. Theoretically, the identification of multiple dimensions could contribute to the development of a more precise and comprehensive conceptualization of autonomy support. Unlike unitary concepts, autonomy support is an organizational construct, in which many different teacher behaviors can serve the function of supporting students' autonomy. Hence, identifying the most commonly-utilized and theoretically-sound components adds to a more comprehensive theoretical base. The current study — by clearly distinguishing and defining four components that are commonly represented in extant measures - attempts to contribute to theoretical progress in this regard.

In addition to a more comprehensive definition of autonomy support, clarifying its components can contribute to research in this area in at least two ways. On the one hand, scrutinizing the specific components of autonomy support contained in each measure makes it easier for researchers to compare or aggregate findings across different measures 
of the construct. Until this is accomplished, it is possible that inconsistencies in studies examining the consequences of autonomy support may be due to differences among the specific components of autonomy support that are captured by different assessments. On the other hand, by distinguishing among the components of autonomy support, researchers can parse apart the unique contributions of each component, for example, on student motivation and engagement. Separating the construct into distinct elements allows more precise study of the relative or unique contributions of different teacher behaviors (i.e., autonomy support components). Furthermore, these specific teacher behaviors might be associated with these outcomes differently for students from one grade to the next. Thus, the current study also attempts to surface these components, so that research questions can more precisely and comprehensively address how autonomy support promotes important motivational outcomes for students across grades.

Finally, along with the implications for theory and research, the findings from this study can be applied to identify targets for preservice or in-service teacher training aimed at enhancing student motivation. Due to the traditional hierarchical power dynamics between teachers and students, many teachers are unaware of the benefits and components of autonomy-supportive instruction, and as a result engage in a more coercive motivational style (Reeve, 2004). If professional development trainings designed to highlight the benefits of supporting student autonomy rely on global aggregate conceptualizations, then teachers may not intuitively understand the kinds of actions students are likely to experience as autonomysupportive or as controlling. Therefore, concrete guidelines on specific autonomy- 
supportive teacher practices may increase the likelihood that this motivational style will be utilized in the classroom (Reeve, 2004). Hence, by elucidating the connections between specific autonomy support components and motivational outcomes at different grades, the proposed study may uncover new recommendations for teacher intervention. Among the 15 examined measures of autonomy support, the four components that will be used in this study — respect, choice, relevance, and coercion-figure prominently.

Respect. The aspect of autonomy support most consistently incorporated in the examined measures was the provision of respect, which appeared in all 15 measures. In the classroom context, respect can be defined as teachers' validation of their students' opinions, emotions, and ideas, as well as teachers' encouragement of active student participation through listening and power-sharing (Center for Prevention Research and Development, 1993; Rocchi, M., Pelletier, L., Cheung, S., Baxter, D., \& Beaudry, S., 2017; Skinner \& Belmont, 1993). One example respect item--featured in multiple autonomy support measures--is, "the teacher allows us to talk about things that we find unacceptable in school” (Assor \& Kaplan, 2001; Assor, Kaplan, \& Roth, 2002; Wallace, Sung, \& Williams, 2014). Offering respect communicates to students that their opinions matter to the functioning of the class. If teachers express respect for their students, those students may feel free to act agentically in the safe space provided. Within the 15 autonomy support measures that included respect, only two explicitly labeled this component as "respect". Nine of the remaining autonomy support measures contained items featuring provisions of respect, but were classified using alternative terms (e.g., allowing criticism and encouraging independent thinking, Assor \& Kaplan, 2001; Assor, 
Kaplan, \& Roth, 2002) and the final four measures included items that encompassed the target construct, but did not differentiate their autonomy support items by components (see Table 3.1). 
Table 3.1

Autonomy Support Measures using Respect Component, in Chronological Order

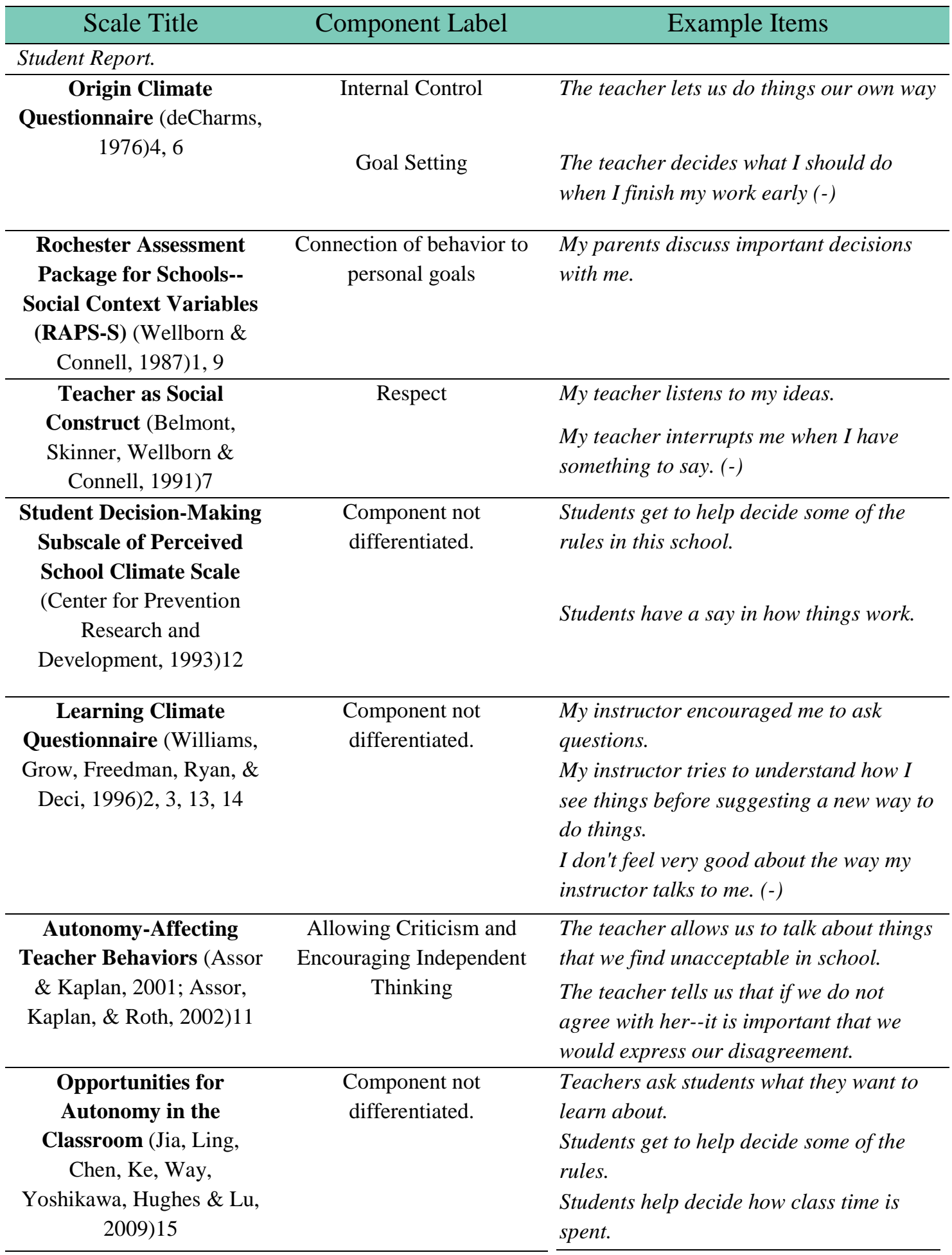


Table 3.1 Continued

\begin{tabular}{|c|c|c|}
\hline Scale Title & Component Label & Example Items \\
\hline $\begin{array}{c}\text { Teacher Practices Scale } \\
\text { (Patall, Dent, Oyer, \& } \\
\text { Wynn, 2013) }\end{array}$ & $\begin{array}{l}\text { Consideration for Student } \\
\text { Preferences }\end{array}$ & $\begin{array}{l}\text { My teacher is accepting when students } \\
\text { express negative feelings about course } \\
\text { material. } \\
\text { My teacher asks students their opinions } \\
\text { about various assignments. }\end{array}$ \\
\hline $\begin{array}{c}\text { The Interpersonal } \\
\text { Behaviours } \\
\text { Questionnaire (Rocchi, et } \\
\text { al., 2017) }\end{array}$ & Decision-Making & $\begin{array}{l}\text { Support the choices that I make for } \\
\text { myself. } \\
\text { Encourage me to make my own decisions. }\end{array}$ \\
\hline Teacher Report. & & \\
\hline $\begin{array}{l}\text { Problems in Schools } \\
\text { Questionnaire (Deci, } \\
\text { Nezlek, \& Sheinman, } \\
\text { 1981)5, } 8 \\
\end{array}$ & $\begin{array}{l}\text { Component not } \\
\text { differentiated. }\end{array}$ & $\begin{array}{l}\text { Talk to him about it, expressing her } \\
\text { confidence in him and attempting to } \\
\text { understand why he did it. }\end{array}$ \\
\hline $\begin{array}{c}\text { Teacher as Social } \\
\text { Construct (Wellborn, } \\
\text { Connell, Skinner, \& } \\
\text { Pierson, 1991)7 } \\
\end{array}$ & Respect & $\begin{array}{l}\text { I let this student make a lot of his/her own } \\
\text { decisions regarding schoolwork. }\end{array}$ \\
\hline $\begin{array}{c}\text { Subjective Impressions of } \\
\text { Teacher's Style (Reeve, } \\
\text { Bolt, \& Cai, 1999) }\end{array}$ & $\begin{array}{l}\text { Intrinsic Motivation } \\
\text { Support }\end{array}$ & Noncontrolling Communication \\
\hline Observations. & & \\
\hline $\begin{array}{l}\text { Behavioral Indicators of } \\
\text { Autonomy Support } \\
\text { (Reeve, Jang, Carrell, Jeon, } \\
\text { \& Barch, 2004) }\end{array}$ & $\begin{array}{c}\text { Listens and Accepts } \\
\text { Student Negative Affect } \\
\text { Reaction to Negative } \\
\text { Affect: Is Not OK: Change } \\
\text { it }\end{array}$ & $\begin{array}{l}\text { Listens carefully } \\
\text { Open to complaints } \\
\text { Tries to fix, counter, or change into } \\
\text { something else (-) }\end{array}$ \\
\hline $\begin{array}{l}\text { Autonomy-Supportive } \\
\text { Instructional Interactions } \\
\text { (Wallace, Sung, \& } \\
\text { Williams, 2014) }\end{array}$ & $\begin{array}{c}\text { Remaining Adaptive in } \\
\text { Practice } \\
\text { Using Open } \\
\text { Communication }\end{array}$ & $\begin{array}{l}\text { Placing responsibility on the students to } \\
\text { delegate group roles and tasks }\end{array}$ \\
\hline $\begin{array}{l}\text { Observed Autonomy- } \\
\text { Supportive Practices } \\
\text { (Rogat, Witham, \& Chinn, } \\
\text { 2014) }\end{array}$ & $\begin{array}{l}\text { Organizational and } \\
\text { Procedural Autonomy }\end{array}$ & $\begin{array}{l}\text { Using students' own phrases and ideas in } \\
\text { responses and when elaborating on } \\
\text { students' ideas } \\
\text { Informing decision of which group leads } \\
\text { discussion }\end{array}$ \\
\hline
\end{tabular}

Note. Scales used by: 1. Assor \& Kaplan, 2001 2. Black \& Deci, 2000 3. Chatzisarantis \& Hagger, 2009 4. Deci, Nezlek, \& Sheinman, 1981 5. Reeve, Bolt, \& Cai, 1999 Study 1 6. Ryan \& Grolnick, 1986 7. Skinner \& Belmont, 1993 8. Sosic-Vasic, Keis, Lau, Spitzer, \& Streb, 2015 9. Tucker, Zayco, Herman, Reinke, Trujillo, Carraway, \& Ivery, 2002 10. Vallerand, Fortier, \& Guay, 1997 11. Wallace, Sung, \& Williams, 2014 12. Way, Reddy, \& Rhodes, 2007 13. Williams \& Deci 1996 14. Williams, Saizow, Ross, \& Deci 1997 15. Yu, Li, Wang, \& Zhang, 2016 
Choice. The second most common autonomy support component, detailed in 12 of the 15 autonomy support measures, was the provision of choice, which is defined in the classroom context as providing students with options for class- and homework, such that students can choose topics and modalities most interesting to them (Assor, Kaplan, \& Roth, 2002; Skinner \& Belmont, 1993). One example survey item characterizing choice is, "my teacher allows me to choose how to do my work in the classroom" (Patall, Dent, Oyer, \& Wynn, 2013). If students are permitted to choose academic tasks and strategies for completing tasks, it follows then that their academic endeavors will be more consistent with their own preferences and goals, and thus, self-determined. Of the 12 autonomy support measures containing the choice component, seven explicitly characterized the component as choice, whereas three of the measures labeled the construct differently (e.g., organizational and procedural autonomy, Rogat, Witham, \& Chinn, 2014), and two measures included choice items as part of an omnibus measure that was not differentiated into individual components (see Table 3.2).

Table 3.2

Autonomy Support Measures using Choice Component, in Chronological Order

\begin{tabular}{|c|c|c|}
\hline Scale Title & Component Label & Example Items \\
\hline \multicolumn{3}{|l|}{ Student Report. } \\
\hline $\begin{array}{l}\text { Origin Climate Questionnaire } \\
\text { (deCharms, 1976) } 4,6\end{array}$ & Instrumental Activity & $\begin{array}{l}\text { The teacher lets us try new ways of } \\
\text { doing things. }\end{array}$ \\
\hline $\begin{array}{c}\text { Rochester Assessment Package for } \\
\text { Schools--Social Context Variables } \\
\text { (RAPS-S) (Wellborn \& Connell, } \\
\text { 1987)1, } 9\end{array}$ & Choice & $\begin{array}{l}\text { My teacher lets me do my schoolwork } \\
\text { according to my own schedule. }\end{array}$ \\
\hline $\begin{array}{c}\text { Teacher as Social Construct } \\
\text { (Belmont, Skinner, Wellborn \& } \\
\text { Connell, 1991)7 }\end{array}$ & Choice & $\begin{array}{l}\text { When it comes to assignments, my } \\
\text { teacher gives me all kinds of things to } \\
\text { choose from. }\end{array}$ \\
\hline
\end{tabular}


Table 3.2 Continued

\begin{tabular}{|c|c|c|}
\hline Scale Title & Component Label & Example Items \\
\hline $\begin{array}{c}\text { Learning Climate Questionnaire } \\
\text { (Williams, Grow, Freedman, Ryan, \& } \\
\text { Deci, 1996)2, 3, 11, } 12\end{array}$ & $\begin{array}{l}\text { Component not } \\
\text { differentiated. }\end{array}$ & $\begin{array}{l}\text { Ifeel that my instructor provides me } \\
\text { choices and options. }\end{array}$ \\
\hline $\begin{array}{l}\text { Autonomy-Affecting Teacher } \\
\text { Behaviors (Assor \& Kaplan, 2001; } \\
\text { Assor, Kaplan, \& Roth, 2002)10 }\end{array}$ & Provide Choice & $\begin{array}{l}\text { The teacher allows me to choose to } \\
\text { study topics that interest me. } \\
\text { When I choose a topic for a paper, the } \\
\text { teacher tries to influence my choice too } \\
\text { much. (-) }\end{array}$ \\
\hline $\begin{array}{l}\text { Teacher Practices Scale (Patall, } \\
\text { Dent, Oyer, \& Wynn, 2013) }\end{array}$ & Provision of Choices & $\begin{array}{l}\text { My teacher allows me to choose how to } \\
\text { do my work in the classroom. }\end{array}$ \\
\hline $\begin{array}{c}\text { The Interpersonal Behaviours } \\
\text { Questionnaire (Rocchi, M., Pelletier, } \\
\text { L., Cheung, S., Baxter, D., \& } \\
\text { Beaudry, S., 2017) }\end{array}$ & $\begin{array}{l}\text { Opportunities to } \\
\text { Provide Choice }\end{array}$ & $\begin{array}{l}\text { The people in my life... give me the } \\
\text { freedom to make my own choices. }\end{array}$ \\
\hline \multicolumn{3}{|l|}{ Teacher Report. } \\
\hline $\begin{array}{l}\text { Problems in Schools Questionnaire } \\
\text { (Deci, Nezlek, \& Sheinman, 1981)5, } 8\end{array}$ & $\begin{array}{l}\text { Component not } \\
\text { differentiated. }\end{array}$ & $\begin{array}{l}\text { Let him know that he doesn't have to } \\
\text { finish all of his work now and see if she } \\
\text { can help him work out the cause of the } \\
\text { listlessness. }\end{array}$ \\
\hline $\begin{array}{l}\text { Teacher as Social Construct-- } \\
\text { Teacher Report (Wellborn, Connell, } \\
\text { Skinner, \& Pierson, 1991)7 }\end{array}$ & Choice & $\begin{array}{l}\text { I try to give this student a lot of choices } \\
\text { about classroom assignments. }\end{array}$ \\
\hline
\end{tabular}
Observations.

Behavioral Indicators of Autonomy Intrinsic Motivational Choice-Making

Support (Reeve, Jang, Carrell, Jeon, Resources \& Barch, 2004)
Autonomy-Supportive Instructional Providing Meaningful Builds in choice for the completion
Interactions (Wallace, Sung, \& Choice strategy or order in which tasks are Williams, 2014) completed in the assignment

Observed Autonomy-Supportive Organizational and Choice of activity after completing

Practices (Rogat, Witham, \& Chinn, Procedural Autonomy assigned task 2014) selecting partners

Note. Scales used by: 1. Assor \& Kaplan, 2001 2. Black \& Deci, 2000 3. Chatzisarantis \& Hagger, 2009 4. Deci, Nezlek, \& Sheinman, 1981 5. Reeve, Bolt, \& Cai, 1999 Study 1 6. Ryan \& Grolnick, 1986 7. Skinner \& Belmont, 1993 8. Sosic-Vasic, Keis, Lau, Spitzer, \& Streb, 2015 9. Tucker, Zayco, Herman, Reinke, Trujillo, Carraway, \& Ivery, 2002 10. Wallace, Sung, \& Williams, 201411. Williams \& Deci 1996. 12. Williams, Saizow, Ross, \& Deci 1997 
Relevance. The next autonomy support component, featured in 10 of the 15 autonomy support measures, encompassed relevance, such that teachers provide intrinsically meaningful class material and explicitly communicate the objectives and value of each assignment (Reeve, 2006; Wallace, Sung, \& Williams, 2014). An example teacher-report item that embodies the relevance construct is, "I explain to this student why we learn certain things in school" (Skinner \& Belmont, 1993; Wellborn, Connell, Skinner, \& Pierson, 1991). When teachers clearly state how class material will be useful, students may internalize the motivation to engage with that material, and, in turn, participate in that academic work more autonomously. Amongst the 10 autonomy support measures that included relevance, four measures explicitly labeled this component relevance, whereas five measures used an alternative label (e.g., rationale provision, Patall, Oyer, Dent, \& Wynn, 2013), and one measure included items encompassing the relevance construct, but did not separate autonomy support into components (see Table $3.3)$.

Table 3.3

Autonomy Support Measures using Relevance Component, in Chronological Order

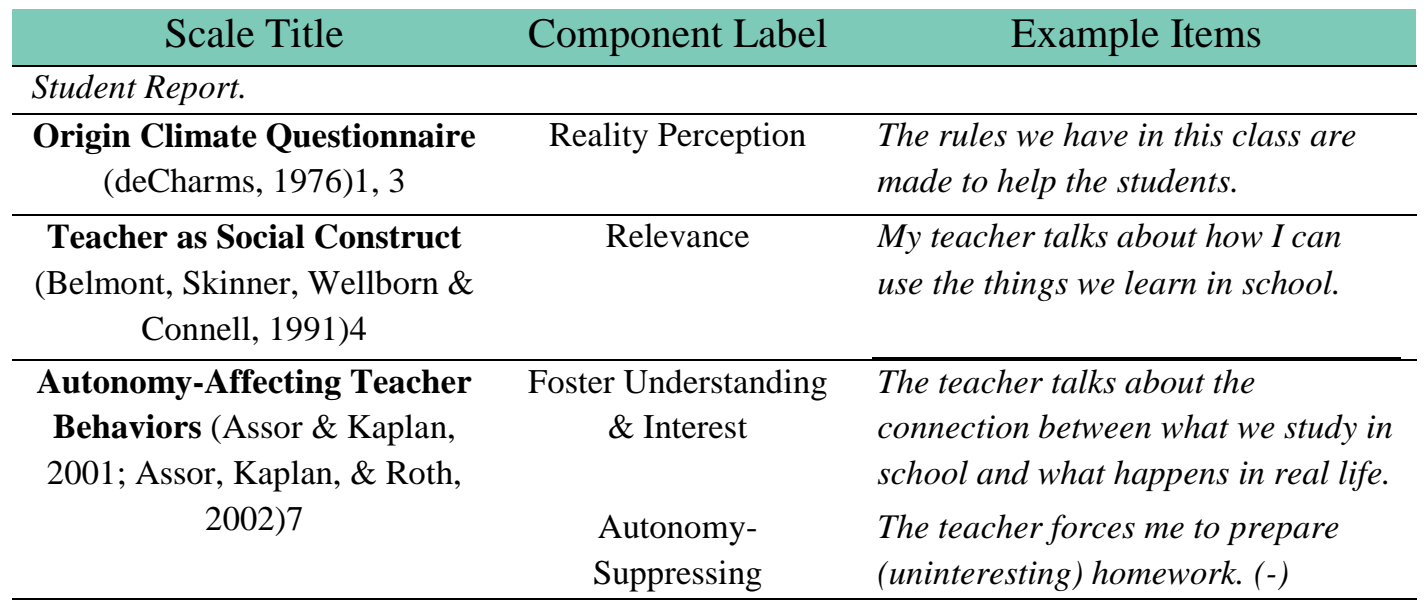


Table 3.3 Continued

\begin{tabular}{|c|c|c|}
\hline Scale Title & Component Label & Items \\
\hline $\begin{array}{c}\text { Teacher Practices Scale } \\
\text { (Patall, Dent, Oyer, \& Wynn, } \\
\text { 2013) }\end{array}$ & Rationale Provision & $\begin{array}{l}\text { My teacher demonstrates how what } \\
\text { we are learning is useful. } \\
\text { My teacher provides reasons for } \\
\text { what we are learning in class. }\end{array}$ \\
\hline \multicolumn{3}{|l|}{ Teacher Report. } \\
\hline $\begin{array}{c}\text { Problems in Schools } \\
\text { Questionnaire (Deci, Nezlek, } \\
\text { \& Sheinman, 1981)2, 5 }\end{array}$ & $\begin{array}{l}\text { Component not } \\
\text { differentiated. }\end{array}$ & $\begin{array}{l}\text { Encourage her to talk about her } \\
\text { report card and what it means for } \\
\text { her. }\end{array}$ \\
\hline $\begin{array}{c}\text { Teacher as Social Construct } \\
\text { (Wellborn, Connell, Skinner, \& } \\
\text { Pierson, 1991)4 }\end{array}$ & Relevance & $\begin{array}{l}\text { I explain to this student why we } \\
\text { learn certain things in school. } \\
\text { I encourage this student to think } \\
\text { about how schoolwork can be useful } \\
\text { to him/her. }\end{array}$ \\
\hline $\begin{array}{c}\text { Subjective Impressions of } \\
\text { teacher's Style (Reeve, Bolt, \& } \\
\text { Cai, 1999) }\end{array}$ & $\begin{array}{l}\text { Intrinsic Motivation } \\
\text { Support } \\
\text { Internalization } \\
\text { Support }\end{array}$ & $\begin{array}{l}\text { Provide Rationale } \\
\text { Promote Valuing of task }\end{array}$ \\
\hline \multicolumn{3}{|l|}{ Observations. } \\
\hline \multirow[t]{2}{*}{$\begin{array}{c}\text { Behavioral Indicators of } \\
\text { Autonomy Support (Reeve, } \\
\text { Jang, Carrell, Jeon, \& Barch, } \\
\text { 2004) }\end{array}$} & $\begin{array}{c}\text { Nurtures Intrinsic } \\
\text { Motivational } \\
\text { Resources } \\
\text { Identifies Value, } \\
\text { Importance or } \\
\text { Task/Lesson/Behavior }\end{array}$ & Identifies meaning, use, benefit \\
\hline & $\begin{array}{l}\text { Neglects Value, } \\
\text { Importance or } \\
\text { Task/Lesson/Behavior }\end{array}$ & Neglects meaning, use, benefit (-) \\
\hline $\begin{array}{c}\text { Autonomy-Supportive } \\
\text { Instructional Interactions } \\
\text { (Wallace, Sung, \& Williams, } \\
\text { 2014) }\end{array}$ & Fostering Relevance & $\begin{array}{l}\text { Making explicit connections among } \\
\text { topics and linking content and } \\
\text { students' ideas and experiences } \\
\text { Articulating the purpose behind } \\
\text { tasks }\end{array}$ \\
\hline $\begin{array}{c}\text { Observed Autonomy- } \\
\text { Supportive Practices (Rogat, } \\
\text { Witham, \& Chinn, 2014) }\end{array}$ & $\begin{array}{l}\text { Rationale and } \\
\text { Relevance }\end{array}$ & $\begin{array}{l}\text { Building toward key lesson points } \\
\text { using students' examples } \\
\text { Highlight interesting- ness and } \\
\text { relevance of examples during } \\
\text { content representation }\end{array}$ \\
\hline
\end{tabular}

Note. Scales used by: 1. Deci, Nezlek, \& Sheinman, 1981 2. Reeve, Bolt, \& Cai, 1999 Study 13. Ryan \& Grolnick, 1986 4. Skinner \& Belmont, 1993 5. Sosic-Vasic, Keis, Lau, Spitzer, \& Streb, 2015 6. Vallerand, Fortier, \& Guay, 1997 7. Wallace, Sung, \& Williams, 2014 
Coercion. The final component, mentioned in more than half of the examined autonomy support measures, refers to the lack of coercive teacher behaviors that might suppress student autonomy. Skinner \& Belmont (1993) define coercive teacher behavior as, "control through force or authority" (p. 574). This concept contributes to the autonomy support construct through the absence of these behaviors. One example item, which is reverse-coded, is, "I feel that my teachers pressure me to do what they want" (Pelletier, 1992; Vallerand, Fortier, \& Guay, 1997). Whereas teachers who use coercive behaviors in the classroom (e.g., suppress criticism and independent opinions; Assor \& Kaplan, 2001; Assor, Kaplan, \& Roth, 2002) undermine students' intrinsic motivation for learning, teachers who refrain from coercive behaviors allow for the organic unfolding of authentic student participation and productive student-teacher exchange. Of the eight measures featuring coercion, two of which use the vernacular given, whereas four measures use different labels (e.g., uses controlling language, Reeve, Jang, Carroll, Jeon, \& Barch, 2004), and the remaining two autonomy support measures that utilize coercion items did not differentiate the construct by components (see Table 3.4). In sum, although these four autonomy support components do not exhaust possibilities, respect, choice, relevance, and coercion are prominent, well defined features of autonomy support. 
Table 3.4

\section{Autonomy Support Measures using Coercion Component, in Chronological Order}

\begin{tabular}{|c|c|c|}
\hline Scale Title & $\begin{array}{l}\text { Component } \\
\text { Label }\end{array}$ & Example Items \\
\hline \multicolumn{3}{|l|}{ Student Report. } \\
\hline $\begin{array}{c}\text { Origin Climate } \\
\text { Questionnaire } \\
\text { (deCharms, } \\
\text { 1976)1, } 3\end{array}$ & Goal Setting & The teacher makes us do what she wants us to do (-) \\
\hline $\begin{array}{l}\text { Teacher as Social } \\
\text { Construct } \\
\text { (Belmont, } \\
\text { Skinner, Wellborn } \\
\text { \& Connell, } \\
\text { 1991)4 }\end{array}$ & $\begin{array}{l}\text { Coercive } \\
\text { Behavior }\end{array}$ & $\begin{array}{l}\text { My teacher is always getting on my case about } \\
\text { schoolwork. (-) } \\
\text { My teacher tries to control everything I do. (-) }\end{array}$ \\
\hline $\begin{array}{c}\text { Perceived } \\
\text { Interpersonal } \\
\text { Style Scale } \\
\text { (Pelletier, 1992)6 }\end{array}$ & $\begin{array}{l}\text { Component not } \\
\text { differentiated. }\end{array}$ & $\begin{array}{l}\text { Ifeel that my teachers pressure me to do what they want. } \\
\text { (-) }\end{array}$ \\
\hline \multirow{5}{*}{$\begin{array}{c}\text { Autonomy- } \\
\text { Affecting } \\
\text { Teacher } \\
\text { Behaviors (Assor } \\
\text { \& Kaplan, 2001; } \\
\text { Assor, Kaplan, \& } \\
\text { Roth, 2002)7 }\end{array}$} & $\begin{array}{c}\text { Suppress } \\
\text { Criticism and } \\
\text { Independent }\end{array}$ & $\begin{array}{l}\text { The teacher is not willing to acknowledge her mistakes. } \\
\text { (-) }\end{array}$ \\
\hline & $\begin{array}{l}\text { Opinions } \\
\text { (autonomy- } \\
\text { suppressing) }\end{array}$ & $\begin{array}{l}\text { The teacher is willing to listen only to answers that are in } \\
\text { complete agreement with his/her approach. (-) }\end{array}$ \\
\hline & $\begin{array}{l}\text { Intruding } \\
\text { (autonomy- } \\
\text { suppressing) }\end{array}$ & $\begin{array}{l}\text { The teacher interrupts me in the middle of activities } \\
\text { which interest me. (-) } \\
\text { The teacher stops me in the middle when I write or read } \\
\text { interesting things. (-) }\end{array}$ \\
\hline & $\begin{array}{l}\text { Force } \\
\text { Meaningless } \\
\text { and }\end{array}$ & $\begin{array}{l}\text { The teacher (forces) me to prepare uninteresting } \\
\text { homework. (-) }\end{array}$ \\
\hline & $\begin{array}{l}\text { Uninteresting } \\
\text { Activities } \\
\text { (autonomy- } \\
\text { suppressing) }\end{array}$ & $\begin{array}{l}\text { The teacher (forces) me to work on sheets that do not } \\
\text { help me to understand the material we study. (-) }\end{array}$ \\
\hline $\begin{array}{c}\text { The } \\
\text { Interpersonal } \\
\text { Behaviours }\end{array}$ & $\begin{array}{l}\text { Autonomy- } \\
\text { Thwarting }\end{array}$ & Impose their opinions on me. (-) \\
\hline $\begin{array}{l}\text { Questionnaire } \\
\text { (Rocchi et al., } \\
\text { 2017) }\end{array}$ & & Pressure me to adopt certain behaviors. (-) \\
\hline
\end{tabular}


Table 3.4 Continued

\begin{tabular}{|c|c|c|}
\hline Scale Title & $\begin{array}{l}\text { Component } \\
\text { Label }\end{array}$ & Example Items \\
\hline \multicolumn{3}{|l|}{ Teacher Report. } \\
\hline $\begin{array}{c}\text { Problems in } \\
\text { Schools } \\
\text { Questionnaire } \\
\text { (Deci, Nezlek, \& } \\
\text { Sheinman, } \\
\text { 1981)2, } 5\end{array}$ & $\begin{array}{l}\text { Component not } \\
\text { differentiated. }\end{array}$ & $\begin{array}{l}\text { Give him a good scolding; stealing is something which } \\
\text { cannot be tolerated and he has to learn that. (-) } \\
\text { Make him miss tomorrow's game to study; soccer has } \\
\text { been interfering too much with his school work. (-) }\end{array}$ \\
\hline $\begin{array}{c}\text { Teacher as Social } \\
\text { Construct } \\
\text { (Wellborn, } \\
\text { Connell, Skinner, } \\
\text { \& Pierson, 1991)4 }\end{array}$ & $\begin{array}{l}\text { Coercive } \\
\text { Behavior }\end{array}$ & $\begin{array}{l}\text { I find myself telling this student every step to make when } \\
\text { it comes to schoolwork. (-) } \\
\text { When it comes to assignments, I'm always having to tell } \\
\text { this student what to do. (-) }\end{array}$ \\
\hline \multicolumn{3}{|l|}{ Observations. } \\
\hline $\begin{array}{c}\text { Behavioral } \\
\text { Indicators of } \\
\text { Autonomy } \\
\text { Support (Reeve, } \\
\text { Jang, Carrell, } \\
\text { Jeon, \& Barch, } \\
\text { 2004) }\end{array}$ & $\begin{array}{c}\text { Relies on } \\
\text { Extrinsic } \\
\text { Motivational } \\
\text { Resources } \\
\text { Uses } \\
\text { Informational } \\
\text { Language } \\
\text { Uses } \\
\text { Controlling } \\
\text { Language }\end{array}$ & $\begin{array}{l}\text { Incentives, Consequences (-) } \\
\text { Not at all Controlling }\end{array}$ \\
\hline $\begin{array}{l}\text { Note. Scales used l } \\
\text { Ryan \& Grolnick, }\end{array}$ & $\begin{array}{l}\text { 1. Deci, Nezlek, } \\
\text { 6 4. Skinner \& }\end{array}$ & $\begin{array}{l}\text { Sheinman, } 1981 \text { 2. Reeve, Bolt, \& Cai, } 1999 \text { Study } 13 \\
\text { mont, } 1993 \text { 5. Sosic-Vasic, Keis, Lau, Spitzer, \& Streb, }\end{array}$ \\
\hline
\end{tabular}

Unique effects of components of autonomy support. Although components of autonomy support have been distinguished in at least nine measures, only three studies have examined academic outcomes unique to a particular component of autonomy support, two of which using the same sample.

Assor and Kaplan (2001). In one of their studies, Assor and Kaplan (2001) surveyed 862 Jewish-Israeli third to eighth grade students on their perceptions of their teachers' provision of autonomy-supportive behaviors (i.e., choice; relevance, labeled as 
fostering understanding and interest; and respect, labeled as allowing criticism and encouraging independent thinking), as well as their experience of academic enjoyment. Academic enjoyment refers to students' intrinsic motivation to engage with the learning material, or autonomy. Regression analyses that examined the effects of three components of autonomy support on academic enjoyment in third through fifth grade students revealed that students' perception of teacher provision of respect and relevance (labeled as fostering understanding and interest) both positively and uniquely predicted students' academic enjoyment. Choice did not significantly predict enjoyment. The same analyses on students in sixth through eighth grades revealed that relevance and choice significantly predicted academic enjoyment, but this time respect did not. These findings suggest that content relevance, choice, and respect are all predictive of student autonomy at certain grades, but relevance might be a more central predictor across grades. Despite the strong predictive power of content relevance found in this study in both grade brackets, further research is required to test the differential predictive power of these three components.

Assor, Kaplan, and Roth (2002). A follow-up study was conducted by Assor, Kaplan, and Roth (2002) ( $n=862$; grades 3-8) to assess how teacher autonomysupportive behaviors might predict student behavioral and cognitive engagement. Here, regression analyses looking at the four components revealed that only students' perceptions of teachers' provision of relevance (labeled as fostering understanding and interest) significantly predicted student engagement. Neither perceptions of choice nor respect (labeled as allowing criticism and encouraging independent thinking) 
significantly predicted student engagement. Together, these studies highlight the unique connection between making academic work relevant to students and fostering their autonomy and engagement.

Patall et al. (2013). To examine unique contribution of the various components of autonomy support in more detail, Patall and colleagues (2013) surveyed 278 ninth through twelfth grade students on their experiences of teacher autonomy support, as well as their feelings of autonomy. The researchers used choice, relevance (labeled as rationale provision), and respect (labeled as and separated into student perspective-taking and consideration of student preferences) to embody the autonomy support construct. Zero-order correlations showed that autonomy was positively and significantly related to provision of choice, respect (labeled as student perspective-taking; consideration of student preferences), and relevance (labeled as rationale provision), with correlations ranging .44 to .52 .

Additionally, the researchers created "teacher-practice profiles" by conducting a median-split for each autonomy support component, resulting in sixteen profiles encompassing every combination of high and low provisions of each autonomy support component. Utilizing a between-subjects Analysis of Variance (ANOVA), the researchers then examined how student autonomy differed significantly between the various teacher-practice profiles. The students experiencing high provisions of all four autonomy support components felt significantly more autonomy need satisfaction than students experiencing low provisions of all, one, two, or three autonomy support components. Similarly, students encountering low levels of all four autonomy support 
components felt significantly less autonomy need satisfaction than all other profiles of students. Because no significant differences were found amongst students experiencing high levels of one, two, or three autonomy support components, only 10 of the 16 profiles were relevant for comparison. Amongst the 10 relevant profiles, only seven were large enough to be examined.

Results comparing students experiencing high levels of all four autonomy support components against students experiencing high levels of three autonomy support components and a low level of one component revealed that taking away choice significantly reduced student autonomy, whereas low levels of only respect (labeled as perspective-taking) did not significantly reduce feelings of student autonomy. Conversely, when comparing student profiles of low levels of all four components against low levels of three components and a high level of one component, students with increased choice provision felt significantly more autonomous, students with increased respect only (labeled as perspective-taking) experienced a marginally significant $(\mathrm{p}=.07)$ increase in autonomy, and students with high levels of relevance only (labeled as rationale provision) did not experience more autonomy than students with all autonomy support components low. This study suggests that teacher provisions of choice play a key role in fostering student autonomy, above and beyond the other autonomy support components.

Tentative hypotheses on unique effects of autonomy support components. Although these three studies do not provide a unified landscape of how the different autonomy support components uniquely connect to student motivation, they do suggest 
the need for more research on the differentiated autonomy support construct. For the purposes of this study, the overarching component themes that emerged from the literature-respect, choice, relevance, and coercion - will be used to examine the impacts of teacher autonomy support.

It is expected that each component of teacher autonomy support will uniquely predict the four motivational outcomes, namely, student autonomy, competence, relatedness, and engagement. Despite the above findings that suggest a weighted impact of one component over another on autonomy, here, with comprehensive and distinct components, the relative importance of all four components for student autonomy is expected to be equal across all four predictors, as they theoretically and empirically make up the elements of nurturing student autonomy. Although the relative importance of the components on the remaining motivational outcomes (i.e., competence, relatedness, and engagement) is not clear from extant research, perhaps student competence will be more strongly associated with the choice and relevance components because, of the four components, they deal the most with instructional practices. If students are presented with relevant and intrinsically interesting material, paired with choices on how to demonstrate their mastery, it is likely that they will feel (and actually be) more competent in their academic work. Conversely, it is possible that respect and coercion more strongly impact student relatedness because offering respect and refraining from coercive behaviors pertain to student-teacher interactions and are relational in nature. Finally, it is also reasonable that coercion holds the strongest weight for student engagement because it is characterized by a highly negative experience for students, whereas the absence of the 
other three supports symbolize a lack of positive teacher behavior. Perhaps negative teacher behavior is more emotionally salient for middle school students' decision to engage in learning material than an absence of a support (e.g., few choices or ample irrelevant busy work).

\section{Developmental Differences}

In addition to dissecting the construct of autonomy support, the current study aims to add a developmental framework by investigating whether this teacher provision seems to function differently in fifth, sixth, and seventh grade students. Identifying the components of autonomy support that are most important at each grade can inform teachers about the best ways to calibrate their support appropriately. Focusing on the grades that surround the transition to middle school will provide information to teachers about how to motivate students during a particularly difficult developmental time period. As mentioned in the previous chapter, the transition to middle school is marked by normative declines in student motivation and accompanied by deteriorating studentteacher relationships (Wigfield et al., 2015).

Mean-level differences in autonomy support. To date, very few studies have looked specifically at whether autonomy-supportive teacher behaviors decline over the middle school transition. However, one such study, exploring academic affect in junior high school students, found that seventh grade students felt greater disrespect from their teachers than did ninth grade students (Murdock, Anderman, \& Hodge, 2000), suggesting that middle school might be a time when teachers either express more disrespect to their 
students or when students are more sensitive to this experience. Even without a clear empirical precedent, it is possible that students' experiences of teacher autonomy support may decrease across the transition to middle school, as part of the well-documented general declines in student-teacher relationships at this time (Wigfield et al., 2015).

Differential contributions of autonomy support. Although there is a paucity of studies in this research arena, a few findings suggest that autonomy support may predict motivational outcomes differentially across grades. For example, in a study examining autonomy support as an omnibus construct, Diseth and Samdal (2014) surveyed tenth and eleventh grade Norwegian students on their perceptions of teacher autonomy support and classroom goals. Structural Equation Modeling revealed that students' perception of their teachers' autonomy support significantly and positively predicted students' desire to develop and demonstrate competence (i.e., mastery and performance goals) in both grades. The relative impact of teacher autonomy support on students' development of competence (i.e., mastery), however, was stronger for tenth graders than it was for eleventh graders. In contrast, the importance of teacher autonomy support in predicting students' desire to demonstrate competence (i.e., performance goals) was stronger for eleventh graders than for tenth graders. Although this study is outside of the grade range of focus in the current study, it still suggests that the influence of autonomy-supportive behaviors on student motivation may differ across grades.

The study by Assor, Kaplan, and Roth (2002) mentioned previously took the construct of autonomy support further and parsed apart its components. Regression analyses revealed that fostering relevance for students was more important to their 
academic interest and enjoyment in third through fifth grade students than it was for sixth through eighth grade students. Conversely, providing choice was more important to students' academic interest and enjoyment in the older grade group than the younger. Because the study did not separate the relations by individual grade it is difficult to draw conclusions about fifth, sixth, and seventh grade differences, but the results can be used as initial evidence that perceptions of the provision of choice may increase in importance for students' motivation from late elementary to middle school, whereas the provision of content relevance may decrease in importance.

Tentative developmental hypotheses. Self-determination theory posits that autonomy is a basic human need all across the lifespan (Ryan \& Deci, 2000). Consistent with this assertion, it is predicted that the provision of autonomy support is important for student motivation in fifth, sixth, and seventh grades. Stage-environment fit theory highlights the unique nature of adolescence, marked by changing developmental needs, paired with the changing academic context (Eccles \& Midgley, 1989). Building on this theory, it is expected that students entering middle school may need more autonomy than students in elementary school. Unfortunately, it appears that middle school students may experience even lower levels of autonomy support as compared to their elementary school counterparts (Eccles \& Midgley, 1989). The high levels of disrespect experienced by seventh grade students in Murdock, Anderman, \& Hodge's (2000) work also suggests a perceived deprivation at that time. Related to this idea, it is speculated that autonomysupportive classrooms may take on added importance for student motivation once students enter middle school (i.e., sixth grade). 
To date, no studies have examined whether components of autonomy support are important for different outcomes at different grades. However, pulling from basal findings, some tentative hypotheses can be articulated. In conjunction with Assor, Kaplan, and Roth's (2002) findings, it is expected that provisions of relevance will be most important for students' motivational outcomes in fifth grade, as compared to sixth and seventh. Before the two big transitions have begun (i.e., changing schools and puberty for most), students might focus more so on how fun learning activities are, rather than the nature of their interactions with teachers. Provisions of respect, on the other hand, are likely to be most strongly associated with students' motivational outcomes in sixth grade, when students transition from elementary school to middle school. This expectation mirrors Murdock, Anderman, and Hodge's (2000) finding that students in their first year of secondary school (seventh graders for junior high and sixth graders for middle school) report experiencing the most disrespect. At a time when identity is especially fragile, providing respect for adolescents in the thick of pubertal changes seems crucial. Similarly, and in conjunction with Assor, Kaplan, and Roth (2002), it is possible that as student motivation is waning, then provisions of choice may be most important to motivational outcomes for seventh grade students. Refraining from coercion is expected to steadily impact student motivation throughout because even though the others may change in importance, the absence of a support may not be noticed as readily as the presence of a frustration.

As has just been demonstrated, a large body of literature on self-determination theory has been built; however, a gap still exists in the functioning of autonomy support 
and its components across different developmental moments. As established by this research, the middle school transition can be quite turbulent, and as such, researchers and practitioners alike continue to search for methods to ameliorate negative school-related experiences during this time. Thus, the purpose of the current study is first to identify age-graded levels of multiple components of autonomy support and then to evaluate their unique contributions to students' motivational outcomes surrounding the middle school transition years. This study's exploration of the autonomy support components in fifth, sixth, and seventh grade students will provide much needed actionable information on how to support students' motivation in developmentally appropriate ways in order to help circumvent the negative decline in motivation that exists during the pivotal middle school transition period.

\section{Research Questions and Hypotheses}

\section{Research Question 1: Effects of teacher autonomy support on changes in} student motivational outcomes, overall and differentially by grade level.

RQ1a. Does teacher autonomy support in fall predict changes in students' motivational outcomes (namely, autonomy, perceived competence, relatedness, and engagement) from fall to spring?

Hypothesis $1 a$. Teacher autonomy support will significantly predict all four Spring student motivation variables (i.e., autonomy, competence, relatedness, engagement), controlling for Fall student motivation levels. 
RQ1b. Does teacher autonomy support predict changes in students' motivational outcomes differentially for students in fifth, sixth, and seventh grades?

Hypothesis $1 b$. Teacher autonomy support will significantly predict changes in students' motivational outcomes for fifth, sixth, and seventh grade students and this relation will be just as strong for all three grades of students.

Research Question 2: Individual effects of each of the components of teacher autonomy support on students' motivational outcomes, overall and differentially by grade level.

RQ2a. Do each of the components of autonomy support (i.e., respect, choice, relevance, coercion) in fall individually predict changes in students' motivational outcomes from fall to spring?

Hypothesis 2a. Each component of teacher autonomy support is expected to individually predict changes in students' motivational outcomes from fall to spring.

RQ2b. Do each of the components of teacher autonomy support (i.e., respect, choice, relevance, coercion) in fall predict changes in students' motivational outcomes from fall to spring differentially for students in fifth, sixth, and seventh grades?

Hypothesis $2 b$. Because research in this area has conflicting findings, this question remains exploratory in nature, and thus without formal hypothesized relations among the components and the motivational outcomes.

Research Question 3: Unique effects of the components of teacher autonomy support on students' motivational outcomes (and changes in their motivational outcomes), overall and for each grade level. 
RQ3a.a. Do the components of teacher autonomy support (i.e., respect, choice, relevance, coercion) in fall uniquely predict students' motivational outcomes in fall?

Hypothesis 3a.a. Each component of teacher autonomy support is expected to uniquely predict students' motivational outcomes in fall.

RQ3a.b. Do the components of teacher autonomy support (i.e., respect, choice, relevance, coercion) in fall uniquely predict changes in students' motivational outcomes from fall to spring?

Hypothesis 3a.b. Each component of teacher autonomy support is expected to uniquely predict changes in students' motivational outcomes from fall to spring.

RQ3b.a. Do the components of autonomy support in fall uniquely predict fall motivational outcomes for students in fifth, sixth, and seventh grades?

Hypothesis 3 b.a. Because research in this area is sparse, this question remains exploratory in nature, and thus without formal hypothesized relations among the components and the motivational outcomes.

RQ3b.b. Do the components of autonomy support in fall uniquely predict changes in motivational outcomes from fall to spring for students in fifth, sixth, and seventh grades?

Hypothesis 3 b.a. Because research in this area is sparse, this question remains exploratory in nature, and thus without formal hypothesized relations among the components and the motivational outcomes.

Research Question 4: Normative grade differences in teacher autonomy support and students' motivational outcomes. 
RQ4. Do autonomy support, its components, and the motivational outcomes show the typical patterns of grade differences among fifth, sixth, and seventh grades, suggesting normative declines across the transition to middle school?

Hypothesis 4. Autonomy support, all four of its components and all four motivational outcomes will show the highest levels in fifth grade, followed by sixth grade, and the lowest levels in seventh grade.

\section{Research Question 5: Buffering effects of autonomy support on student motivation during the middle school transition.}

RQ5a. Do differences in teacher autonomy support across fifth, sixth, and seventh grade students underlie grade level differences in students' motivational outcomes, such that when teacher provisions of autonomy support are accounted for, differences in motivational outcomes across fifth, sixth, and seventh grade disappear?

Hypothesis $5 a$. It is expected that when teacher provisions of autonomy support are accounted for, differences in motivational outcomes across fifth, sixth, and seventh grade will disappear.

RQ5b. Do patterns of grade differences in students' motivational outcomes differ depending on the level of teacher autonomy support students experience, such that students who experience higher levels of teacher autonomy support show a more adaptive pattern of grade differences in autonomy, competence, relatedness, and engagement, suggesting that they maintain high levels of motivation, whereas students who experience lower levels of teacher autonomy support show patterns suggesting marked declines in motivation? 
Hypothesis $5 b$. Students across all three grades who experience higher levels of autonomy support from their teachers will experience higher levels of autonomy,

competence, relatedness, and engagement as compared to their counterpart peers, who experience lower levels of fall autonomy support. 


\section{Chapter IV: Research Design and Methods}

The current study proposes to use data collected for a larger longitudinal study. This study examined the motivational development of third to seventh grade students, in a rural-suburban public school district, located in upstate New York. Assessments were conducted using a cohort-sequential design. Collection occurred in the Fall (October) and Spring (May) of three consecutive years and the present study will utilize data from Year four (time points 7 and 8). For a more detailed description of the study, see Skinner, Zimmer-Gembeck, and Connell (1998).

\section{Participants}

A sample of 908 students, between the ages of 10 and 14 (fifth to seventh grade), was used for the current study. Amongst these students, 224 were fifth graders, 339 were sixth graders, and 345 were seventh graders. The sample was approximately equally divided by sex and consisted of predominately working and middle class Caucasians. Socio-Economic Status (SES) was measured through parental education and occupation. Less than three percent of student participants were of color; though, of those students, Hispanic students were the largest minority.

\section{Design and Procedure}

The entire school district was invited to participate in the study and students were given consent forms to take home. Passive consent was obtained, such that parents who did not want their children participating indicated so. All others were presumed to give consent. Additionally, students gave verbal assent during survey administration. Students 
were administered questionnaires by two trained interviewers, in three 45-minute sessions. As one interviewer read questions aloud, the second was available to answer clarification questions and to give general assistance to individual students. Teachers were not present during the administration. At the end of the study, students were given a presentation of the major findings.

\section{Measures}

Student participants completed items pertaining to their experiences in the classroom, with their teachers, and of their own academic self-perceptions. All measures included a four-point Likert-type scale, ranging from 1 (not at all true for me) to 4 (very true for me). Negatively worded items were reverse-coded, and then all items were averaged in each scale to form a summary score. Higher scores, ranging from 1 to 4, indicate more of a specific construct (i.e., more engagement, more autonomy). The complete scales can be found in Appendix A.

Autonomy support. Teacher provision of autonomy support and coercion were assessed by students using a scale that consists of 18 items tapping four core components of autonomy support (Skinner \& Belmont, 1993): (1) choice, or the extent to which students feel that they are given options from their teachers according to their own interests, consisting of five items (e.g., "My teacher lets me do things my own way"); content relevance, or the extent to which students feel their teachers provide rationales and bring meaning to instruction, consisting of five items (e.g., "My teachers explain why the things I learn in school are important"); (3) respect, or the extent to which students 
perceive their teachers acknowledge the importance of student ideas and opinions, consisting of five items (e.g., "My teacher listens to my opinion"); (4) coercion, or the extent to which students perceive their teachers exert control through force or authority, a motivating style thought to undermine autonomy, consisting of three items (e.g., "My teacher tries to control everything I do" (-)).

Student autonomy. Student autonomy levels will be assessed using a modified version of Ryan and Connell's (1989) Self-Regulatory Style (Autonomy) Questionnaire. This survey consists of 9 items, measuring two distinct aspects of student autonomy. The first subscale is intrinsic motivation, which consists of four items characterized by doing schoolwork for students' own personal interest and enjoyment (e.g., "I do my homework because it's interesting"). The second subscale, identified motivation, is comprised of five items characterized by the desire to learn or to attain a goal (e.g., "I do my homework because I think classwork is important for my learning").

Student perceived competence. Student perceived competence, known by some researchers as perceived control (e.g., Skinner, Chapman, \& Baltes, 1988; Skinner, Wellborn, \& Connell, 1990; Skinner et al., 1998), was measured using one portion of the Student Perceptions of Control Questionnaire (Skinner, Wellborn, \& Connell, 1990). These six items tapped into the extent to which students feel they have control over their ability to excel in school, in which three were positively worded and three were negatively worded. One positive example item is, "If I decide to learn something hard, I can" and one negative example item, which was reverse-coded, is, "I can't do well in school, even if I want to" (-). 
Student relatedness. The amount that students feel that they belong, or student relatedness, was assessed using a 4-item scale (Connell \& Wellborn, 1991; Furrer \& Skinner, 2003). This scale included one main facet of student relatedness, namely, emotional security with teachers. This scale included four items, (e.g., "When I'm with my teacher, I feel important").

Student engagement. Student engagement was assessed using Skinner, Kindermann, and Furrer's (2009) adaptation of the Rochester Assessment Package for Schools (Wellborn \& Connell, 1987). This scale, consisting of 9 items, evaluated studentreport engagement, including behavioral engagement (e.g., "I try very hard in school"), emotional engagement (e.g., "When I'm working on my classwork, I feel involved"), behavioral disaffection (e.g., "In class, I try to do just enough to get by") and emotional disaffection (e.g., "When I'm doing my work in class, I feel bored"). Behavioral and emotional disaffection items were reverse-coded. 


\section{Chapter V: Results}

This study explored the impact of teacher autonomy support on student motivation in fifth, sixth, and seventh grade students. Presented in this section are the preliminary analyses, including assessment and handling of missingness, descriptive statistics, as well as the shape of the data. The results from each research question follow the preliminary analyses. All data were examined using SPSS version 24.

\section{Initial Analyses}

Missingness. From a larger item pool, the present study utilized 46 items, corresponding to measures of the five target constructs. Every item had at least one missing value from a student respondent. Three hundred forty-one students had complete survey data; the remaining students had at least one missing item. Eight hundred sixtytwo students had at least some data for fall and Seven hundred thirty-nine students had at least some data for spring. One hundred sixty-nine students had no data in the spring and forty-six students had no data in the fall. Missing data was examined to determine if missingness occurred completely at random (MCAR), at random (MAR), or not at random (MNAR). Little's MCAR test was significant, suggesting a pattern of missingness among the data. Upon further analysis using independent samples t-tests, it appears that the one hundred sixty-nine students who had no data for the spring collection point scored significantly lower on autonomy in the fall $(\mathrm{M}=2.60, \mathrm{SD}=.67)$ than did the students who had at least some data for the spring $(\mathrm{M}=2.83, \mathrm{SD}=.71) ; t(234.23)=3.80$, $p<.001$. Similarly, students without any spring data scored significantly lower on 
competence in the fall $(\mathrm{M}=3.32, \mathrm{SD}=.56)$ than did students who had at least some spring data $(\mathrm{M}=3.46, \mathrm{SD}=.55) ;) ; t(209.78)=2.81, p<.01$. No significant differences were found in either relatedness or engagement in the fall between students with no spring data and students with some spring data. Because some of the motivational outcomes were significantly different between students with and without spring data, the decision was made to retain the fall data of students who lacked spring data, so as not to exclude the very students likely to be in the most motivational danger.

Imputation. Despite the MNAR data result, the dataset was imputed with caution, using the EM-ML procedure (estimation and maximization algorithm and maximum likelihood estimation; Cohen, Cohen, West, \& Aiken, 2003). This method was employed to increase power.

\section{Descriptive Statistics and Measurement Properties}

Descriptive statistics. A summary of the descriptive statistics for each variable of interest is presented in Table 5.1. This table includes the number of items, internal consistencies, means, and standard deviations. Upon examination of these descriptive statistics, it appears that all scales have adequate internal consistency (i.e., $\alpha>.70$ ), as measured by Cronbach's alpha. As was expected, Coercion exhibited the lowest internal consistency, since it was comprised of only three items. 
Table 5.1

Summary of Descriptive Statistics for each Construct

\begin{tabular}{|c|c|c|c|c|c|c|c|}
\hline \multirow[b]{2}{*}{ Scale } & \multirow{2}{*}{$\begin{array}{l}\text { Number } \\
\text { of Items }\end{array}$} & \multicolumn{3}{|c|}{ Fall } & \multicolumn{3}{|c|}{ Spring } \\
\hline & & $\alpha$ & $M$ & $S D$ & $\alpha$ & $M$ & $S D$ \\
\hline \multicolumn{8}{|l|}{$\begin{array}{l}\text { Teacher } \\
\text { Support }\end{array}$} \\
\hline $\begin{array}{l}\text { Teacher } \\
\text { Autonomy } \\
\text { Support }\end{array}$ & 18 & .91 & 2.85 & .59 & -- & -- & -- \\
\hline Respect & 5 & .81 & 3.01 & .70 & -- & -- & -- \\
\hline Choice & 5 & .76 & 2.65 & .71 & -- & -- & -- \\
\hline Relevance & 5 & .75 & 2.88 & .68 & -- & -- & -- \\
\hline Coercion & 3 & .70 & 2.14 & .77 & -- & -- & -- \\
\hline \multicolumn{8}{|l|}{$\begin{array}{l}\text { Motivational } \\
\text { Outcomes }\end{array}$} \\
\hline Autonomy & 9 & .87 & 2.76 & .67 & .84 & 2.63 & .61 \\
\hline $\begin{array}{l}\text { Perceived } \\
\text { Competence }\end{array}$ & 6 & .74 & 3.39 & .56 & .74 & 3.28 & .57 \\
\hline Relatedness & 4 & .83 & 2.97 & .78 & .83 & 2.83 & .79 \\
\hline Engagement & 9 & .78 & 3.04 & .53 & .75 & 2.94 & .52 \\
\hline
\end{tabular}

Note. $N=908$. Scores could range from 1-4. Higher scores indicate more of the respective construct.

Univariate analyses and non-normality. The data were also tested for

distributional non-normality, using the skewness and kurtosis for each variable as criteria.

All 13 variables displayed within normal range $(-1<$ and $>1)$ for skewness and kurtosis.

Upon examining histograms of each variable's distribution, it appears that levels of teacher coercion are slightly positively skewed, meaning that students experienced lower levels of coercive teacher behavior. Additionally, histograms revealed a slight negative skew of student competence in the fall, which means that students' feelings of 
competence in the fall were, on the whole, relatively high. Finally, the histogram for teacher autonomy support in the fall displays a distribution leaning toward leptokurtic, suggesting that students' rating of teacher autonomy support fell close to the median.

Correlation analyses. Correlations were conducted to assess zero-order relations between teacher autonomy support and motivational outcomes, autonomy support components with each other, and motivational outcomes concurrently and between fall and spring. Understanding initial patterns of significance help explain subsequent regression and ANOVA analyses more fully.

Inter-correlations. As Table 5.2 shows, all correlations showed the expected patterns, in which fall teacher autonomy support was positively and significantly correlated with all four motivational outcomes, both concurrently and from fall to spring. Also as expected, cross-time stabilities of the motivation variables from fall and spring were all significant, with especially high stabilities found for student autonomy and engagement. These high cross-time stabilities may make it difficult to predict changes in motivation from fall to spring.

Table 5.2

Inter-Correlations among Constructs in Fall and Spring

\begin{tabular}{lccccc}
\hline & $\begin{array}{c}\text { Aut. } \\
\text { Support }\end{array}$ & Aut. & $\begin{array}{c}\text { Perceived } \\
\text { Comp. }\end{array}$ & Relat. & Eng. \\
\hline Aut. Support & & $.35^{* *}$ & $.34 * *$ & $.41^{* *}$ & $.45^{* *}$ \\
Autonomy & $.52 * *$ & $.63^{* *}$ & $.27 * *$ & $.38^{* *}$ & $.47 * *$ \\
Perceived & $.46^{* *}$ & $.32^{* *}$ & $.51^{* *}$ & $.27 * *$ & $.53 * *$ \\
Relatedness & $.66^{*}$ & $.44^{* *}$ & $.36^{* *}$ &. $\mathbf{4 2 * *}$ & $.45^{* *}$ \\
Engagement & $.62^{* *}$ & $.56^{* *}$ & $.57 * *$ & $.36^{* *}$ &. $\mathbf{6 1 * *}$ \\
\hline
\end{tabular}

Note. $N=908$. Fall correlations depicted below the diagonal; Spring correlations depicted above the diagonal; Cross-time stabilities depicted on the diagonal. **p<. 01 . 
Intra-construct correlations. Correlations among each autonomy support component were significant, as is expected for variables within the same organizational construct. The correlation between teacher coercion and teacher respect was especially high. This multicollinearity may make it difficult to detect the unique effects of these components. Intra-correlations can be seen in Table 5.3 below.

Table 5.3

Intra-Correlations among Autonomy Support Components in Fall and Spring

\begin{tabular}{lcccc}
\hline & Respect & Choice & Relev. & Coercion \\
\hline Respect & 1 & - & - & - \\
Choice & $.54^{* *}$ & 1 & - & - \\
Relevance & $.62^{* *}$ & $.57^{* *}$ & 1 & \\
Coercion & $-.65^{* *}$ & $-.49^{* *}$ & $-.49^{* *}$ & 1 \\
\hline
\end{tabular}

Note. $N=908 . * * p<.01$.

Covariate t-tests. Independent samples $t$-tests were conducted to compare each motivational outcome variable, in both fall and spring, across genders. The results indicate that there is a significant difference between boys' and girls' feelings of autonomy, competence, relatedness, and engagement, such that girls had significantly higher mean levels on each variable at both fall and spring collections (see Table 5.4). Despite these significant findings, covariate variables were not included in subsequent analyses because although mean level differences between boys and girls are well documented in the literature, generally they do not indicate process differences between genders. 


\section{Table 5.4}

t-test Results Comparing Males and Females on Motivational Outcomes in Fall and Spring

\begin{tabular}{|c|c|c|c|c|c|}
\hline & \multicolumn{2}{|c|}{ Female } & \multicolumn{2}{|c|}{ Male } & \multirow[t]{2}{*}{$t$-test } \\
\hline & M & SD & M & SD & \\
\hline $\begin{array}{l}\text { Fall } \\
\text { Autonomy }\end{array}$ & 2.87 & .66 & 2.66 & .68 & $-4.83 * * *$ \\
\hline $\begin{array}{l}\text { Spring } \\
\text { Autonomy }\end{array}$ & 2.70 & .65 & 2.58 & .57 & $-2.75^{* *}$ \\
\hline $\begin{array}{l}\text { Fall } \\
\text { Competence }\end{array}$ & 3.48 & .53 & 3.32 & .57 & $-4.18 * * *$ \\
\hline $\begin{array}{l}\text { Spring } \\
\text { Competence }\end{array}$ & 3.38 & .56 & 3.18 & .56 & $-5.39 * * *$ \\
\hline $\begin{array}{l}\text { Fall } \\
\text { Relatedness }\end{array}$ & 3.10 & .74 & 2.85 & .79 & $-4.96 * * *$ \\
\hline $\begin{array}{l}\text { Spring } \\
\text { Relatedness }\end{array}$ & 2.93 & .79 & 2.74 & .78 & $-3.70 * * *$ \\
\hline $\begin{array}{l}\text { Fall } \\
\text { Engagement }\end{array}$ & 3.12 & .50 & 2.96 & .54 & $-4.60 * * *$ \\
\hline $\begin{array}{l}\text { Spring } \\
\text { Engagement }\end{array}$ & 3.01 & .51 & 2.88 & .51 & $-4.00 * * *$ \\
\hline
\end{tabular}

Note. $N_{\text {female }}=438, N_{\text {male }}=464,6$ participants lacked gender data. $* p<.05 * * p<.01 * * * p<.001$. 


\section{Research Question 1: Effects of teacher autonomy support on changes in students' motivational outcomes, overall and differentially by grade level.}

RQ1a. Does teacher autonomy support in fall predict changes in students'

motivational outcomes (namely, autonomy, perceived competence, relatedness, and engagement) from fall to spring?

Ordinary Least Squares (OLS) regressions were used to evaluate whether students' perceptions of their teachers' autonomy support in fall predicted their own motivation (i.e., autonomy, competence, relatedness, engagement) in spring, when accounting for their motivation in fall. To do so, teacher autonomy support, as well as all four motivational outcomes in fall, were grand mean centered for all analyses.

Autonomy in spring. Teacher autonomy support in fall and student autonomy in fall together explained $40.2 \%$ of the variance of student autonomy in spring, where $\mathrm{R}^{2}=$ $.40, F(2,905)=304.41, p<.001$. Although teacher autonomy support was significantly correlated with autonomy in spring $(r=.35)$, it was not a significant predictor of changes in autonomy from fall to spring $(\beta=.03, t(905)=.89, p=.38)$, due to the high stability in autonomy from fall to spring $(r=.63, p<.01)$. Results can be seen in Figure 5.1 . 


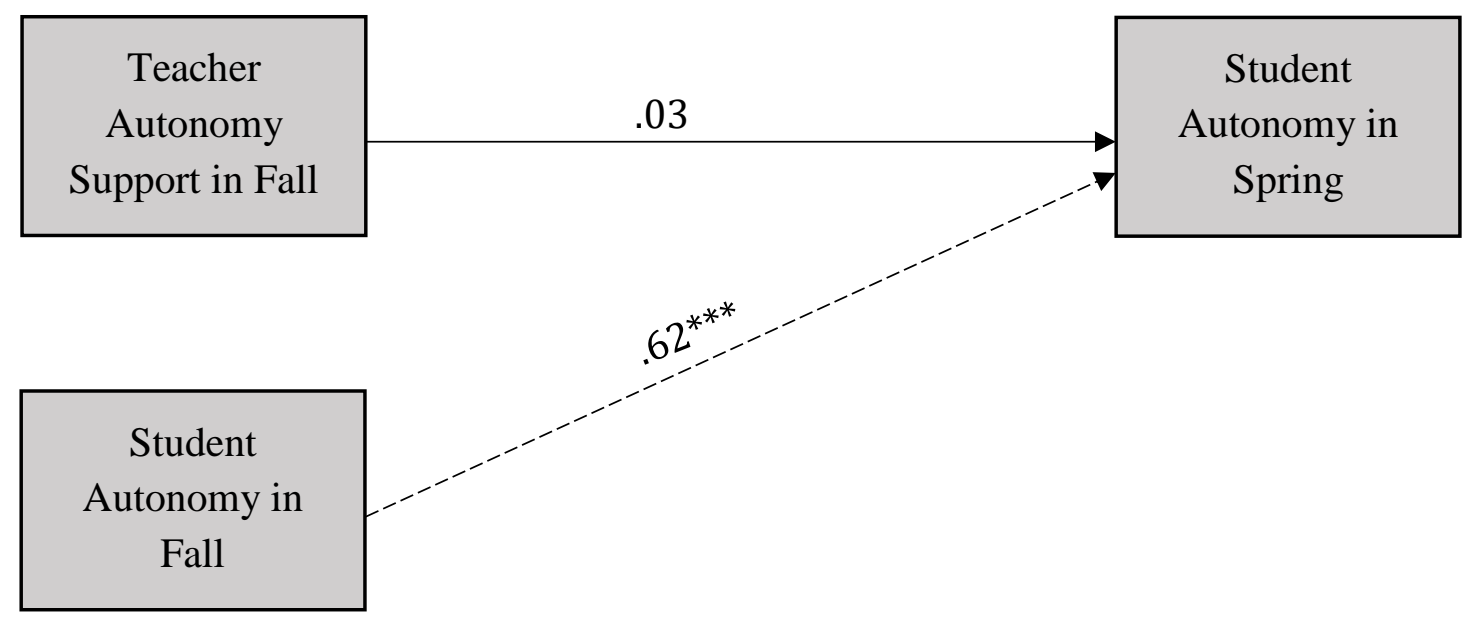

Figure 5.1. Teacher autonomy support in fall as a predictor of student autonomy in spring, controlling for student autonomy in fall.

Competence in spring. Teacher autonomy support in fall and student competence in fall together explained $27.8 \%$ of the variance of student competence in spring, where $\mathrm{R}^{2}=.28, F(2,905)=173.92, p<.001$. Despite the high stability of competence over the school year $(r=.51, p<.01)$, teacher autonomy support was a significant predictor of changes in student competence from fall to spring $(\beta=.13, t(905)=4.2, p<.001)$.

Results can be seen in Figure 5.2.

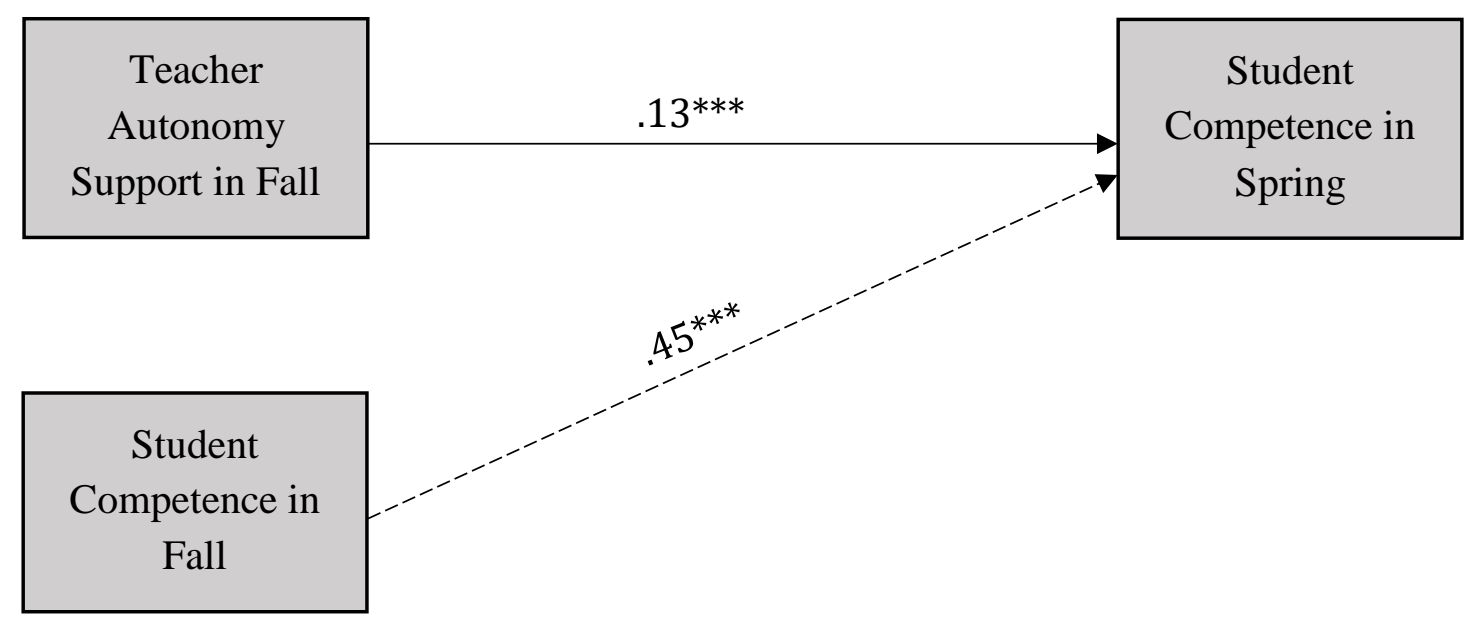

Figure 5.2. Teacher autonomy support in fall as a predictor of student competence in spring, controlling for student competence in fall. 
Relatedness in spring. Teacher autonomy support in fall and student relatedness in fall together explained $20.8 \%$ of the variance of student relatedness in spring, where $\mathrm{R}^{2}=$ $.208, F(2,905)=118.77, p<.001$. As can be seen in Figure 5.3, when accounting for student relatedness in fall $(\beta=.25, t(905)=6.45, p<.001)$, teacher autonomy support in fall significantly and uniquely predicted student relatedness in spring $(\beta=.25, t(905)=$ $6.34, p<.001)$. Here, not only did teacher autonomy support in fall predict student relatedness in spring despite the high stability of student relatedness from fall to spring ( $r$ $=.42, p<.01)$, but unexpectedly, the unique contribution of teacher autonomy support to relatedness in spring was just as high as the unique contribution of relatedness in fall.

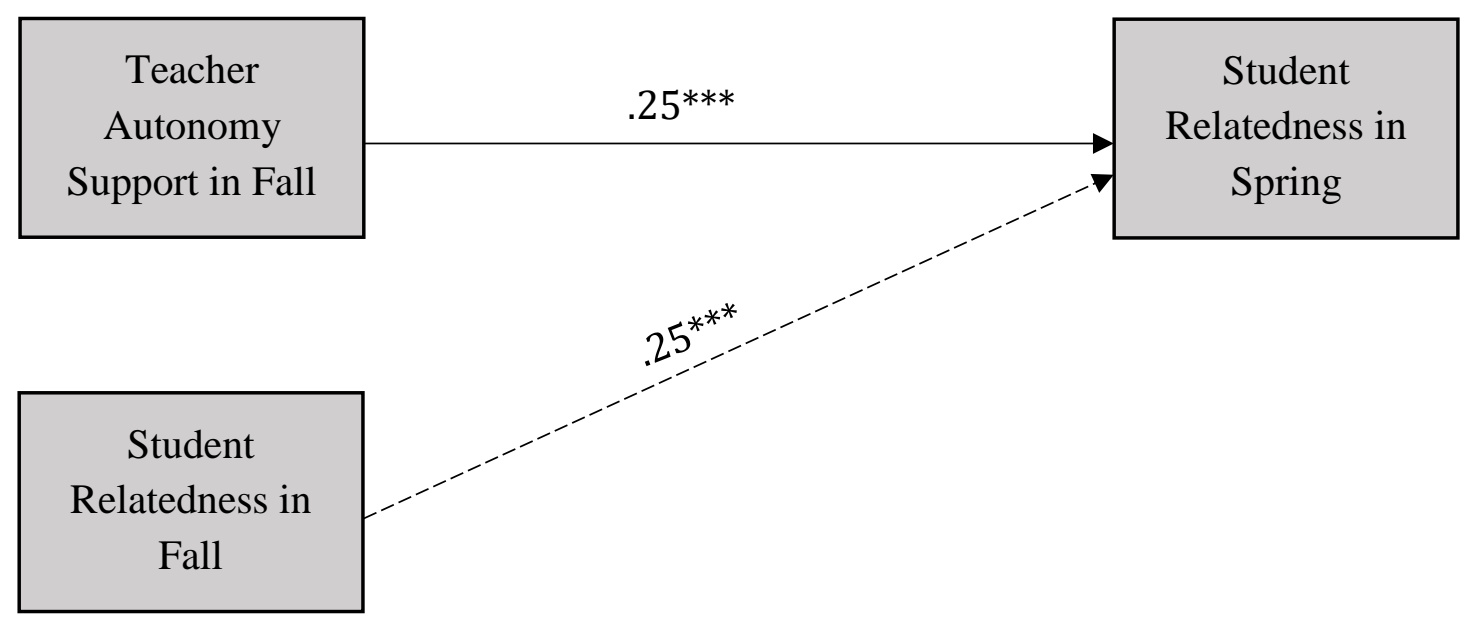

Figure 5.3. Standardized betas of teacher autonomy support in fall as a predictor of student relatedness in spring, controlling for student relatedness in fall.

Engagement in spring. Teacher autonomy support in fall and student engagement in fall together explained $37.4 \%$ of the variance of student engagement in spring, where $\mathrm{R}^{2}=.37, F(2,905)=270.87, p<.001$. Despite the high stability of engagement over the 
school year $(r=.61, p<.01)$, teacher autonomy support was a significant predictor of changes in engagement from fall to spring $(\beta=.12, t(905)=3.53, p<.001)$. Results can be seen in Figure 5.4.

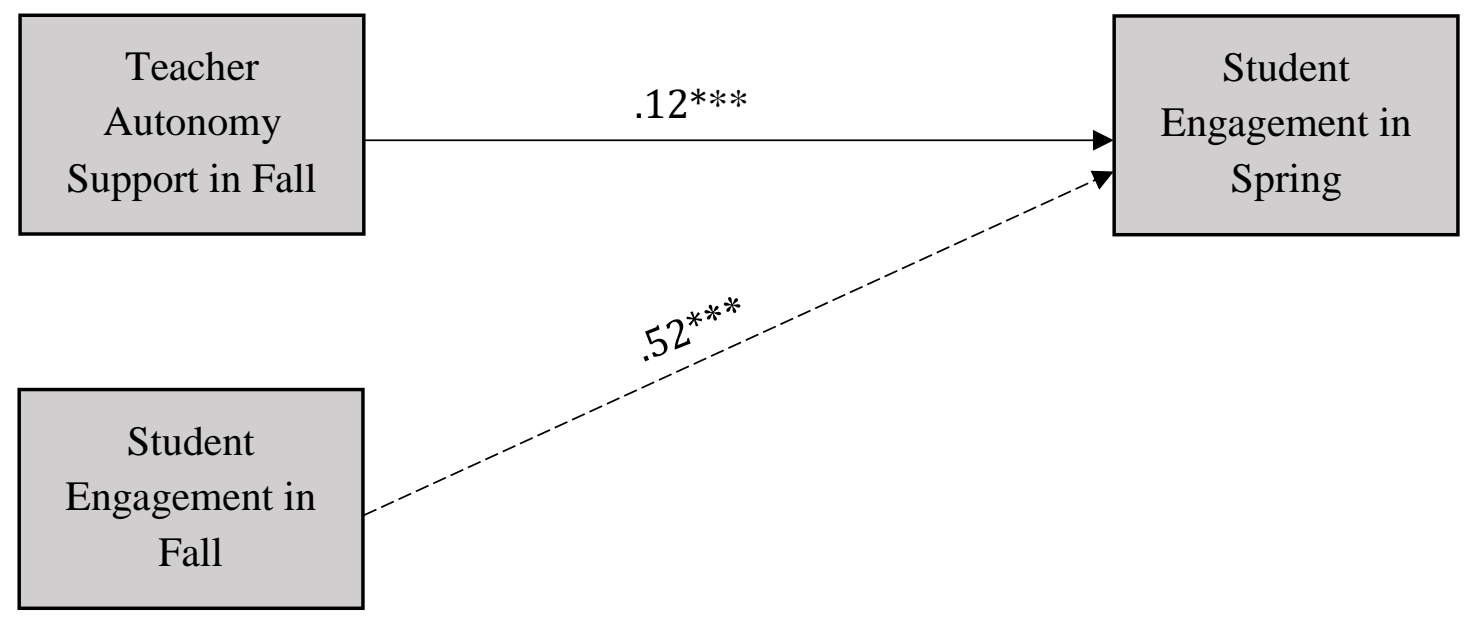

Figure 5.4. Teacher autonomy support in fall as a predictor of student engagement in spring, controlling for student engagement in fall.

RQ1b. Does teacher autonomy support predict changes in students' motivational outcomes differentially for students in fifth, sixth, and seventh grades?

Given the results from Research Question 1a, further analyses were conducted to examine whether the impact of teacher autonomy support on student motivation differed amongst fifth, sixth, and seventh grade students. To do so, teacher autonomy support, as well as each motivational variable in fall, were again grand mean centered. Grade was centered at fifth grade.

Grade. The sample in this study was weighted toward sixth and seventh grade students, surveying 224 fifth grade students, 339 sixth grade students, and 345 seventh 
grade students. As Table 5.5 shows, all scales exhibited adequate internal consistency, with alpha levels ranging from .70 (sixth grade competence in spring) to .92 (fifth grade teacher autonomy support). Although there were no apparent patterns of difference in alpha levels across grades, it appears that scales in fall had higher internal consistency on the whole than did scales in spring. Mean levels and standard deviations of autonomy support and the four motivational outcomes are presented in Table 5.6 by grade and collection season. These results suggest that student motivation was highest for fifth grade students, followed by sixth, and lowest for seventh grade students. Additionally, motivation levels on the whole appear to be higher for all students in fall than in spring. As was consistent with the preliminary analyses, on average students in each grade reported the highest levels of competence and the lowest levels of autonomy. The intercorrelations by grade show that in all three grades teacher autonomy support has a particularly high correlation with student relatedness. Additionally, cross-time stabilities show that student relatedness may be the least stable of the motivational variables. Together, it seems that relations including student relatedness could be the easiest to detect. These results can be seen in Table 5.7. 
Table 5.5

Alpha Levels of Scales by Grade

\begin{tabular}{|c|c|c|c|c|c|c|c|}
\hline & \multirow{3}{*}{$\begin{array}{l}\text { Number } \\
\text { of Items }\end{array}$} & \multicolumn{3}{|c|}{ Fall } & \multicolumn{3}{|c|}{ Spring } \\
\hline & & $5^{\text {th }}$ & $6^{\text {th }}$ & $7^{\text {th }}$ & $5^{\text {th }}$ & $6^{\text {th }}$ & $7^{\text {th }}$ \\
\hline & & $\alpha$ & $\alpha$ & $\alpha$ & $\alpha$ & $\alpha$ & $\alpha$ \\
\hline Teacher AS & 18 & .92 & .89 & .90 & -- & -- & -- \\
\hline Student Autonomy & 9 & .89 & .88 & .81 & .86 & .83 & .78 \\
\hline Student Comp & 6 & .75 & .77 & .71 & .72 & .70 & .78 \\
\hline Student Related & 4 & .87 & .79 & .82 & .86 & .83 & .78 \\
\hline Student Eng & 9 & .77 & .76 & .77 & .76 & .72 & .73 \\
\hline
\end{tabular}

Table 5.6

Descriptive Statistics, including Mean Levels and Standard Deviations, by Grade

\begin{tabular}{|c|c|c|c|c|c|c|}
\hline & \multicolumn{3}{|c|}{ Fall } & \multicolumn{3}{|c|}{ Spring } \\
\hline & $5^{\text {th }}$ & $6^{\text {th }}$ & $7^{\text {th }}$ & $5^{\text {th }}$ & $6^{\text {th }}$ & $7^{\text {th }}$ \\
\hline & $\begin{array}{c}M \\
(S D)\end{array}$ & $\begin{array}{c}M \\
(S D)\end{array}$ & $\begin{array}{c}M \\
(S D)\end{array}$ & $\begin{array}{c}M \\
(S D)\end{array}$ & $\begin{array}{c}M \\
(S D)\end{array}$ & $\begin{array}{c}M \\
\text { (SD) }\end{array}$ \\
\hline Teacher & 3.07 & 2.88 & 2.68 & -- & -- & -- \\
\hline Autonomy Support & $(.62)$ & $(.54)$ & $(.57)$ & & & \\
\hline Student Autonomy & $\begin{array}{l}3.02 \\
(.70)\end{array}$ & $\begin{array}{l}2.85 \\
(.66)\end{array}$ & $\begin{array}{l}2.50 \\
(.58)\end{array}$ & $\begin{array}{l}2.85 \\
(.68)\end{array}$ & $\begin{array}{l}2.67 \\
(.62)\end{array}$ & $\begin{array}{l}2.47 \\
(.51)\end{array}$ \\
\hline Student & 3.49 & 3.43 & 3.30 & 3.47 & 3.31 & 3.12 \\
\hline Competence & $(.55)$ & $(.57)$ & $(.55)$ & $(.53)$ & $(.56)$ & $(.55)$ \\
\hline Student Relatedness & $\begin{array}{l}3.19 \\
(.81)\end{array}$ & $\begin{array}{l}2.97 \\
(.75)\end{array}$ & $\begin{array}{l}2.82 \\
(.76)\end{array}$ & $\begin{array}{l}3.00 \\
(.84)\end{array}$ & $\begin{array}{l}2.82 \\
(.80)\end{array}$ & $\begin{array}{l}2.72 \\
(.72)\end{array}$ \\
\hline Student & 3.19 & 3.07 & 2.91 & 3.14 & 2.95 & 2.79 \\
\hline Engagement & $(.52)$ & $(.50)$ & $(.53)$ & $(.52)$ & $(.51)$ & $(.47)$ \\
\hline
\end{tabular}

Note. $N_{5 \text { th graders }}=224, N_{6 \text { th } \text { graders }}=339, N_{7 \text { th } \text { graders }}=345$. 
Table 5.7

Inter-Correlations among Constructs in Fall and Spring, for Fifth, Sixth, and Seventh Grade Students

\begin{tabular}{|c|c|c|c|c|c|c|c|c|c|c|c|c|c|c|c|}
\hline & \multicolumn{3}{|c|}{$\begin{array}{c}\text { Autonomy } \\
\text { Support (AS) }\end{array}$} & \multicolumn{3}{|c|}{$\begin{array}{l}\text { Autonomy } \\
\text { (Aut) }\end{array}$} & \multicolumn{3}{|c|}{$\begin{array}{c}\text { Perceived } \\
\text { Competence } \\
\text { (PC) }\end{array}$} & \multicolumn{3}{|c|}{$\begin{array}{l}\text { Relatedness } \\
\quad \text { (Rel) }\end{array}$} & \multicolumn{3}{|c|}{$\begin{array}{l}\text { Engagement } \\
\text { (Eng) }\end{array}$} \\
\hline & $5^{\text {th }}$ & $6^{\text {th }}$ & $7^{\text {th }}$ & $5^{\text {th }}$ & $6^{\text {th }}$ & $7^{\text {th }}$ & $5^{\text {th }}$ & $6^{\text {th }}$ & $7^{\text {th }}$ & $5^{\text {th }}$ & $6^{\text {th }}$ & $7^{\text {th }}$ & $5^{\text {th }}$ & $6^{\text {th }}$ & $7^{\text {th }}$ \\
\hline AS & -- & -- & -- & .39 & .27 & .25 & .34 & .31 & .26 & .52 & .38 & .32 & .47 & .42 & .35 \\
\hline Aut & .54 & .44 & .46 & .72 & .61 & .49 & .27 & .23 & .18 & .49 & .32 & .30 & .54 & .41. & .38 \\
\hline $\mathrm{PC}$ & .45. & .42 & .46. & .32 & .30 & .27 & .49 & .52 & .48 & .29 & .26 & .22 & .50 & .51 & .49 \\
\hline Rel & .65 & .60 & .67 & .50 & .35 & .43. & .37 & .24 & .22 & .44 & .41 & .37 & .52 & .42 & .38 \\
\hline Eng & .63 & .60 & .58 & .60 & .54 & .48 & .54 & .48 & .57 & .56 & .54 & .58 & 69. & .57 & .52 \\
\hline
\end{tabular}

Note. $N_{\text {sth graders }}=224, N_{6 \text { th graders }}=339, N_{7 \text { th graders }}=345$. Fall correlations depicted below the diagonal; Spring correlations depicted above the diagonal; Cross-time stabilities depicted on the diagonal. All correlations are significant at $\mathrm{p}<.01$.

Autonomy in spring. A moderation analysis was conducted to examine whether the relation between teacher autonomy support and student autonomy differed for students from fifth, sixth, and seventh grades. Teacher autonomy support, student autonomy in fall, and grade were entered in the first step of the regression analysis. In the second step of the regression, the interaction between autonomy support and grade was entered. This result revealed a significant interaction between teacher autonomy support in fall and grade, indicating that the connection between autonomy support in fall and changes in autonomy from fall to spring differed as a function of students' grade, $\beta=$ $.09, t(903)=-2.11, p<.05$. Results can be seen in Figure 5.5. 


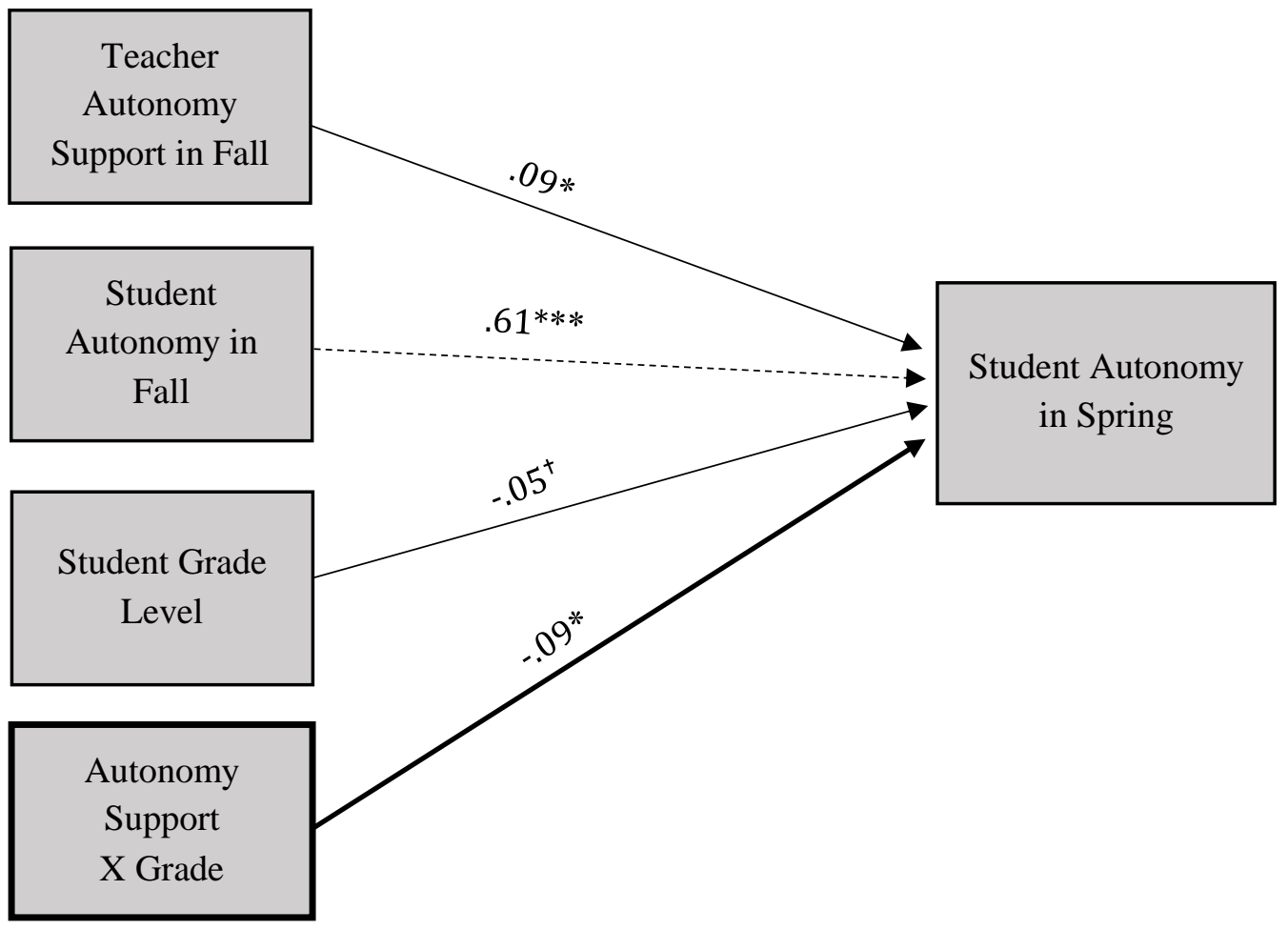

Figure 5.5. Testing grade differences in the effects of teacher autonomy support as a predictor of changes in students' autonomy, by including an interaction term for the cross-product of autonomy support and grade level

Pairwise grade comparisons revealed a marginal significance in the impact of teacher autonomy support on student autonomy for fifth grade students as compared to seventh grade students, $\beta=-.10, p=.05$. The relation among variables was not significantly different for either the fifth and sixth grade comparison or the sixth and seventh grade comparison. Follow up regression analyses, examining simple effects, showed that although teacher autonomy support was significantly correlated with student autonomy in all three grades $(r=.39, .27, .25)$, it did not significantly predict changes in student autonomy from fall to spring for fifth grade students $(\beta=.01, t(221)=.18, p=$ 
.86 ), sixth grade students $(\beta=.01, t(336)=.15, p=.88)$, or seventh grade students $(\beta=$ $.04, t(342)=.68, p=.50)$. Despite the interaction trending toward significance between fifth and seventh graders in how teacher autonomy support predicts changes in student autonomy, it appears that the high cross-time stability in autonomy, prevented a detectable relation between teacher autonomy support and autonomy in the simple effects.

Competence in spring. A moderated regression was conducted for competence, using the same steps as the previous moderation for autonomy. This moderated regression revealed that the interaction of autonomy support and grade was not significant $\beta=-.04, t(903)=-.87, p=.39$, suggesting that the impact of teacher autonomy support on changes in student competence did not differ by grade (see Figure $5.6)$. 


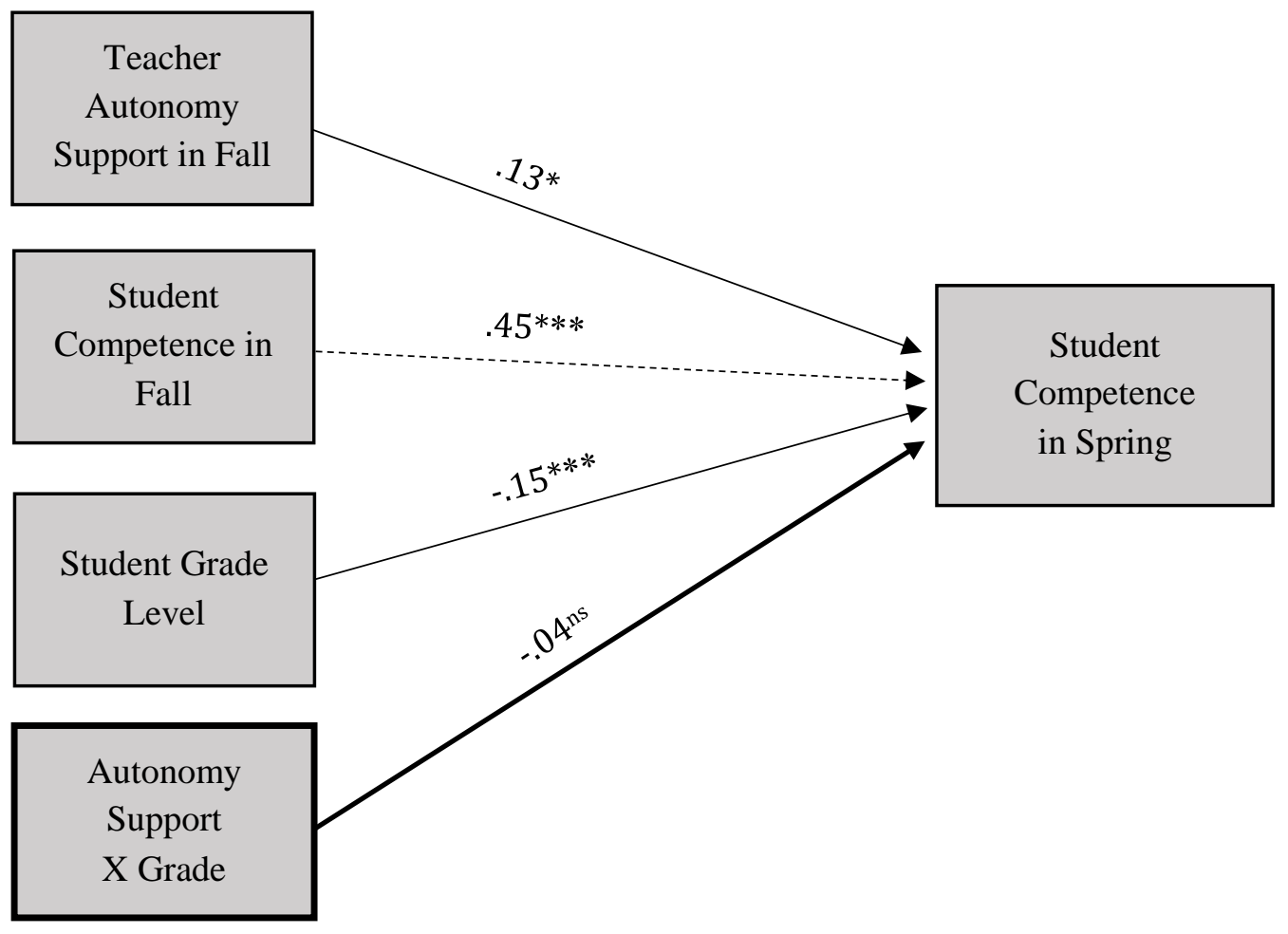

Figure 5.6. Testing grade differences in the effects of teacher autonomy support as a predictor of changes in students' competence, by including an interaction term for the cross-product of autonomy support and grade level

Relatedness in spring. The moderation analysis, which included teacher autonomy support, student relatedness in fall, grade, and the interaction of autonomy support and grade as predictors of students' feelings of relatedness in spring, revealed a significant interaction between teacher autonomy support and grade. This finding indicates that the connection between autonomy support in fall and changes in student relatedness from fall to spring differed as a function of grade, $\beta=-.16, t(903)=-3.21, p<$ .01 (see Figure 5.7). 


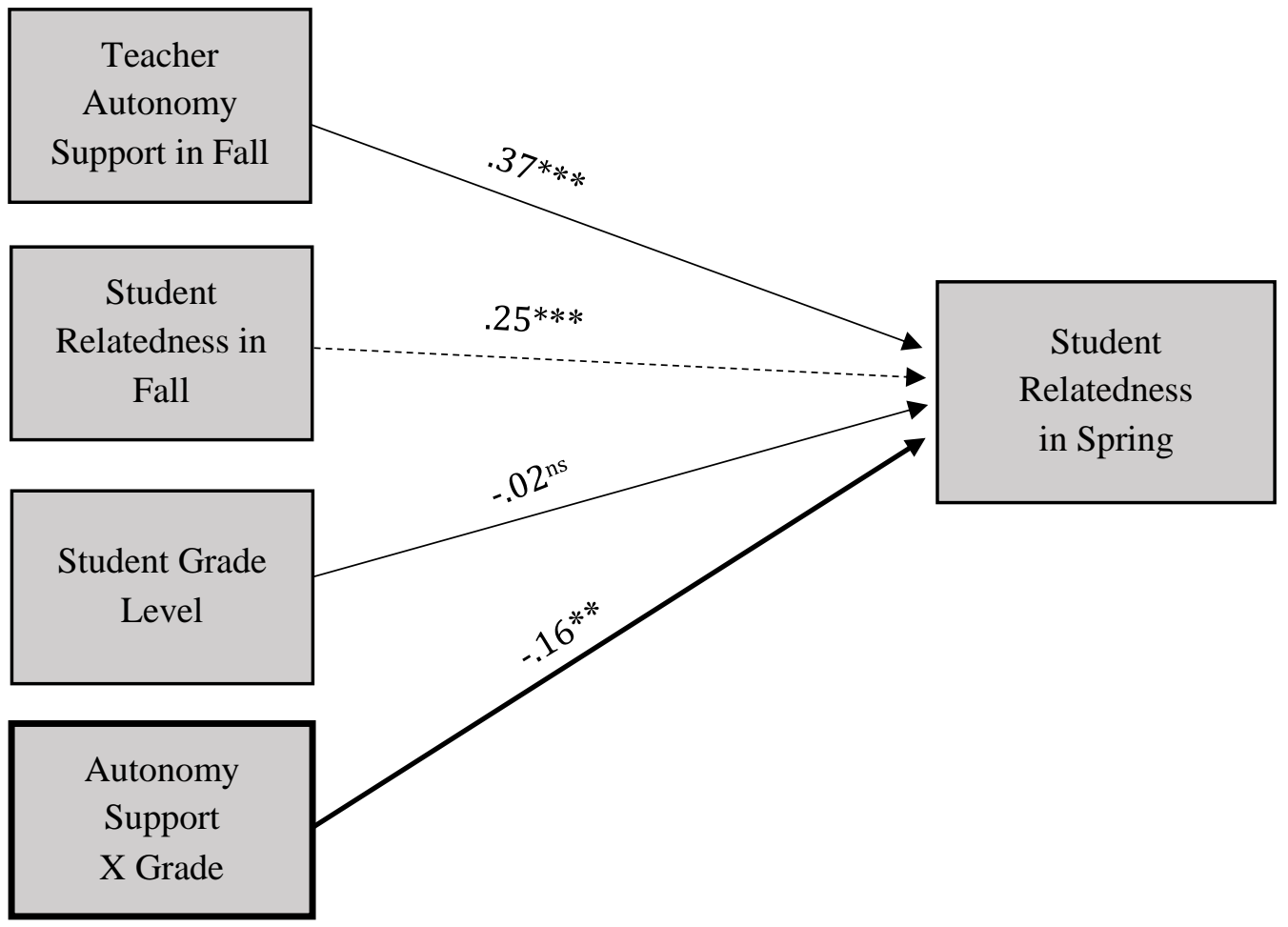

Figure 5.7. Testing grade differences in the effects of teacher autonomy support as a predictor of changes in students' relatedness, by including an interaction term for the cross-product of autonomy support and grade level

Due to the significant interaction, follow up analyses were conducted to examine how teacher autonomy support impacted changes in student relatedness from fall to spring differently across grades. Follow up regression analyses, examining simple effects, revealed that teacher autonomy support in fall significantly predicted changes in student relatedness from fall to spring for fifth grade students $(\beta=.40, t(221)=5.36, p<.001)$, sixth grade students $(\beta=.21, t(336)=3.37, p<.01)$, and seventh grade students $(\beta=.14$, $t(342)=2.04, p<.05)$. Pairwise moderation analyses showed that fifth grade students differed significantly from seventh grade students, whereby teacher autonomy support 
influenced changes in fifth grade students' relatedness significantly more than for seventh grade students, $\beta=-.18, p<.01$. Additionally, a smaller relation between these variables in seventh grade students, as compared to sixth grade students, is trending toward significance, $\beta=-.09, p=.08$. Results can be seen in Figures 5.8-5.10.

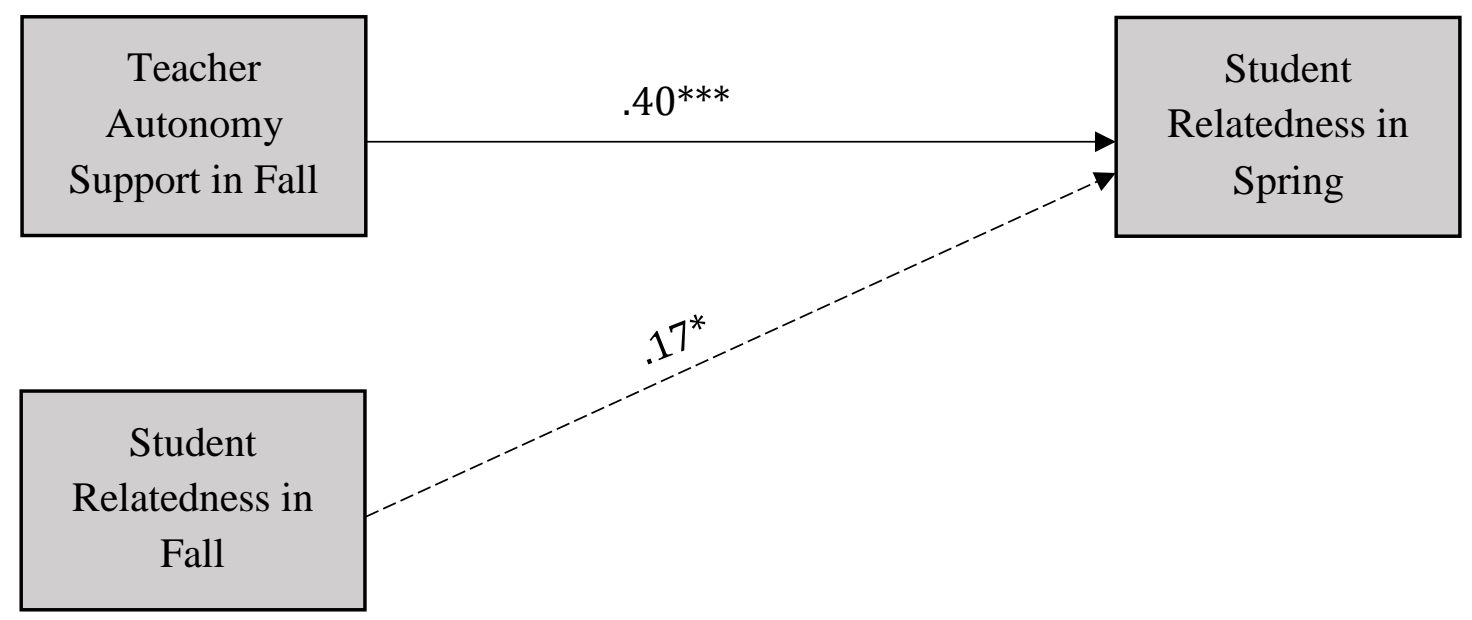

Figure 5.8. Standardized betas of teacher autonomy support in fall as a predictor of student relatedness in Spring, controlling for student relatedness in fall for fifth grade students.

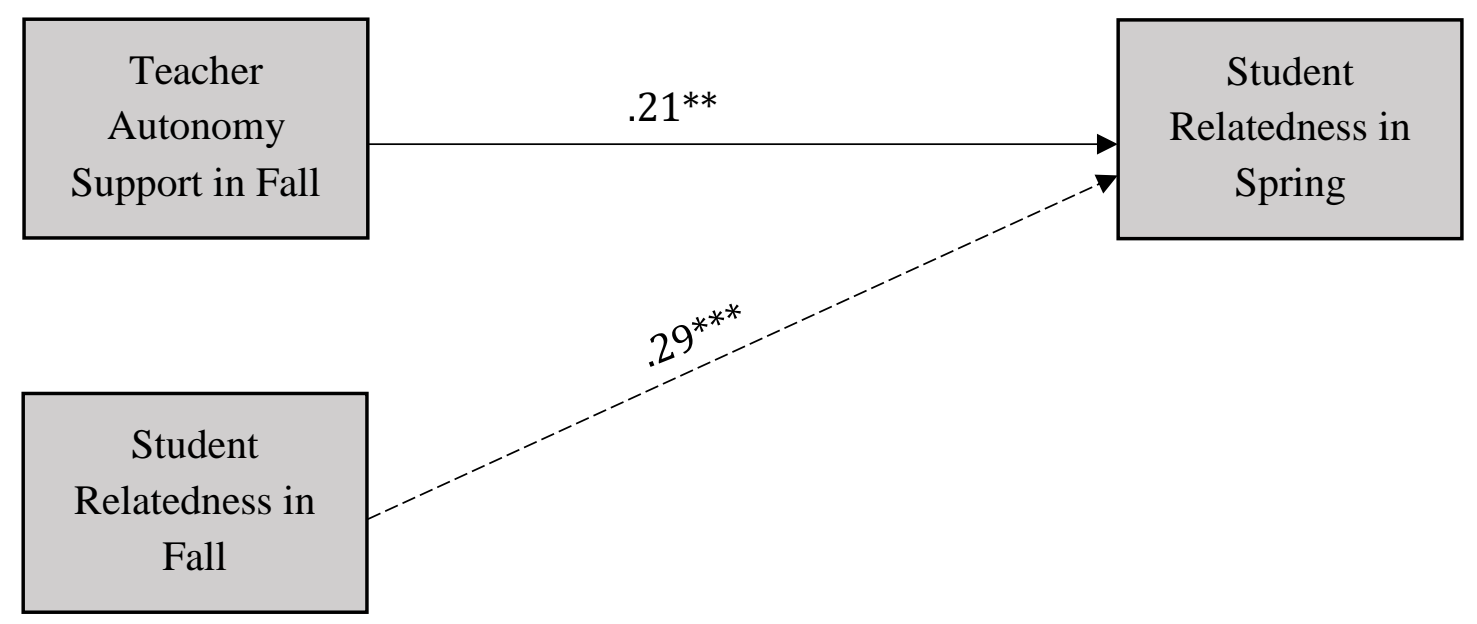

Figure 5.9. Standardized betas of teacher autonomy support in fall as a predictor of student relatedness in Spring, controlling for student relatedness in fall for sixth grade students. 


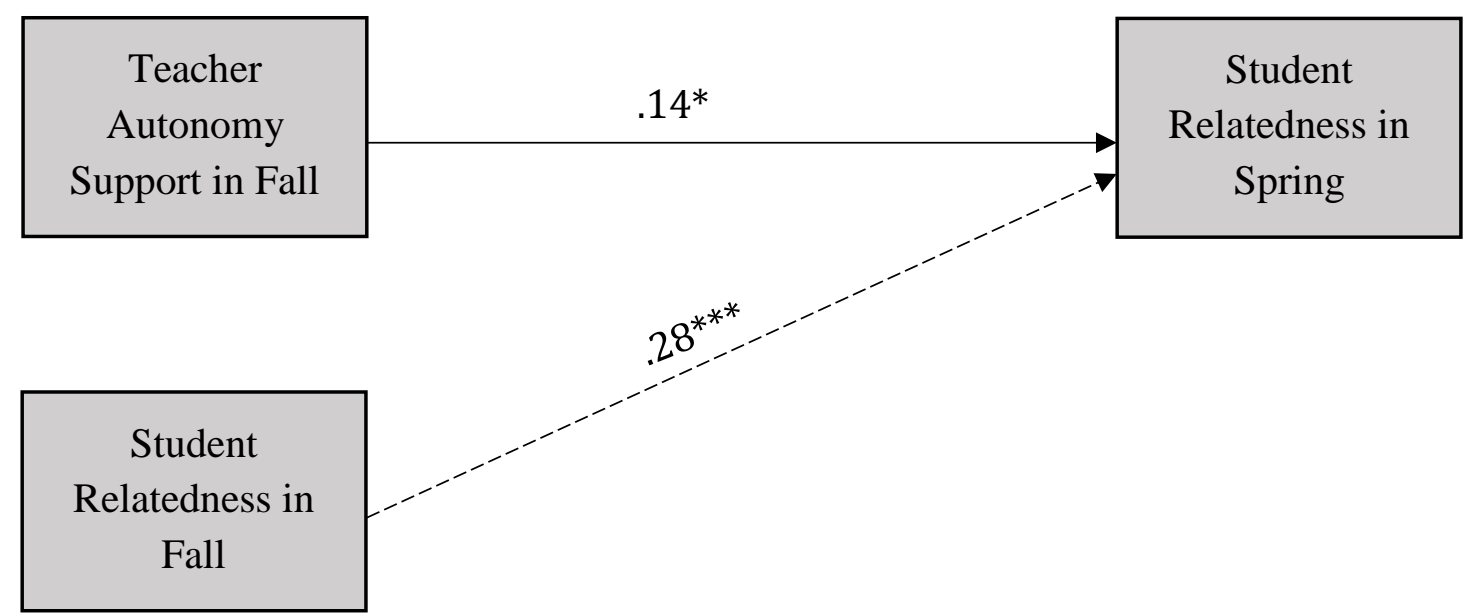

Figure 5.10. Standardized betas of teacher autonomy support in fall as a predictor of student relatedness in spring, controlling for student relatedness in fall for seventh grade students.

Engagement in spring. The final moderation analysis for this research question included student engagement in fall, grade, and the interaction of autonomy support and grade as predictors of student engagement in spring. This analysis revealed a significant interaction between teacher autonomy support and grade on changes in student engagement $(\beta=-.10, t(903)=-2.22, p<.05)$, indicating that the impact of autonomy support on changes in engagement differed as a function of grade, as can be seen in Figure 5.11. 


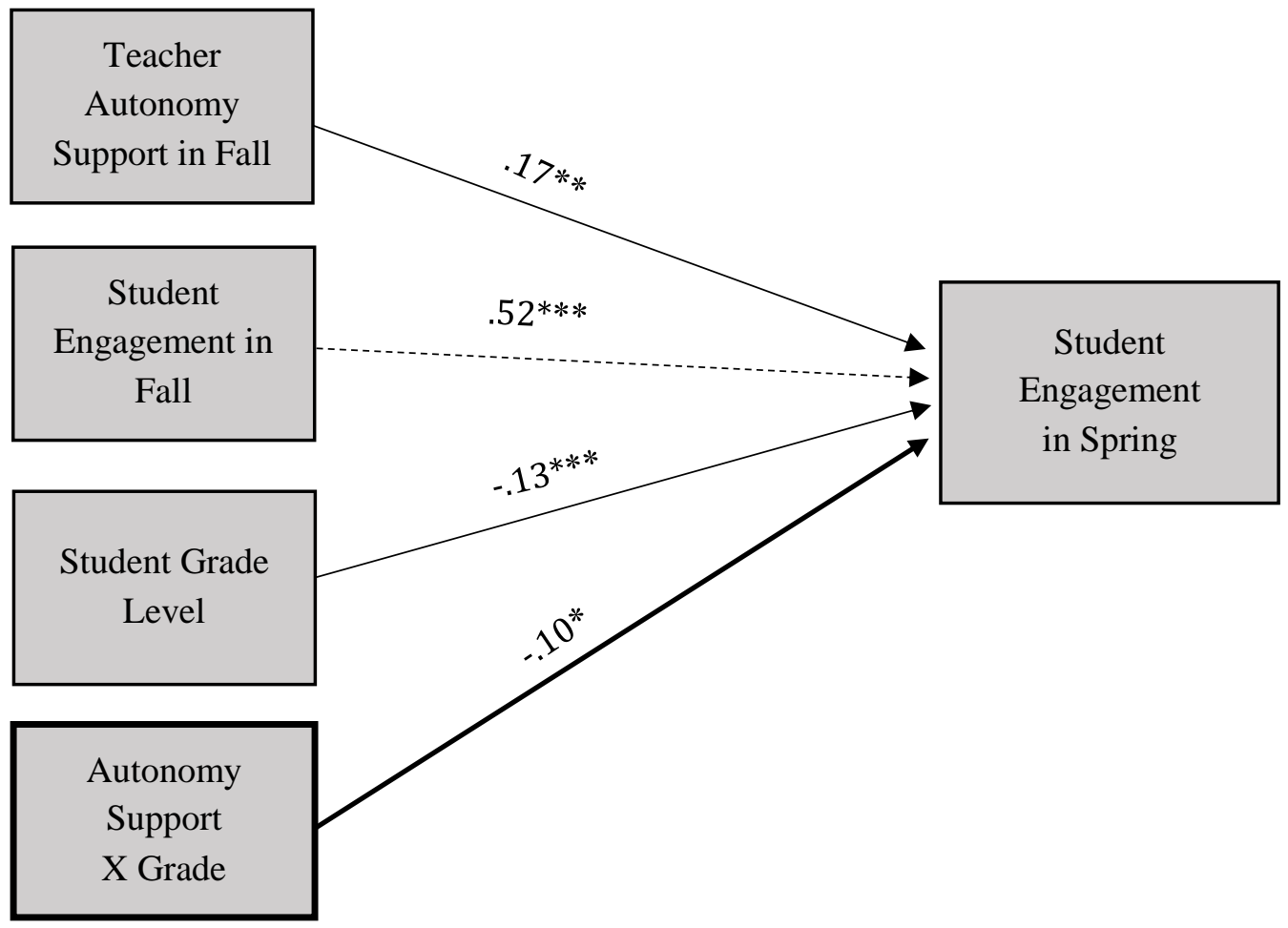

Figure 5.11. Testing grade differences in the effects of teacher autonomy support as a predictor of changes in students' engagement, by including an interaction term for the cross-product of autonomy support and grade level

These results led to pairwise moderation analyses, which showed that seventh graders' changes in engagement were statistically less impacted by their teachers' autonomy support than were fifth graders, $\beta=-.10, p<.05$. Additionally, a trending toward significant finding suggests that teacher autonomy support for sixth grade students is more important for their engagement than it is for seventh grade students' engagement, $\beta=-.09, p=.07$.

Follow up regression analyses revealed that teacher autonomy support in fall significantly predicted changes in student engagement from fall to spring for sixth grade 
students $(\beta=.12, t(336)=2.13, p<.05)$, but did not significantly predict these changes for either fifth grade students $(\beta=.07, t(221)=1.05, p=.296)$ or for seventh grade students $(\beta=.07, t(342)=1.15, p=.25)$. Significant results are presented in Figure 5.12.

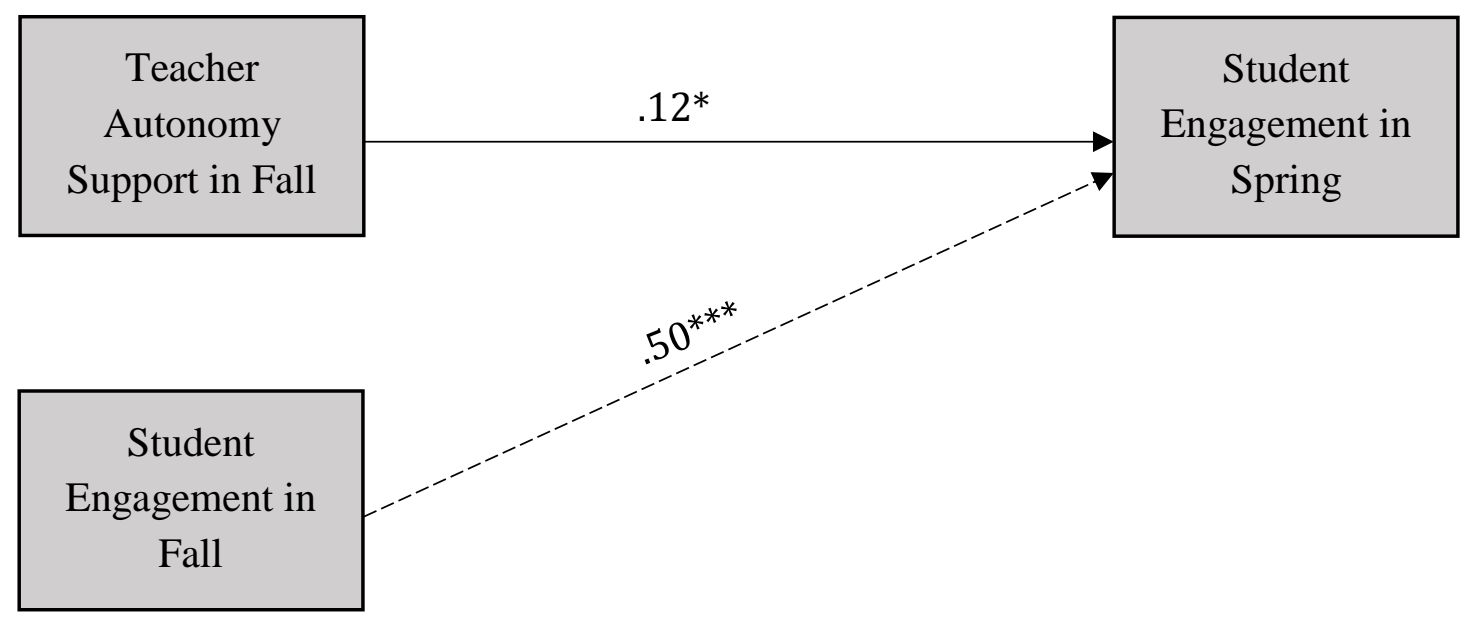

Figure 5.12. Standardized betas of teacher autonomy support in fall as a predictor of student engagement in spring, controlling for student engagement in fall for sixth grade students. 


\section{Research Question 2: Individual effects of each of the components of teacher autonomy support on students' motivational outcomes, overall and differentially by grade level.}

RQ2a. Do each of the components of autonomy support (i.e., respect, choice, relevance, coercion) in fall individually predict changes in students' motivational outcomes from fall to spring?

Ordinary Least Squares (OLS) regressions were used to evaluate whether students' perceptions of their teachers' autonomy supportive behaviors (i.e., respect, choice, relevance, and coercion) in fall predicted their own motivation (i.e., autonomy, competence, relatedness, engagement) in spring, when accounting for their levels of motivation in fall. To do so, each component of teacher autonomy support, as well as all four motivational outcomes in fall, were grand mean centered for all analyses.

Autonomy in spring. Four separate analyses, examining how each component of teacher autonomy support predicted changes in student autonomy from fall to spring, were conducted. Of the four components of autonomy support, only choice trended toward significance as a predictor of changes in autonomy from fall to spring. Results can be seen in Table 5.8. 
Table 5.8

Individual Effects of Four Components of Teachers' Provision of Autonomy Support in Fall on Changes in Student Autonomy from Fall to Spring

\begin{tabular}{ccccccc}
\hline & \multicolumn{6}{c}{ Student Autonomy in Spring } \\
\cline { 2 - 7 } Fall Predictors & $\beta$ & SE & $t$ & $F$ & $d f$ & $\mathrm{R}^{2}$ \\
\hline Regression 1: Teacher Respect & -.01 & .03 & -.25 & 303.80 & 2,905 & .40 \\
Student Autonomy & $.64^{* * *}$ & .03 & 22.28 & 303.80 & 2,905 & .40 \\
\hline Regression 2: Teacher Choice & $.05^{\dagger}$ & .02 & 1.68 & 306.10 & 2,905 & .40 \\
Student Autonomy & $.61^{* * *}$ & .03 & 21.65 & 306.10 & 2,905 & .40 \\
\hline Regression 3: Teacher Relevance & .04 & .03 & 1.32 & 305.20 & 2,905 & .40 \\
Student Autonomy & $.62^{* * *}$ & .03 & 21.27 & 305.20 & 2,905 & .40 \\
\hline Regression 4: Teacher Coercion & .00 & .02 & .08 & 303.76 & 2,905 & .40 \\
Student Autonomy & $.64 * * *$ & .03 & 22.86 & 303.76 & 2,905 & .40 \\
\hline
\end{tabular}

Note. ${ }^{\dagger} p<.10 * p<.05 * * p<.01 * * * p<.001$.

Competence in spring. An additional four analyses were conducted, examining

how each component of teacher autonomy support predicted changes in student

competence from fall to spring. As Table 5.9 shows, all components of teacher autonomy support were significant individual predictors of changes in student competence from fall to spring.

Table 5.9

Individual Effects of Four Components of Teachers' Provision of Autonomy Support in Fall on Changes in Student Competence from Fall to Spring

\begin{tabular}{cllllll}
\hline \multirow{2}{*}{ Fall Predictors } & \multicolumn{5}{c}{ Student Competence in Spring } \\
\cline { 2 - 7 } & \multicolumn{1}{c}{$\beta$} & $\mathrm{SE}$ & $t$ & $F$ & $d f$ & $\mathrm{R}^{2}$ \\
\hline Regression 1: Teacher Respect & $.12^{* * *}$ & .03 & 3.60 & 170.80 & 2,905 & .27 \\
Student Competence & $.46^{* * *}$ & .03 & 14.36 & 170.80 & 2,905 & .27 \\
\hline Regression 2: Teacher Choice & $.08^{*}$ & .02 & 2.57 & 166.46 & 2,905 & .27 \\
Student Competence & $.49^{* * *}$ & .03 & 16.71 & 166.46 & 2,905 & .27 \\
\hline Regression 3: Teacher Relevance & $.10^{* *}$ & .03 & 3.18 & 168.84 & 2,905 & .27 \\
Student Competence & $.48^{* * *}$ & .03 & 15.73 & 168.84 & 2,905 & .27 \\
\hline Regression 4: Teacher Coercion & -.14 & .02 & -4.40 & 175.13 & 2,905 & .28 \\
Student Competence & $.46^{* * *}$ & .03 & 14.93 & 175.13 & 2,905 & .28 \\
\hline
\end{tabular}

Note. ${ }^{\dagger} p<.10 * p<.05 * * p<.01 * * * p<.001$. 
Relatedness in spring. As with the previous two outcomes, four more analyses

were conducted, examining how each component of teacher autonomy support predicted changes in student relatedness from fall to spring. All four components of autonomy support were significant individual predictors of changes in student relatedness from fall to spring, which can be seen in Table 5.10.

Table 5.10

Individual Effects of Four Components of Teachers' Provision of Autonomy Support in Fall on Changes in Student Relatedness from Fall to Spring

\begin{tabular}{|c|c|c|c|c|c|c|}
\hline \multirow[b]{2}{*}{ Fall Predictors } & \multicolumn{6}{|c|}{ Student Relatedness in Spring } \\
\hline & $\beta$ & SE & $t$ & $F$ & $d f$ & $\mathrm{R}^{2}$ \\
\hline Regression 1: Teacher Respect & $.27 * * *$ & .04 & 7.00 & 124.03 & 2,905 & .22 \\
\hline Student & $.24 * * *$ & .04 & 6.26 & 124.03 & 2,905 & .22 \\
\hline \multicolumn{7}{|l|}{ Relatedness } \\
\hline Regression 2: Teacher Choice & $.11 * *$ & .04 & 3.27 & 100.94 & 2,905 & .18 \\
\hline Student & $.36 * * *$ & .03 & 10.71 & 100.94 & 2,905 & .18 \\
\hline \multicolumn{7}{|l|}{ Relatedness } \\
\hline Regression 3: Teacher & $.14 * * *$ & .04 & 4.11 & 104.67 & 2,905 & .19 \\
\hline Relevance & & & & & & \\
\hline Student & $.34 * * *$ & .04 & 9.68 & 104.67 & 2,905 & .19 \\
\hline \multicolumn{7}{|l|}{ Relatedness } \\
\hline Regression 4: Teacher Coercion & $-.15 * * *$ & .04 & -4.33 & 105.77 & 2,905 & .19 \\
\hline Student & $.34 * * *$ & .04 & 9.57 & 105.77 & 2,905 & .19 \\
\hline Relatedness & & & & & & \\
\hline
\end{tabular}

Engagement in spring. A final set of four analyses were conducted, examining how each component of teacher autonomy support predicted changes in student engagement from fall to spring. Three of the four components (i.e., respect, choice, and coercion) were significant individual predictors of changes in student engagement from fall to spring (See Table 5.11). 
Table 5.11

Individual Effects of Four Components of Teachers' Provision of Autonomy Support in Fall on Changes in Student Relatedness from Fall to Spring

Student Engagement in Spring

\begin{tabular}{cllllll} 
Fall Predictors & $\beta$ & $\mathrm{SE}$ & $t$ & $F$ & $d f$ & $\mathrm{R}^{2}$ \\
\hline Regression 1: Teacher Respect & $.15^{* * *}$ & .02 & 4.78 & 279.08 & 2,905 & .38 \\
Student Engagement & $.52^{* * *}$ & .03 & 16.41 & 279.08 & 2,905 & .38 \\
\hline Regression 2: Teacher Choice & $.06 *$ & .02 & 2.13 & 264.62 & 2,905 & .37 \\
Student Engagement & $.58^{* * *}$ & .03 & 19.76 & 100.94 & 2,905 & .18 \\
\hline Regression 3: Teacher Relevance & .02 & .02 & .52 & 261.26 & 2,905 & .37 \\
Student Engagement & $.60^{* * *}$ & .03 & 19.37 & 261.26 & 2,905 & .37 \\
\hline Regression 4: Teacher Coercion & $-.10^{* *}$ & .02 & -3.12 & 268.74 & 2,905 & .37 \\
Student Engagement & $.55^{* * *}$ & .03 & 17.73 & 268.74 & 2,905 & .37 \\
\hline
\end{tabular}

Note. ${ }^{\dagger} p<.10 * p<.05 * * p<.01 * * * p<.001$.

RQ2b. Do each of the components of teacher autonomy support (i.e., respect, choice, relevance, coercion) in fall predict changes in students' motivational outcomes from fall to spring differentially for students in fifth, sixth, and seventh grades?

Given the results from Research Question 2a, further analyses were conducted to examine whether the four components of teacher autonomy support impacted motivation differently for fifth, sixth, and seventh grade students. To do so, each component of autonomy support, as well as each motivational variable in fall, were again grand mean centered. Grade was centered at fifth grade. As Table 5.12 shows, all scales, with the exception of teacher relevance for sixth graders and teacher coercion for seventh graders, showed adequate internal consistency. The low alphas suggest it might be more difficult to detect significant relations in these two scales. 
Table 5.12

Alpha Levels of Fall Autonomy Support Scales by Grade

\begin{tabular}{|c|c|c|c|c|}
\hline & $\begin{array}{l}\text { Number of } \\
\text { Items }\end{array}$ & $\begin{array}{c}5^{\text {th }} \\
\alpha\end{array}$ & $\begin{array}{c}6^{\text {th }} \\
\alpha\end{array}$ & $\begin{array}{c}7^{\text {th }} \\
\alpha\end{array}$ \\
\hline Teacher Autonomy Support & 18 & .92 & .89 & .90 \\
\hline Teacher Respect & 5 & .85 & .79 & .80 \\
\hline Teacher Choice & 5 & .77 & .74 & .74 \\
\hline Teacher Relevance & 5 & .81 & .66 & .77 \\
\hline Teacher Coercion & 3 & .77 & .71 & .65 \\
\hline
\end{tabular}

For each motivational outcome (i.e., autonomy, competence, relatedness, engagement), four sets of moderated regression analyses (totaling in 16 analyses) were conducted to examine whether the relation between components of teacher autonomy support (i.e., respect, choice, relevance, coercion) and student motivation differed for students from fifth, sixth, and seventh grades. For each analysis, the component of autonomy support, student motivation in fall, and grade were entered in the first step of the regression analysis. In the second step of each regression, the interaction between the component of autonomy support and grade was entered. When interaction terms were significant, follow up analyses were conducted to test pairwise comparisons, and to examine the simple effects of the components on changes in motivation from fall to spring for each grade.

Autonomy in spring. Two of the four components of teacher autonomy support (i.e., relevance and coercion) differed by grade in their impacts on changes in student 
autonomy. Additionally, the interaction term for teacher respect also trended toward significance. Results can be seen in Table 5.13.

Table 5.13

Unique Effects of Four Components of Teachers' Provision of Autonomy Support in Fall on changes in Student Autonomy from Fall to Spring, Differentially by Grade

\begin{tabular}{cllllll}
\hline & \multicolumn{6}{c}{ Student Autonomy in Spring } \\
\cline { 2 - 7 } Fall Predictors & $\beta$ & SE & $t$ & $F$ & $d f$ & $\mathrm{R}^{2}$ \\
\hline Regression 1: Teacher Respect & .06 & .04 & 1.25 & 154.74 & 4,903 & .40 \\
Student Autonomy & $.62^{* * *}$ & .03 & 20.94 & 154.74 & 4,903 & .40 \\
Student Grade & $-.05^{*}$ & .02 & -2.00 & 154.74 & 4,903 & .40 \\
Respect*Grade & $-.08^{+}$ & .03 & -1.91 & 154.74 & 4,903 & .40 \\
\hline Regression 2: Teacher Choice & .06 & .04 & 1.30 & 154.09 & 4,903 & .40 \\
Student Autonomy & $.60^{* * *}$ & .03 & 20.72 & 154.09 & 4,903 & .40 \\
Student Grade & $-.05^{+}$ & .02 & -1.69 & 154.09 & 4,903 & .40 \\
Choice*Grade & -.03 & .03 & -.56 & 154.09 & 4,903 & .40 \\
\hline Regression 3: Teacher Relevance & $.12^{* *}$ & .04 & 2.67 & 156.29 & 4,903 & .41 \\
Student Autonomy & $.60^{* * *}$ & .03 & 20.11 & 156.29 & 4,903 & .41 \\
Student Grade & $-.05^{+}$ & .02 & -1.83 & 156.29 & 4,903 & .41 \\
Relevance*Grade & $-.11^{*}$ & .03 & -2.46 & 156.29 & 4,903 & .41 \\
\hline Regression 4: Teacher Coercion & $-.08^{+}$ & .04 & -1.72 & 155.45 & 4,903 & .41 \\
Student Autonomy & $.62^{* * *}$ & .03 & 21.58 & 155.45 & 4,903 & .41 \\
Student Grade & $-.05^{+}$ & .02 & -1.92 & 155.45 & 4,903 & .41 \\
Coercion*Grade & $.10^{*}$ & .03 & 2.33 & 155.45 & 4,903 & .41 \\
\hline
\end{tabular}

Note. ${ }^{\dagger} p<.10 * p<.05 * * p<.01 * * * p<.001 . \mathrm{T}=$ Teacher; $\mathrm{S}=$ Student.

Relevance predicting changes in autonomy by grade. Although the interaction term suggested significant differences in these relations across grade, the simple effects revealed that relevance in fall did not significantly predict changes in student autonomy from fall to spring for fifth grade students $(\beta=.04, t(221)=.77, p=.44)$, sixth grade students $(\beta=.05, t(336)=.97, p=33)$, or seventh grade students $(\beta=.02, t(342)=.38, p$ $=.70)$. Because relevance for fifth graders, sixth graders, and seventh graders was 
significantly correlated with autonomy in spring $(r=.37, .29, .22$, respectively), it appears that the high stability in autonomy from fall to spring obstructed this relation.

Coercion predicting changes in autonomy by grade. Following the significant interaction between teacher coercion and grade, further regression analyses were conducted, revealing that coercive teacher behaviors in fall did not significantly predict changes in student autonomy from fall to spring for fifth grade students $(\beta=-.04, t(221)$ $=-.72, p=.47)$, sixth grade students $(\beta=-.04, t(336)=.89, p=.37)$, or seventh grade students $(\beta=.01, t(342)=.09, p=.93)$. Because coercion for fifth graders, sixth graders, and seventh graders was significantly correlated with autonomy in spring $(r=-.34,-.12$, .18 , respectively), again it appears that the high stability of autonomy from fall to spring obstructed this relation.

Respect predicting changes in autonomy by grade. Follow up regression analyses, examining simple effects of teacher respect on changes in student autonomy, showed that although teacher provision of respect was significantly correlated with student autonomy in spring in all three grades $(r=.34, .24, .14)$, it did not significantly predict changes in student autonomy from fall to spring for fifth grade students $(\beta=-.03, t(221)=-.49, p=$ $.62)$, sixth grade students $(\beta=-.01, t(336)=-.19, p=.85)$, or seventh grade students $(\beta=$ $-.02, t(342)=-.48, p=.63)$.

Competence in spring. Of the four components of teacher autonomy support, only teacher provision of relevance showed grade differences in its impact on student competence. Results of all interaction analyses can be seen in Table 5.14. 
Table 5.14

Unique Effects of Four Components of Teachers' Provision of Autonomy Support in Fall on changes in Student Competence from Fall to Spring, Differentially by Grade

\begin{tabular}{cllllll}
\hline & \multicolumn{5}{c}{ Student Competence in Spring } \\
\cline { 2 - 7 } Fall Predictors & $\beta$ & $\mathrm{SE}$ & $t$ & $F$ & $d f$ & $\mathrm{R}^{2}$ \\
\hline Regression 1: Teacher Respect & $.12^{*}$ & .04 & 2.43 & 96.46 & 4,903 & .30 \\
Student Competence & $.45^{* * *}$ & .03 & 14.31 & 96.46 & 4,903 & .30 \\
Student Grade & $-.16^{* * *}$ & .02 & -5.63 & 96.46 & 4,903 & .30 \\
Respect*Grade & -.04 & .03 & -.87 & 96.46 & 4,903 & .30 \\
\hline Regression 2: Teacher Choice & .08 & .04 & 1.57 & 94.46 & 4,903 & .30 \\
Student Competence & $.48^{* * *}$ & .03 & 16.52 & 94.46 & 4,903 & .30 \\
Student Grade & $-.16^{* * *}$ & .02 & -5.60 & 94.46 & 4,903 & .30 \\
Choice*Grade & -.05 & .03 & -1.05 & 94.46 & 4,903 & .30 \\
\hline Regression 3: Teacher Relevance & $.15^{* *}$ & .04 & 3.05 & 96.93 & 4,903 & .30 \\
Student Competence & $.47^{* * *}$ & .03 & 15.59 & 96.93 & 4,903 & .30 \\
Student Grade & $-.16^{* * *}$ & .02 & -5.65 & 96.93 & 4,903 & .30 \\
Relevance*Grade & $-.10^{*}$ & .03 & -2.05 & 96.93 & 4,903 & .30 \\
\hline Regression 4: Teacher Coercion & $-.09^{\dagger}$ & .04 & -1.83 & 98.26 & 4,903 & .30 \\
Student Competence & $.45^{* * *}$ & .03 & 14.73 & 98.26 & 4,903 & .30 \\
Student Grade & $-.16^{* * *}$ & .02 & -5.60 & 98.26 & 4,903 & .30 \\
Coercion*Grade & -.02 & .03 & -.49 & 98.26 & 4,903 & .30 \\
\hline Note. ${ }^{\dagger} p<.10 * p<.05 * * p<.01 * * * p<.001 . \mathrm{T}=$ Teacher; S = Student. & &
\end{tabular}

Relevance predicting changes in competence by grade. Follow up analyses of the impact of relevance on student competence revealed that the provision of relevance in fall significantly predicted changes in student competence from fall to spring for fifth grade students only $(\beta=.19, t(221)=3.07, p<.01)$. This relation was not significant for either sixth grade students $(\beta=.07, t(336)=1.49, p=.14)$ or seventh grade students $(\beta=-.004$, $t(342)=-.08, p=.94)$. Although the correlations between relevance in fall and student competence in spring were significant for both sixth grade and seventh grade students $(r$ $=.22$ and .18 , respectively), the highly stable student competence from fall to spring obstructed the regression. 
Relatedness in spring. As Table 5.15 shows, all four components of teacher autonomy support significantly differed in their impacts on relatedness by grade level.

Table 5.15

Unique Effects of Four Components of Teachers' Provision of Autonomy Support in Fall on changes in Student Relatedness from Fall to Spring, Differentially by Grade

\begin{tabular}{|c|c|c|c|c|c|c|}
\hline \multirow{2}{*}{ Fall Predictors } & \multicolumn{6}{|c|}{ Student Relatedness in Spring } \\
\hline & $\beta$ & SE & $t$ & $F$ & $d f$ & $\mathrm{R}^{2}$ \\
\hline Regression 1: Teacher Respect & $.35 * * *$ & .06 & 6.27 & 63.85 & 4,903 & .20 \\
\hline Student & $.24 * * *$ & .04 & 6.14 & 63.85 & 4,903 & .20 \\
\hline \multicolumn{7}{|l|}{ Relatedness } \\
\hline Student Grade & -.04 & .03 & -1.19 & 63.85 & 4,903 & .20 \\
\hline Respect*Grade & $-.11 *$ & .04 & -2.17 & 63.85 & 4,903 & .20 \\
\hline Regression 2: Teacher Choice & $.23 * * *$ & .06 & 4.06 & 53.40 & 4,903 & .19 \\
\hline Student & $.36 * * *$ & .03 & 10.55 & 53.40 & 4,903 & .19 \\
\hline \multicolumn{7}{|l|}{ Relatedness } \\
\hline Student Grade & -.03 & .03 & -1.16 & 53.40 & 4,903 & .19 \\
\hline Choice*Grade & $-.15^{* *}$ & .04 & -2.85 & 53.40 & 4,903 & .19 \\
\hline Regression 3: T Relevance & $.26 * * *$ & .06 & 4.74 & 55.48 & 4,903 & .19 \\
\hline Student & $.34 * * *$ & .04 & 9.53 & 55.48 & 4,903 & .19 \\
\hline \multicolumn{7}{|l|}{ Relatedness } \\
\hline Student Grade & -.04 & .03 & -1.43 & 55.48 & 4,903 & .19 \\
\hline & $-.15^{* *}$ & .04 & -2.88 & 55.48 & 4,903 & .19 \\
\hline \multicolumn{7}{|l|}{ Relevance*Grade } \\
\hline Regression 4: Teacher & $-.27 * * *$ & .06 & -4.80 & 55.89 & 4,903 & .20 \\
\hline Coercion & & & & & & \\
\hline Student & $.33 * * *$ & .04 & 9.39 & 55.89 & 4,903 & .20 \\
\hline \multicolumn{7}{|l|}{ Relatedness } \\
\hline Student Grade & -.04 & .03 & -1.44 & 55.89 & 4, 903 & .20 \\
\hline Coercion*Grade & $.14 * *$ & .04 & 2.79 & 55.89 & 4, 903 & .20 \\
\hline
\end{tabular}

Note. ${ }^{\dagger} p<.10 * p<.05 * * p<.01 * * * p<.001 . \mathrm{T}=$ Teacher; $\mathrm{S}=$ Student.

Respect predicting changes in relatedness by grade. Follow up regression analyses of these relations separately by grade, revealed that the provision of respect in fall significantly predicted changes in student relatedness from fall to spring for fifth 
grade students $(\beta=.40, t(221)=5.24, p<.001)$, sixth grade students $(\beta=.17, t(336)=$ $2.75 p<.01)$, and seventh grade students $(\beta=.26, t(342)=4.06, p<.001)$. Although higher levels of respect predicted higher feelings of relatedness for all three grades, pairwise grade comparisons revealed that teacher provision of respect predicted student autonomy more strongly for fifth grade students than it did for seventh grade students, $\beta$ $=-.12, p=.03$. There was no significant difference in the impact of respect on changes in relatedness between fifth and sixth grade students, nor between sixth and seventh grade students.

Choice predicting changes in relatedness by grade. The provision of choice in fall significantly predicted changes in student relatedness from fall to spring for fifth grade students $(\beta=.18, t(221)=2.63, p<.01)$ and sixth grade students $(\beta=.15, t(336)=2.68$, $p<.01)$. However, despite a significant zero-order correlation between provisions of choice and relatedness in spring for seventh grade students $(r=.15)$, the simple effect was not significant for seventh grade students $(\beta=-.01, t(342)=-.14, p=.89)$, due to the stability of relatedness from fall to spring $(\beta=.37, t(342)=6.60, p<.001)$. Pairwise grade comparisons revealed that there was no significant difference for fifth and sixth grade students in the impact of choice on changes in relatedness. As expected, these relations were significantly different between fifth and seventh grade students $(\beta=-.16, p$ $<.01)$, as well as sixth and seventh grade students $(\beta=-.28, p<.05)$.

Relevance predicting changes in relatedness by grade. Follow up regression analyses of these relations separately by grade revealed that the provision of relevance in fall significantly predicted changes in student relatedness from fall to spring for fifth 
grade students $(\beta=.25, t(221)=3.64, p<.001)$ and sixth grade students $(\beta=.14, t(336)$ $=2.49, p<.05)$. Similar to the findings involving choice for seventh grade students, despite a significant zero-order correlation between provisions of relevance and relatedness in spring for seventh grade students $(r=.24)$, the simple effect was not significant for seventh grade students $(\beta=.05, t(342)=.88, p=.38)$, due to the stability of relatedness from fall to spring $(\beta=.34, t(342)=5.63, p<.001)$. As expected, these relations were significantly different between fifth and seventh grade students $(\beta=-.16, p$ $<.01)$, and marginally significant when comparing sixth and seventh grade students $(\beta=-$ $.22, p=.06)$.

\section{Coercion predicting changes in relatedness by grade. Follow up analyses} revealed that teacher coercion in fall significantly predicted changes in student relatedness from fall to spring for fifth grade students $(\beta=-.28, t(221)=-4.07, p<.001)$ and sixth grade students $(\beta=-.11, t(336)=-1.97, p<.05)$. However, despite a significant negative correlation between coercive teacher behaviors and relatedness in spring for seventh grade students $(r=.-25)$, the simple effect was not significant for students in that grade $(\beta=-.08, t(342)=-1.39, p=.16)$, due to the stability of relatedness from fall to spring $(\beta=.32, t(342)=5.48, p<.001)$. Pairwise grade comparisons revealed a trending toward significant difference between fifth and sixth grade students in the impact of teacher coercion on changes in relatedness $(\beta=.11, p=.08)$, such that coercion had a greater negative impact on relatedness for fifth grade students than for sixth grade students. Additionally, fifth and seventh grade students significantly differed on the 
impact of coercion on relatedness $(\beta=.16, p<.01)$. Surprisingly, sixth and seventh grade students did not differ significantly in these relations $(\beta=.12, p=.3)$.

Engagement in spring. Moderation analyses revealed that teacher provision of relevance had a significant interaction with grade in its impact on changes in student engagement from fall to spring. Similarly, teacher provision of respect had a marginally significant interaction with grade on the impact of student engagement. Results can be seen in Table 5.16.

Table 5.16

Unique Effects of Four Components of Teachers' Provision of Autonomy Support in Fall on changes in Student Engagement from Fall to Spring, Differentially by Grade Respect predicting changes in engagement by grade.

\begin{tabular}{cllllll}
\hline & \multicolumn{6}{c}{ Student Engagement in Spring } \\
\cline { 2 - 7 } Fall Predictors & $\beta$ & SE & $t$ & $F$ & $d f$ & $\mathrm{R}^{2}$ \\
\hline Regression 1: Teacher Respect & $.20^{* * *}$ & .04 & 4.24 & 150.35 & 4,903 & .40 \\
Student Engagement & $.50^{* * *}$ & .03 & 15.90 & 150.35 & 4,903 & .40 \\
Student Grade & $-.13^{* * *}$ & .02 & -4.88 & 150.35 & 4,903 & .40 \\
Respect*Grade & $-.08^{+}$ & .02 & -1.85 & 150.35 & 4,903 & .40 \\
\hline Regression 2: Teacher Choice & .07 & .04 & 1.52 & 142.38 & 4,903 & .39 \\
Student Engagement & $.56^{* * *}$ & .03 & 19.32 & 142.38 & 4,903 & .39 \\
Student Grade & $-.13^{* * *}$ & .02 & -4.93 & 142.38 & 4,903 & .39 \\
Choice*Grade & -.05 & .02 & -1.03 & 142.38 & 4,903 & .39 \\
\hline Regression 3: Teacher Relevance & $.12^{*}$ & .04 & 2.56 & 146.06 & 4,903 & .39 \\
Student Engagement & $.58^{* * *}$ & .03 & 18.88 & 146.06 & 4,903 & .39 \\
Student Grade & $-.14^{* * *}$ & .02 & -5.22 & 146.06 & 4,903 & .39 \\
Relevance*Grade & $-.15^{* *}$ & .02 & -3.38 & 146.06 & 4,903 & .39 \\
\hline Regression 4: Teacher Coercion & $-.14^{* *}$ & .03 & -2.88 & 145.28 & 4,903 & .39 \\
Student Engagement & $.53^{* * *}$ & .03 & 17.16 & 145.28 & 4,903 & .39 \\
Student Grade & $-.13^{* * *}$ & .02 & -5.03 & 145.28 & 4,903 & .39 \\
Coercion*Grade & -.07 & .02 & 1.50 & 145.28 & 4,903 & .39 \\
\hline
\end{tabular}

Note. ${ }^{\dagger} p<.10 * p<.05 * * p<.01 * * * p<.001 . \mathrm{T}=$ Teacher; $\mathrm{S}=$ Student. 
Follow up regression analyses separately by grade revealed that teacher respect in fall significantly predicted changes in student relatedness from fall to spring for fifth grade students $(\beta=.13, t(221)=2.20, p<.05)$, sixth grade students $(\beta=.12, t(336)=$ $2.29, p<.05)$, and seventh grade students $(\beta=.14, t(342)=2.62, p<.01)$. Pairwise grade comparisons revealed a trending toward significant difference between fifth and seventh grade students in the impact of teacher respect on changes in engagement $(\beta=-.09, p=$ $.08)$, such that the impact of students' experiences of teacher coercion on their feelings of relatedness was greater for fifth graders' than for seventh graders'. No other significant differences between groups was found.

Relevance predicting changes in engagement by grade. Despite the significant moderation, follow up regression analyses separately by grade revealed that teacher relevance in fall was not a significant predictor of changes in student relatedness from fall to spring for fifth grade students $(\beta=.05, t(221)=.84, p=.40)$ sixth grade students $(\beta=$ $.04, t(336)=.84, p=.40)$, or seventh grade students $(\beta=-.09, t(342)=-1.66, p=.10)$. 


\section{Research Question 3: Unique effects of the components of teacher autonomy support on students' motivational outcomes (and changes in their motivational outcomes), overall and for each grade level.}

RQ3a.a. Do the components of teacher autonomy support (i.e., respect, choice, relevance, coercion) in fall uniquely predict students' motivational outcomes in fall?

Ordinary Least Squares (OLS) regressions were conducted to assess how each provision of teacher autonomy support in fall (i.e., respect, choice, relevance, coercion) uniquely predicted each of the four motivational outcomes for students concurrently (i.e., autonomy, competence, relatedness, engagement in fall). To do so, four separate regressions for each outcome in fall were run and each included all four components of teacher autonomy support as predictors. All predictors were grand mean centered to enhance interpretation.

As expected, results showed that all four teacher behavioral components of autonomy support uniquely predicted students' feelings of autonomy concurrently. Student competence in fall was significantly and uniquely predicted by respect, relevance, and coercion, but not by choice. Much like autonomy, student perceived relatedness was significantly and uniquely predicted by all four components of autonomy support. Finally, student engagement in fall was significantly and uniquely predicted by respect, relevance, and coercion, but not by choice. Results for all four regressions can be seen in Tables 5.17-5.20. 
Table 5.17

Unique Effects of Four Components of Teachers' Provision of Autonomy Support in Fall on Student Autonomy in Fall

\begin{tabular}{|c|c|c|c|c|c|c|}
\hline \multirow[b]{2}{*}{$\begin{array}{l}\text { Fall } \\
\text { Predictors }\end{array}$} & \multicolumn{6}{|c|}{ Student Autonomy in the Fall } \\
\hline & $\beta$ & $\mathrm{SE}$ & $t$ & $F$ & $d f$ & $\mathrm{R}^{2}$ \\
\hline Respect & $.15 * *$ & .04 & 3.41 & 85.94 & 4,903 & .28 \\
\hline Choice & $.17 * * *$ & .04 & 4.66 & & & \\
\hline Relevance & $.23 * * *$ & .04 & 6.04 & & & \\
\hline Coercion & $-.08 *$ & .03 & -2.24 & & & \\
\hline
\end{tabular}

Table 5.18

Unique Effects of Four Components of Teachers' Provision of Autonomy Support in Fall on Student Competence in Fall

\begin{tabular}{lllllll}
\hline & \multicolumn{5}{c}{ Student Competence in the Fall } \\
\cline { 2 - 6 } Pall & $\beta$ & $\mathrm{SE}$ & $t$ & $F$ & $d f$ & $\mathrm{R}^{2}$ \\
\hline Respect & $.32 * * *$ & .04 & 7.29 & 71.35 & 4,903 & .24 \\
Choice & -.05 & .03 & -1.20 & & & \\
Relevance & $.11 * *$ & .03 & 2.84 & & & \\
Coercion & $-.16^{* * *}$ & .03 & -4.10 & & & \\
\hline
\end{tabular}

Note. ${ }^{\dagger} p<.10 * p<.05 * * p<.01 * * * p<.001$

Table 5.19

Unique Effects of Four Components of Teachers' Provision of Autonomy Support in Fall on Student Relatedness in Fall

\begin{tabular}{lllllll}
\hline & \multicolumn{6}{c}{ Student Relatedness in the Fall } \\
\cline { 2 - 7 } Pall & $\beta$ & SE & $t$ & $F$ & $d f$ & $\mathrm{R}^{2}$ \\
\hline Respect & $.42 * * *$ & .04 & 11.41 & 191.94 & 4,903 & .46 \\
Choice & $.09 * *$ & .04 & 2.81 & & & \\
Relevance & $.15 * * *$ & .04 & 4.39 & & & \\
Coercion & $-.14 * * *$ & .03 & -4.14 & & & \\
\hline Note. ${ }^{\dagger} p<.10 * p<.05 * * p<.01 * * * p<.001$ & & & &
\end{tabular}


Table 5.20

Unique Effects of Four Components of Teachers' Provision of Autonomy Support in Fall on Student Engagement in Fall

\begin{tabular}{|c|c|c|c|c|c|c|}
\hline \multirow[b]{2}{*}{$\begin{array}{l}\text { Fall } \\
\text { Predictors }\end{array}$} & \multicolumn{6}{|c|}{ Student Engagement in the Fall } \\
\hline & $\beta$ & $\mathrm{SE}$ & $t$ & $F$ & $d f$ & $\mathrm{R}^{2}$ \\
\hline Respect & $.24 * * *$ & .03 & 6.32 & 151.244 & 4,903 & .40 \\
\hline Choice & .06 & .03 & 1.83 & & & \\
\hline Relevance & $.21 * * *$ & .03 & 5.82 & & & \\
\hline Coercion & $-.25 * * *$ & .03 & -7.12 & & & \\
\hline
\end{tabular}

RQ3a.b. Do the components of teacher autonomy support (i.e., respect, choice, relevance, coercion) in fall uniquely predict changes in students' motivational outcomes from fall to spring?

This question examined the unique effects of all components of teacher autonomy support in predicting change from fall to spring of each motivational outcome variable. Similar to research question 3a.a, a set of four regressions were conducted, for each motivational outcome, and all four components of autonomy support were entered as predictors for all analyses. In contrast to the previous research question, however, change was assessed by including motivational variables in fall as predictors and spring motivational variables as outcomes.

Results showed that none of the autonomy support predictors remained significant on student autonomy when including student autonomy in fall into the model. Because all four components were significant predictors in the concurrent analysis, it appears that the insertion of autonomy in fall absorbed too much of the variance to show other relations. Changes in student competence from fall to spring were predicted significantly and 
uniquely only by teachers' coercive behaviors. Changes in student relatedness were predicted significantly and uniquely only by provision of respect. This finding is expected because the concurrent relation between teacher respect and student relatedness was notably high. Finally, changes in student engagement were predicted significantly and uniquely by both provisions of respect and relevance. Results for all four regressions can be seen in Tables 5.21-5.24.

Table 5.21

Unique Effects of Four Components of Teachers' Provision of Autonomy Support in Fall on Changes in Student Autonomy from Fall to Spring

Student Autonomy in Spring

\begin{tabular}{ccccccc}
\cline { 2 - 7 } Predictors in Fall & $\beta$ & SE & $t$ & $F$ & $d f$ & $\mathrm{R}^{2}$ \\
\hline Teacher Provisions & & & & & & \\
Respect & -.04 & .03 & -1.14 & 122.92 & 5,902 & .41 \\
Choice & .05 & .03 & 1.58 & & & \\
Relevance & .04 & .03 & 1.16 & & & \\
Coercion & .01 & .03 & .38 & & & \\
Student Motivation & & & & & & \\
Autonomy & $.62 * * *$ & .03 & 20.43 & & & \\
\hline Note. ${ }^{\dagger} p<.10^{*} p<.05 * * p<.01 * * * p<.001$ & & & &
\end{tabular}


Table 5.22

Unique Effects of Four Components of Teachers' Provision of Autonomy Support in Fall on Changes in Student Competence from Fall to Spring

\begin{tabular}{ccccccc}
\hline & \multicolumn{6}{c}{ Student Competence in Spring } \\
\cline { 2 - 7 } Predictors in Fall & $\beta$ & SE & $t$ & $F$ & $d f$ & $\mathrm{R}^{2}$ \\
\hline Teacher Provisions & & & & & & \\
Respect & .03 & .04 & .76 & 70.65 & 5,902 & .28 \\
Choice & -.00 & .03 & -.03 & & & \\
Relevance & .04 & .03 & 1.03 & & \\
Coercion & $-.10^{* * *}$ & .03 & -2.64 & & \\
Student Motivation & & & & & & \\
Competence & $.44^{* * *}$ & .03 & 13.70 & & \\
\hline
\end{tabular}

Note. ${ }^{+} p<.10 * p<.05 * * p<.01 * * * p<.001$

Table 5.23

Unique Effects of Four Components of Teachers' Provision of Autonomy Support in Fall on Changes in Student Relatedness from Fall to Spring

\begin{tabular}{|c|c|c|c|c|c|c|}
\hline \multirow[b]{2}{*}{ Predictors in Fall } & \multicolumn{6}{|c|}{ Student Relatedness in Spring } \\
\hline & $\beta$ & SE & $t$ & $F$ & $d f$ & $\mathrm{R}^{2}$ \\
\hline \multicolumn{7}{|l|}{ Teacher Provisions } \\
\hline Respect & $.22 * * *$ & .05 & 4.74 & 50.19 & 5,902 & .22 \\
\hline Choice & .01 & .04 & .35 & & & \\
\hline Relevance & .04 & .05 & .98 & & & \\
\hline Coercion & -.04 & .04 & -1.00 & & & \\
\hline \multicolumn{7}{|c|}{ Student Motivation } \\
\hline Relatedness & $.22 * * *$ & .04 & 5.57 & & & \\
\hline
\end{tabular}


Table 5.24

Unique Effects of Four Components of Teachers' Provision of Autonomy Support in Fall on Changes in Student Engagement from Fall to Spring

\begin{tabular}{ccccccr}
\hline & \multicolumn{7}{c}{ Student Engagement in Spring } \\
\cline { 2 - 7 } Predictors in Fall & $\beta$ & SE & $t$ & $F$ & $d f$ & $\mathrm{R}^{2}$ \\
\hline Teacher Provisions & & & & 113.02 & 5,902 & .39 \\
Respect & $.16^{* * *}$ & .03 & 4.03 & & & \\
Choice & .03 & .03 & .78 & & \\
Relevance & $-.08^{*}$ & .03 & -2.15 & & \\
Coercion & -.03 & .02 & -.92 & & \\
Student Motivation & & & & & & \\
Engagement & $.53 * * *$ & .03 & 15.56 &
\end{tabular}

RQ3b.a. Do the components of autonomy support in fall uniquely predict fall motivational outcomes for students in fifth, sixth, and seventh grades?

To understand the unique effects of each component of autonomy support on student motivational outcomes in fall, four sets of regression analyses were conducted, identical to research question 3a.a. Each set consisted of three regressions, which utilized fifth, sixth, and seventh grade samples separately.

Components on autonomy by grade. All three grades separately showed that teacher relevance significantly and uniquely predicted student autonomy in fall. Both fifth grade and sixth grade students' autonomy were significantly and uniquely predicted by teacher respect. Teachers' provision of choice significantly and uniquely predicted student autonomy only for sixth grade students, and teachers' coercive behaviors 
exclusively predicted seventh grade students' feelings of autonomy. Results can be seen in Tables 5.25-5.27.

Table 5.25

Unique Effects of Four Components of Teachers' Provision of Autonomy Support in Fall on Fifth Grade Student Autonomy in Fall

\begin{tabular}{lllllll}
\hline \multirow{2}{*}{\begin{tabular}{l} 
Fall \\
\cline { 2 - 6 } Predictors
\end{tabular}} & $\beta$ & $\mathrm{SE}$ & $t$ & $F$ & $d f$ & $\mathrm{R}^{2}$ \\
\hline Respect & $.22^{*}$ & .09 & 2.25 & 23.09 & 4,219 & .30 \\
Choice & .10 & .07 & 1.32 & & & \\
Relevance & $.20^{*}$ & .08 & 2.43 & & & \\
Coercion & -.12 & .08 & -1.37 & & & \\
\hline Note. ${ }^{\dagger} p<.10 * p<.05 * * p<.01 * * * p<.001$ & & & &
\end{tabular}

Table 5.26

Unique Effects of Four Components of Teachers' Provision of Autonomy Support in Fall on Sixth Grade Student Autonomy in Fall

\begin{tabular}{lllllll}
\hline \multirow{2}{*}{\begin{tabular}{l} 
Fall \\
\cline { 2 - 6 } Predictors
\end{tabular}} & $\beta$ & $\mathrm{SE}$ & $t$ & $F$ & $d f$ & $\mathrm{R}^{2}$ \\
\hline Respect & $.20^{* *}$ & .07 & 2.84 & 23.61 & 4,334 & .22 \\
Choice & $.14^{*}$ & .06 & 2.32 & & & \\
Relevance & $.22^{* * *}$ & .07 & 3.56 & & & \\
Coercion & .01 & .05 & .18 & & & \\
\hline Note. ${ }^{\dagger} p<.10^{*} p<.05^{* *} p<.01 * * * p<.001$ & & & &
\end{tabular}

Table 5.27

Unique Effects of Four Components of Teachers' Provision of Autonomy Support in Fall on Seventh Grade Student Autonomy in Fall

\begin{tabular}{lllllll}
\hline \multirow{2}{*}{\begin{tabular}{l} 
Fall \\
\cline { 2 - 6 } Predictors
\end{tabular}} & $\beta$ & $\mathrm{SE}$ & $t$ & $F$ & $d f$ & $\mathrm{R}^{2}$ \\
\hline Respect & .01 & .06 & .22 & 25.39 & 4,340 & .22 \\
Choice & $.16^{* *}$ & .05 & 2.67 & & & \\
Relevance & $.26^{* * *}$ & .05 & 4.14 & & & \\
Coercion & $-.15^{*}$ & .05 & -2.42 & & & \\
\hline Note. ${ }^{\dagger} p<.10^{*} p<.05^{* *} p<.01 * * * p<.001$ & & & &
\end{tabular}


Components on competence by grade. Student perceived competence in the Fall was significantly predicted by teacher respect for each grade of students. Sixth grade students' competence was significantly impacted by teacher coercion, whereas seventh grade students' competence was significantly impacted by provision of relevance. Results can be seen in Tables 5.28-5.30.

Table 5.28

Unique Effects of Four Components of Teachers' Provision of Autonomy Support in Fall on Fifth Grade Student Competence in Fall

\begin{tabular}{|c|c|c|c|c|c|c|}
\hline \multirow[b]{2}{*}{$\begin{array}{l}\text { Fall } \\
\text { Predictors }\end{array}$} & \multicolumn{6}{|c|}{ Fifth Grade Student Competence in the Fall } \\
\hline & $\beta$ & SE & $t$ & $F$ & $d f$ & $\mathrm{R}^{2}$ \\
\hline Respect & $.33 * *$ & .06 & 3.18 & 15.68 & 4,219 & .22 \\
\hline Choice & .01 & .07 & .11 & & & \\
\hline Relevance & .08 & .07 & .96 & & & \\
\hline Coercion & -.10 & .06 & -1.08 & & & \\
\hline
\end{tabular}

Table 5.29

Unique Effects of Four Components of Teachers' Provision of Autonomy Support in Fall on Sixth Grade Student Competence in Fall

\begin{tabular}{lllllll}
\hline & \multicolumn{5}{c}{ Sixth Grade Student Competence in the Fall } \\
\cline { 2 - 6 } Pall & $\beta$ & $\mathrm{SE}$ & $t$ & $F$ & $d f$ & $\mathrm{R}^{2}$ \\
\hline Respect & $.22 * *$ & .06 & 3.14 & 21.34 & 4,334 & .20 \\
Choice & -.05 & .05 & -.75 & & & \\
Relevance & .09 & .06 & 1.42 & & & \\
Coercion & $-.25 * * *$ & .05 & -3.99 & & & \\
\hline Note. ${ }^{\dagger} p<.10 * p<.05 * * p<.01 * * * p<.001$ & & & &
\end{tabular}


Table 5.30

Unique Effects of Four Components of Teachers' Provision of Autonomy Support in Fall on Seventh Grade Student Competence in Fall

\begin{tabular}{|c|c|c|c|c|c|c|}
\hline \multirow[b]{2}{*}{$\begin{array}{l}\text { Fall } \\
\text { Predictors }\end{array}$} & \multicolumn{6}{|c|}{ Seventh Grade Student Competence in the Fall } \\
\hline & $\beta$ & SE & $t$ & $F$ & $d f$ & $\mathrm{R}^{2}$ \\
\hline Respect & $.39 * * *$ & .05 & 6.14 & 31.16 & 4,340 & .27 \\
\hline Choice & -.08 & .05 & -1.40 & & & \\
\hline Relevance & $.16^{*}$ & .05 & 2.55 & & & \\
\hline Coercion & -.10 & .05 & -1.64 & & & \\
\hline
\end{tabular}

Components on relatedness by grade. Student relatedness in fall was significantly predicted by teacher respect for all three grades of students. Teacher coercion significantly predicted student relatedness for sixth and seventh grade students only. Choice was a significant predictor of student relatedness only for fifth grade students, whereas relevance was a significant predictor only for seventh grade students. Results can be seen in Tables 5.31-5.33 below.

Table 5.31

Unique Effects of Four Components of Teachers' Provision of Autonomy Support in Fall on Fifth Grade Student Relatedness in Fall

\begin{tabular}{lllllll}
\hline & \multicolumn{5}{c}{ Fifth Grade Student Relatedness in the Fall } \\
\cline { 2 - 6 } Fall & $\beta$ & $\mathrm{SE}$ & $t$ & $F$ & $d f$ & $\mathrm{R}^{2}$ \\
\hline Predictors & & .10 & 5.12 & 45.94 & 4,219 & .45 \\
Choice & $.13^{*}$ & .08 & 2.04 & & & \\
Relevance & .11 & .08 & 1.44 & & & \\
Coercion & -.09 & .08 & -1.18 & & & \\
\hline Note. ${ }^{\dagger} p<.10 * p<.05 * * p<.01 * * * p<.001$ & & & &
\end{tabular}


Table 5.32

Unique Effects of Four Components of Teachers' Provision of Autonomy Support in Fall on Sixth Grade Student Relatedness in Fall

\begin{tabular}{|c|c|c|c|c|c|c|}
\hline \multirow[b]{2}{*}{$\begin{array}{l}\text { Fall } \\
\text { Predictors }\end{array}$} & \multicolumn{6}{|c|}{ Sixth Grade Student Relatedness in the Fall } \\
\hline & $\beta$ & SE & $t$ & $F$ & $d f$ & $\mathrm{R}^{2}$ \\
\hline Respect & $.46^{* * *}$ & .07 & 7.55 & 58.59 & 4,334 & .41 \\
\hline Choice & .06 & .06 & 1.10 & & & \\
\hline Relevance & .09 & .07 & 1.62 & & & \\
\hline Coercion & $-.13 *$ & .05 & -2.44 & & & \\
\hline
\end{tabular}

Table 5.33

Unique Effects of Four Components of Teachers' Provision of Autonomy Support in Fall on Seventh Grade Student Relatedness in Fall

\begin{tabular}{|c|c|c|c|c|c|c|}
\hline \multirow[b]{2}{*}{$\begin{array}{l}\text { Fall } \\
\text { Predictors }\end{array}$} & \multicolumn{6}{|c|}{ Seventh Grade Student Relatedness in the Fall } \\
\hline & $\beta$ & SE & $t$ & $F$ & $d f$ & $\mathrm{R}^{2}$ \\
\hline Respect & $.38 * * *$ & .06 & 7.09 & 75.28 & 4,340 & .47 \\
\hline Choice & .07 & .05 & 1.39 & & & \\
\hline Relevance & $.21 * * *$ & .06 & 4.13 & & & \\
\hline Coercion & $-.16 * *$ & .05 & -3.11 & & & \\
\hline
\end{tabular}

Note. ${ }^{\dagger} p<.10 * p<.05 * * p<.01 * * * p<.001$

Components on engagement by grade. For each grade, student engagement in

fall was significantly predicted by teacher respect, relevance, and coercive behaviors.

Results can be seen in Tables 5.34-5.36.

Table 5.34

Unique Effects of Four Components of Teachers' Provision of Autonomy Support in Fall on Fifth Grade Student Engagement in Fall

\begin{tabular}{lllllll}
\hline \multirow{2}{*}{$\begin{array}{l}\text { Fall } \\
\text { Predictors }\end{array}$} & $\beta$ & $\mathrm{SE}$ & $t$ & $F$ & $d f$ & \multirow{2}{*}{$\mathrm{R}^{2}$} \\
\hline Respect & $.30^{* *}$ & .06 & 3.34 & 38.67 & 4,219 & .41 \\
Choice & .06 & .05 & .84 & & & \\
Relevance & $.20 *$ & .06 & 2.61 & & & \\
Coercion & $-.19 *$ & .05 & -2.41 & & & \\
\hline Note. ${ }^{\dagger} p<.10 * p<.05 * * p<.01 * * * p<.001$ & & & &
\end{tabular}


Table 5.35

Unique Effects of Four Components of Teachers' Provision of Autonomy Support in Fall on Sixth Grade Student Engagement in Fall

\begin{tabular}{|c|c|c|c|c|c|c|}
\hline \multirow[b]{2}{*}{$\begin{array}{l}\text { Fall } \\
\text { Predictors }\end{array}$} & \multicolumn{6}{|c|}{ Sixth Grade Student Engagement in the Fall } \\
\hline & $\beta$ & SE & $t$ & $F$ & $d f$ & $\mathrm{R}^{2}$ \\
\hline Respect & $.24 * * *$ & .05 & 3.89 & 51.74 & 4,334 & .38 \\
\hline Choice & .04 & .04 & .81 & & & \\
\hline Relevance & $.20 * * *$ & .05 & 3.56 & & & \\
\hline Coercion & $-.27 * * *$ & .04 & -4.95 & & & \\
\hline
\end{tabular}

Table 5.36

Unique Effects of Four Components of Teachers' Provision of Autonomy Support in Fall on Seventh Grade Student Engagement in Fall

\begin{tabular}{lllllll}
\hline & \multicolumn{5}{c}{ Seventh Grade Student Engagement in the Fall } \\
\cline { 2 - 7 } Fall & $\beta$ & $\mathrm{SE}$ & $t$ & $F$ & $d f$ & \multirow{2}{*}{$\mathrm{R}^{2}$} \\
\hline Predictors & & .05 & 3.67 & 46.37 & 4,340 & .35 \\
Choice & .04 & .04 & .79 & & & \\
Relevance & $.21 * * *$ & .05 & 3.66 & & & \\
Coercion & $-.25 * * *$ & .04 & -4.39 & & & \\
\hline Note. ${ }^{\dagger} p<.10 * p<.05 * * p<.01 * * * p<.001$ & & &
\end{tabular}

RQ3b.b. Do the components of autonomy support in fall uniquely predict changes in motivational outcomes from fall to spring for students in fifth, sixth, and seventh grades?

This research question was answered by conducting the same analyses as research question 3a.b, separately for each grade. Again, each component of teacher autonomy support, as well as the motivational student variables in fall, were grand mean centered.

Components on changes in autonomy by grade. Of the three grades, only seventh grade students had a significant predictor of teacher choice on changes in their autonomy from fall to spring. Results can be seen in Tables 5.37-5.39. 
Table 5.37

Unique Effects of Four Components of Teachers' Provision of Autonomy Support in Fall on Changes in Fifth Grade Student Autonomy from Fall to Spring

Fifth Grade Student Autonomy in Spring

\begin{tabular}{cccccccc}
\cline { 2 - 7 } Predictors in Fall & $\beta$ & $\mathrm{SE}$ & $t$ & $F$ & $d f$ & $\mathrm{R}^{2}$ \\
\hline Teacher Provisions & & & & & & \\
Respect & -.14 & .08 & -1.65 & 47.90 & 5,218 & .52 \\
Choice & -.04 & .06 & -.63 & & & \\
Relevance & .10 & .07 & 1.39 & & & \\
Coercion & -.10 & .06 & -1.42 & & \\
Student Motivation & & & & & & \\
Autonomy & $.71 * * *$ & .05 & 12.75 & & \\
\hline
\end{tabular}

Note. ${ }^{+} p<.10 * p<.05 * * p<.01 * * * p<.001$ 
Table 5.38

Unique Effects of Four Components of Teachers' Provision of Autonomy Support in Fall on Changes in Sixth Grade Student Autonomy from Fall to Spring

\begin{tabular}{|c|c|c|c|c|c|c|}
\hline \multirow[b]{2}{*}{ Predictors in Fall } & \multicolumn{6}{|c|}{ Sixth Grade Student Autonomy in Spring } \\
\hline & $\beta$ & $\mathrm{SE}$ & $t$ & $F$ & $d f$ & $\mathrm{R}^{2}$ \\
\hline \multicolumn{7}{|l|}{ Teacher Provisions } \\
\hline Respect & -.02 & .06 & -.27 & 40.62 & 5,333 & .38 \\
\hline Choice & .03 & .05 & .48 & & & \\
\hline Relevance & .06 & .06 & 1.12 & & & \\
\hline Coercion & .06 & .05 & 1.08 & & & \\
\hline \multicolumn{7}{|l|}{ Student Motivation } \\
\hline Autonomy & $.60 * * *$ & .05 & 12.23 & & & \\
\hline
\end{tabular}

Table 5.39

Unique Effects of Four Components of Teachers' Provision of Autonomy Support in Fall on Changes in Seventh Grade Student Autonomy from Fall to Spring

\begin{tabular}{lcccccr}
\hline & \multicolumn{6}{c}{ Seventh Grade Student Autonomy in Spring } \\
\cline { 2 - 7 } Predictors in Fall & $\beta$ & SE & $t$ & $F$ & $d f$ & $\mathrm{R}^{2}$ \\
\hline Teacher Provisions & & & & & & \\
Respect & -.07 & .05 & -1.03 & 23.00 & 5,339 & .25 \\
Choice & $.15^{*}$ & .04 & 2.46 & & \\
Relevance & .00 & .05 & .01 & & \\
Coercion & .03 & .04 & .47 & & \\
Student Motivation & & & & & & \\
Autonomy & $.47^{* * *}$ & .05 & 8.69 &
\end{tabular}


Components on changes in competence by grade. Among analyses on changes in student competence from fall to spring, fifth grade students' perceptions of their teachers' relevance only significantly predicted these changes. Results can be seen in tables 5.405.42 .

Table 5.40

Unique Effects of Four Components of Teachers' Provision of Autonomy Support in Fall on Changes in Fifth Grade Student Competence from Fall to Spring

Fifth Grade Student Competence in Spring

\begin{tabular}{cccccccc}
\cline { 2 - 7 } Predictors in Fall & $\beta$ & SE & $t$ & $F$ & $d f$ & $\mathrm{R}^{2}$ \\
\hline Teacher Provisions & & & & & & \\
Respect & .02 & .07 & .19 & 16.20 & 5,218 & .27 \\
Choice & -.04 & .06 & -.49 & & & \\
Relevance & $.19 *$ & .06 & 2.21 & & & \\
Coercion & -.02 & .06 & -.24 & & & \\
Student Motivation & & & & & & \\
Competence & $.41 * * *$ & .06 & 6.29 & &
\end{tabular}


Table 5.41

Unique Effects of Four Components of Teachers' Provision of Autonomy Support in Fall on Changes in Sixth Grade Student Competence from Fall to Spring

Sixth Grade Student Competence in Spring

\begin{tabular}{ccccccc}
\cline { 2 - 7 } Predictors in Fall & $\beta$ & SE & $t$ & $F$ & $d f$ & $\mathrm{R}^{2}$ \\
\hline Teacher Provisions & & & & & & \\
Respect & .06 & .06 & .92 & 26.62 & 5,333 & .29 \\
Choice & -.01 & .05 & -.25 & & & \\
Relevance & .03 & .06 & .49 & & & \\
Coercion & -.06 & .05 & -1.04 & & & \\
Student Motivation & & & & & & \\
Competence & $.47 * * *$ & .05 & 9.02 & & \\
\hline
\end{tabular}

Note. ${ }^{\dagger} p<.10 * p<.05 * * p<.01 * * * p<.001$

Table 5.42

Unique Effects of Four Components of Teachers' Provision of Autonomy Support in Fall on Changes in Seventh Grade Student Competence from Fall to Spring

\begin{tabular}{ccccccc}
\hline & \multicolumn{6}{c}{ Seventh Grade Student Competence in Spring } \\
\cline { 2 - 7 } Predictors in Fall & $\beta$ & SE & $t$ & $F$ & $d f$ & $\mathrm{R}^{2}$ \\
\hline Teacher Provisions & & & & & & \\
Respect & -.01 & .06 & -.09 & 22.90 & 5,339 & .25 \\
Choice & -.06 & .05 & -1.04 & & & \\
Relevance & -.04 & .05 & -.71 & & \\
Coercion & -.18 & .05 & -2.88 & & \\
Student Motivation & & & & & & \\
Competence & $.45^{* * *}$ & .06 & 8.21 & & & \\
\hline
\end{tabular}

Note. ${ }^{\dagger} p<.10^{*} p<.05 * * p<.01 * * * p<.001$ 
Components on changes in relatedness by grade. Changes in student relatedness were significantly predicted by teachers' provision of respect for both fifth and seventh grade students. Results can be seen in Tables 5.43-5.45.

Table 5.43

Unique Effects of Four Components of Teachers' Provision of Autonomy Support in Fall on Changes in Fifth Grade Student Relatedness from Fall to Spring

Fifth Grade Student Relatedness in Spring

\begin{tabular}{|c|c|c|c|c|c|c|}
\hline Predictors in Fall & $\beta$ & SE & $t$ & $F$ & $d f$ & $\mathrm{R}^{2}$ \\
\hline \multicolumn{7}{|l|}{ Teacher Provisions } \\
\hline Respect & $.27 *$ & .12 & 2.60 & 17.74 & 5,218 & .29 \\
\hline Choice & .03 & .09 & .45 & & & \\
\hline Relevance & .08 & .10 & .89 & & & \\
\hline Coercion & -.10 & .09 & -1.11 & & & \\
\hline \multicolumn{7}{|l|}{ Student Motivation } \\
\hline Relatedness & $.15^{\dagger}$ & .08 & 1.94 & & & \\
\hline
\end{tabular}


Table 5.44

Unique Effects of Four Components of Teachers' Provision of Autonomy Support in Fall on Changes in Sixth Grade Student Relatedness from Fall to Spring

Sixth Grade Student Relatedness in Spring

\begin{tabular}{cccccccc}
\cline { 2 - 7 } Predictors in Fall & $\beta$ & SE & $t$ & $F$ & $d f$ & $\mathrm{R}^{2}$ \\
\hline Teacher Provisions & & & & & & \\
Respect & .09 & .10 & 1.12 & 16.26 & 5,333 & .20 \\
Choice & .08 & .07 & 1.25 & & & \\
Relevance & .06 & .08 & .97 & & & \\
Coercion & -.04 & .07 & -.59 & & & \\
Student Motivation & & & & & & \\
Relatedness & $.28 * * *$ & .07 & 4.34 & & \\
\hline Note. ${ }^{\dagger} p<.10^{*} p<.05 * * p<.01 * * * p<.001$ &
\end{tabular}

Table 5.45

Unique Effects of Four Components of Teachers' Provision of Autonomy Support in Fall on Changes in Seventh Grade Student Relatedness from Fall to Spring

Seventh Grade Student Relatedness in Spring

\begin{tabular}{cccccccc}
\cline { 2 - 7 } Predictors in Fall & $\beta$ & $\mathrm{SE}$ & $t$ & $F$ & $d f$ & $\mathrm{R}^{2}$ \\
\hline Teacher Provisions & & & & & & \\
Respect & $.28 * * *$ & .08 & 3.89 & 14.69 & 5,339 & .18 \\
Choice & -.08 & .06 & -1.21 & & \\
Relevance & -.01 & .07 & -.13 & & \\
Coercion & -.01 & .06 & -.18 & & \\
Student Motivation & & & & & \\
Relatedness & $.22 * * *$ & .06 & 3.29 & & \\
\hline
\end{tabular}

Note. ${ }^{\dagger} p<.10 * p<.05 * * p<.01 * * * p<.001$ 
Components on changes in engagement by grade. Both fifth grade and seventh grade students' changes in engagement from fall to spring were significantly predicted by teachers' provision of respect. Additionally, seventh grade students' changes in engagement were significantly and negatively predicted by teacher provision of relevance. Results can be seen in Tables 5.46-5.48.

Table 5.46

Unique Effects of Four Components of Teachers' Provision of Autonomy Support in Fall on Changes in Fifth Grade Student Engagement from Fall to Spring

Fifth Grade Student Engagement in Spring

\begin{tabular}{lrrrrrrr}
\cline { 2 - 7 } Predictors in Fall & $\beta$ & $\mathrm{SE}$ & $t$ & $F$ & $d f$ & $\mathrm{R}^{2}$ \\
\hline Teacher Provisions & & & & & & & \\
Respect & $.19^{*}$ & .06 & 2.26 & 42.25 & 5,218 & .49 \\
Choice & -.05 & .05 & -.72 & & & \\
Relevance & -.01 & .05 & -.09 & & & \\
Coercion & .06 & .05 & .78 & & & \\
Student Motivation & & & & & & \\
Engagement & $.63^{* * *}$ & .06 & 9.96 & & & \\
\hline
\end{tabular}

Note. ${ }^{\dagger} p<.10^{*} p<.05 * * p<.01 * * * p<.001$ 
Table 5.47

Unique Effects of Four Components of Teachers' Provision of Autonomy Support in Fall on Changes in Sixth Grade Student Engagement from Fall to Spring

Sixth Grade Student Engagement in Spring

\begin{tabular}{cccccccc}
\cline { 2 - 7 } Predictors in Fall & $\beta$ & $\mathrm{SE}$ & $t$ & $F$ & $d f$ & $\mathrm{R}^{2}$ \\
\hline Teacher Provisions & & & & & & \\
Respect & .10 & .05 & 1.54 & 34.28 & 5,333 & .34 \\
Choice & -.03 & .04 & -.51 & & & \\
Relevance & -.00 & .05 & -.01 & & & \\
Coercion & -.07 & .04 & -1.21 & & & \\
Student Motivation & & & & & \\
Engagement & $.49 * * *$ & .06 & 8.66 & & \\
\hline Note. ${ }^{\dagger} p<.10^{*} p<.05 * * p<.01 * * * p<.001$ &
\end{tabular}

Table 5.48

Unique Effects of Four Components of Teachers' Provision of Autonomy Support in Fall on Changes in Seventh Grade Student Engagement from Fall to Spring

Seventh Grade Student Engagement in Spring

\begin{tabular}{|c|c|c|c|c|c|c|}
\hline \multirow[b]{2}{*}{ Predictors in Fall } & & & & & & \\
\hline & $\beta$ & $\mathrm{SE}$ & $t$ & $F$ & $d f$ & $\mathrm{R}^{2}$ \\
\hline \multicolumn{7}{|l|}{ Teacher Provisions } \\
\hline Respect & $.19 * *$ & .04 & 2.99 & 30.81 & 5,339 & .31 \\
\hline Choice & .06 & .04 & .98 & & & \\
\hline Relevance & $-.21 * *$ & .04 & -3.40 & & & \\
\hline Coercion & -.05 & .04 & -.76 & & & \\
\hline \multicolumn{7}{|l|}{ Student Motivation } \\
\hline Engagement & $.48 * * *$ & .05 & 8.65 & & & \\
\hline
\end{tabular}




\section{Research Question 4: Normative grade differences in teacher autonomy support and students' motivational outcomes.}

RQ4a. Do autonomy support and its components show the typical patterns of grade differences among fifth, sixth, and seventh grades, suggesting normative declines across the transition to middle school?

To determine the effect of grade on students' perceptions of teacher autonomy support, two sets of analyses were conducted. The first was a one-way analysis of variance (ANOVA), which included grade as the independent variable (fifth, sixth, seventh) and provisions of fall autonomy support as the dependent variable. The results indicated a significant difference in the amount of autonomy support provided by the teachers by grade, $F(2,905)=33.89, p<.001$. Approximately seven percent of the variability in teacher autonomy support was accounted for by grade, $\eta^{2}=.07$. Fifth grade students reported the highest levels of teacher autonomy support $(\mathrm{M}=3.07, \mathrm{SD}=.62)$, followed by sixth grade students $(\mathrm{M}=2.88, \mathrm{SD}=.54)$, while seventh grade students reported the lowest levels of teacher autonomy support $(\mathrm{M}=2.68, \mathrm{SD}=.59)$. Post hoc analyses using Tukey's follow-up tests revealed that the mean levels of autonomy support in each grade were all significantly different from one another.

The second set of analyses entailed a multivariate analysis of variance (MANOVA), with grade again as the independent variable and all four components of autonomy support (i.e., respect, relevance, choice, coercion) as the dependent variables. This omnibus test was significant, Pillai's Trace $=.08, F(8,899)=9.00, p<.001, \eta^{2}=$ .04. Follow-up ANOVAs indicated that all four components of autonomy support 
significantly differed by grade (see Table 5.49). Approximately four percent of the variability in teacher provision of respect, relevance, and coercion were accounted for by students' grade levels. Additionally, students' grade accounted for about seven percent of the variability in provision of choice.

Levene's test of equality of error variances demonstrated that reports of teacher respect, choice, and coercion all had equivalent variances across all three grades. Therefore, Tukey's follow-up test was used for those three constructs. These analyses revealed that levels of respect, choice, and coercion significantly differed amongst all grades. Levene's test demonstrated that relevance did not have equal variances across grades and so Dunnett's C test, which does not assume equal variances was used. Dunnett's C test revealed that levels of relevance differed significantly by each grade, as well. As was expected, respect, choice, and relevance all had highest mean levels in fifth grade students' reports, followed by sixth grade students, and lowest levels in seventh grade students' reports. Conversely, student reports of teacher coercion were lowest for fifth grade students, and higher levels in sixth grade, and higher still in seventh grade. Provisions of both teacher respect and teacher relevance stayed above the mid-point of the scale in all three grades. Mean levels of choice provision dropped below the midpoint of the scale for seventh grade students only. 
Table 5.49

Teachers' Provision of Autonomy Support and Components in fall Across Fifth, Sixth, and Seventh Grades

\begin{tabular}{|c|c|c|c|c|c|c|}
\hline & $\begin{array}{l}\text { Fifth } \\
\text { Grade }\end{array}$ & $\begin{array}{l}\text { Sixth } \\
\text { Grade }\end{array}$ & $\begin{array}{c}\text { Seventh } \\
\text { Grade }\end{array}$ & & & \\
\hline & $\mathrm{M}(\mathrm{SD})$ & $\mathrm{M}(\mathrm{SD})$ & $\mathrm{M}(\mathrm{SD})$ & $d f$ & $\mathrm{~F}$ & $\eta^{2}$ \\
\hline $\begin{array}{l}\text { Autonomy } \\
\text { Support }\end{array}$ & $3.07(.62)$ & $2.88(.54)$ & $2.68(.59)$ & $\begin{array}{l}2, \\
905\end{array}$ & $33.89 * * *$ & .07 \\
\hline Respect & $3.20(.73)$ & $3.06(.65)$ & $2.85(.68)$ & & $19.62 * * *$ & .04 \\
\hline Choice & $2.92(.70)$ & $2.66(.67)$ & $2.45(.69)$ & & $33.02 * * *$ & .07 \\
\hline Relevance & $3.06(.72)$ & $2.91(.61)$ & $2.73(.68)$ & & $17.47 * * *$ & .04 \\
\hline Coercion & $1.93(.78)$ & $2.11(.78)$ & $2.30(.74)$ & & $16.33 * * *$ & .04 \\
\hline
\end{tabular}

Note. $* p<.05 * * p<.01 * * * p<.001$. Fall and spring motivational outcomes averaged.

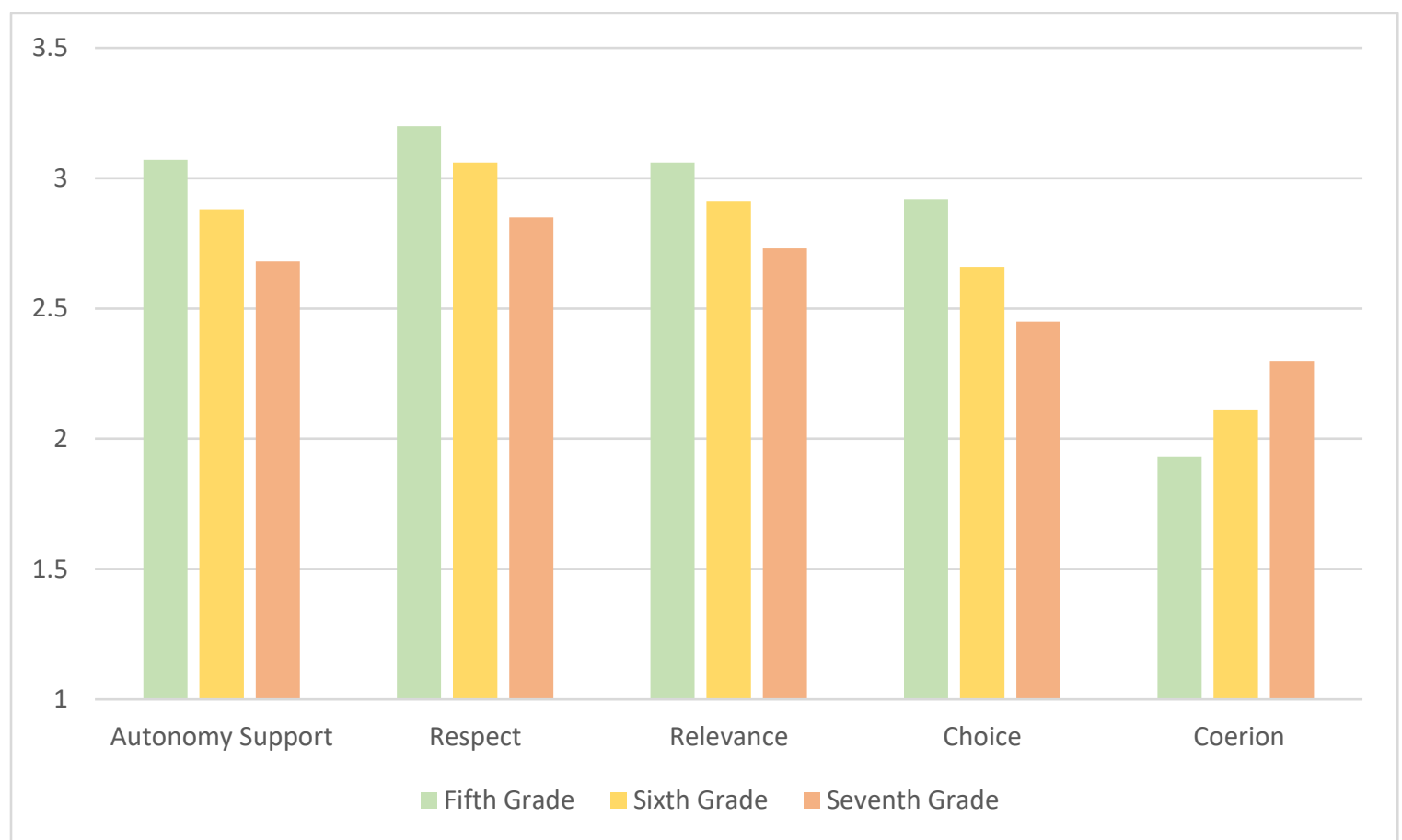

Figure 5.13. Mean Levels of Teacher Autonomy Support and Components in Fifth, Sixth, and Seventh Grades 
RQ4b. Do students' motivational outcomes show the typical patterns of grade differences among fifth, sixth, and seventh grades, suggesting normative declines across the transition to middle school?

A one-way multivariate analysis of variance (MANOVA) was conducted to evaluate differences in four motivational outcomes (i.e., autonomy, competence, relatedness, engagement) across fifth, sixth, and seventh grade students, in which the independent variable was grade and the dependent variables were the four motivational outcomes (fall and spring reports averaged). The omnibus MANOVA was significant, Pillai's Trace $=.12, \mathrm{~F}(8,899)=13.85, \mathrm{p}<.001, \eta^{2}=.06$. Follow-up ANOVAs showed that student autonomy, competence, relatedness, and engagement all significantly differed as a function of grade (see Table 5.50). Levene's test of equality of error variances demonstrated that student competence and engagement had equivalent variances across all three grades, whereas student autonomy and relatedness did not. Therefore, follow up analyses examining grade differences in competence and engagement were assessed using Tukey's test, whereas differences in autonomy and relatedness were assessed using Dunnett's $\mathrm{C}$ test, which does not assume equal variances across grades. Tukey's test revealed that students' reports of both competence and engagement differed significantly from each grade to the next. Dunnett's $C$ test revealed that levels of both autonomy and engagement differed significantly between all grades as well. Competence, relatedness, and engagement maintained mean levels above the scale mid-point, whereas mean levels of autonomy dropped below the scale mid-point in seventh grade students. 
Table 5.50

Student Motivational Outcomes Across Fifth, Sixth, and Seventh Grades

\begin{tabular}{lccccccc}
\hline & $\begin{array}{c}\text { Fifth } \\
\text { Grade }\end{array}$ & $\begin{array}{c}\text { Sixth } \\
\text { Grade }\end{array}$ & $\begin{array}{c}\text { Seventh } \\
\text { Grade }\end{array}$ & & & \\
\cline { 2 - 5 } & $\mathrm{M}(\mathrm{SD})$ & $\mathrm{M}(\mathrm{SD})$ & $\mathrm{M}(\mathrm{SD})$ & $d f$ & $\mathrm{~F}$ & $\eta^{2}$ \\
\hline Autonomy & $2.93(.64)$ & $2.76(.58)$ & $2.49(.47)$ & 2,905 & $46.80 * * *$ & .09 \\
Competence & $3.48(.47)$ & $3.37(.49)$ & $3.21(.47)$ & & $22.94 * * *$ & .05 \\
Relatedness & $3.10(.70)$ & $2.89(.65)$ & $2.78(.61)$ & & $16.52 * * *$ & .04 \\
Engagement & $3.17(.47)$ & $3.01(.45)$ & $2.85(.44)$ & & $33.80 * * *$ & .07 \\
\hline Note $* p<.05 * * p<.01 * * * p<.001$. Fall and spring motivational outcomes averaged.
\end{tabular}

Note. $* p<.05 * * p<.01 * * * p<.001$. Fall and spring motivational outcomes averaged.

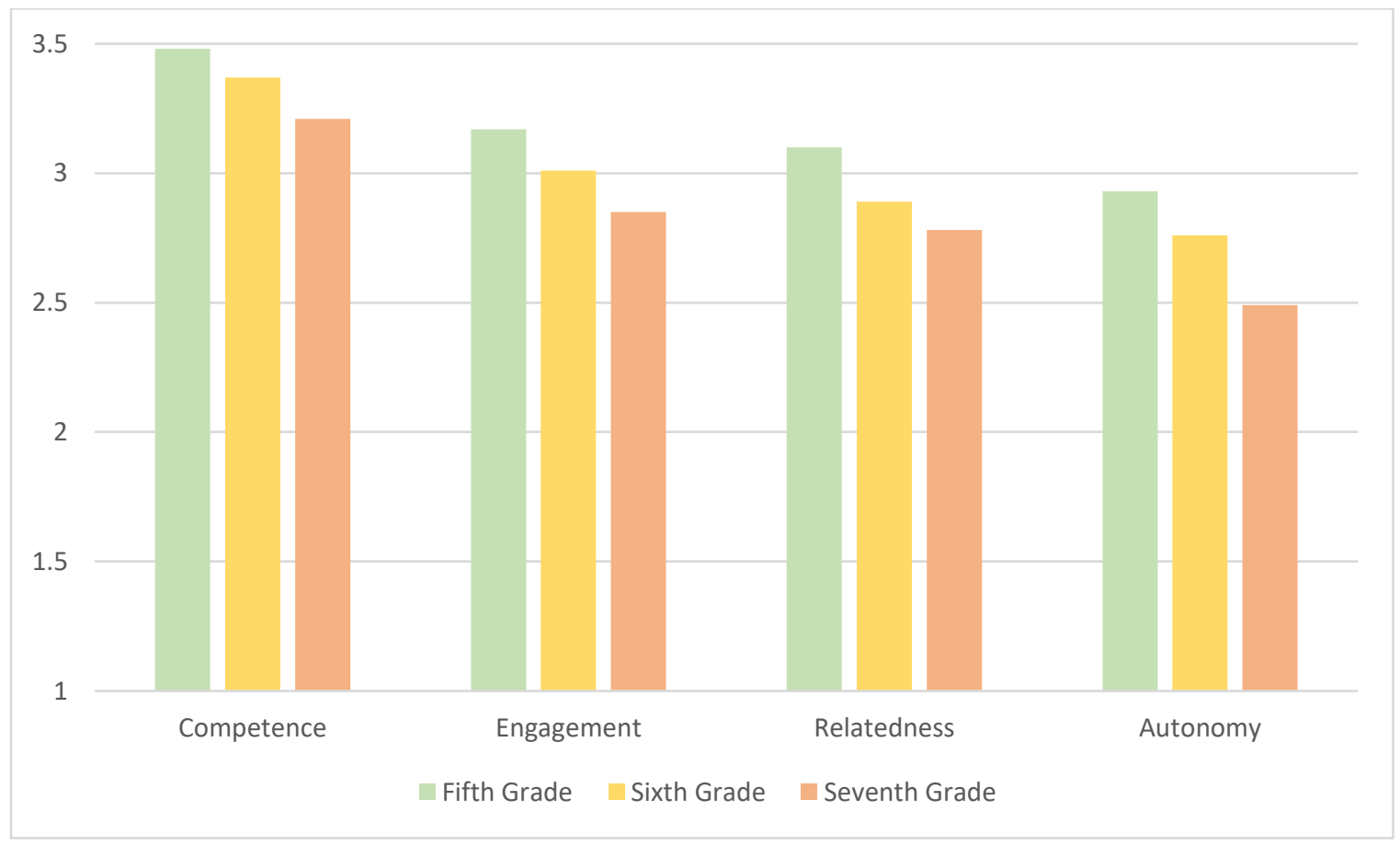

Figure 5.14. Mean Levels of Student Motivational Outcomes in Fifth, Sixth, and Seventh Grades 


\section{Research Question 5: Buffering effects of autonomy support on student motivation during the middle school transition.}

RQ5a. Do differences in teacher autonomy support across fifth, sixth, and seventh grade students underlie grade level differences in students' motivational outcomes, such that when teacher provisions of autonomy support are accounted for, differences in motivational outcomes across fifth, sixth, and seventh grade disappear?

To explore the effects of autonomy support on grade level differences in these motivational outcomes, a Multivariate Analysis of Covariance (MANCOVA) was conducted to examine whether students' age-graded differences in motivational outcomes disappeared when levels of teacher autonomy support were covaried out. Here, grade was entered as the independent variable, with three-levels (i.e., fifth, sixth, and seventh); teacher autonomy support in fall was the covariate; and averages of fall and spring autonomy, competence, relatedness, and engagement were the dependent variables. Grade was centered at fifth grade and teacher autonomy support was grand mean centered. The $F$-values, mean levels, standard deviations, and partial Eta squared can be seen in Table 5.51.

The omnibus MANCOVA was significant, Pillai's trace $=.06, F(8,899)=6.81, p$ $<.001, \eta^{2}=.03$ significant, The follow-up ANOVAS were significant for autonomy, competence, and engagement, such that when accounting for levels of autonomy support provided by teachers, students' feelings of autonomy, competence, and engagement still differed significantly by grade (see Table 5.51). However, grade was no longer a significant predictor of student perceived relatedness, with the insertion of autonomy 
support as a covariate. These findings suggest that the mean-level differences in autonomy, competence, and engagement across fifth, sixth, and seventh grade students cannot be explained by differing levels of autonomy support offered to students in each grade. Conversely, it appears that teacher autonomy support does underlie the grade differences in student relatedness.

\section{Table 5.51}

Student Motivational Outcomes Across Fifth, Sixth, and Seventh Grades Controlling for Autonomy Support

\begin{tabular}{llllllll}
\hline & $\begin{array}{c}\text { Fifth } \\
\text { Grade }\end{array}$ & $\begin{array}{c}\text { Sixth } \\
\text { Grade }\end{array}$ & $\begin{array}{c}\text { Seventh } \\
\text { Grade }\end{array}$ & & & \\
\cline { 2 - 5 } & $\mathrm{M}(\mathrm{SD})$ & $\mathrm{M}(\mathrm{SD})$ & $\mathrm{M}(\mathrm{SD})$ & $d f$ & $\mathrm{~F}$ & $\eta^{2}$ \\
\hline Autonomy & $2.93(.64)$ & $2.76(.58)$ & $2.49(.47)$ & 3,904 & $21.50 * * *$ & .05 \\
Competence & $3.48(.47)$ & $3.37(.49)$ & $3.21(.47)$ & & $6.21 * *$ & .01 \\
Relatedness & $3.10(.70)$ & $2.89(.65)$ & $2.78(.61)$ & & 1.16 & .00 \\
Engagement & $3.17(.47)$ & $3.01(.45)$ & $2.85(.44)$ & & $8.66^{* * *}$ & .02 \\
\hline
\end{tabular}

Note. ${ }^{*} p<.05 * * p<.01 * * * p<.001$. Fall and spring motivational outcomes averaged.

RQ5b. Do patterns of grade differences in students' motivational outcomes differ depending on the level of teacher autonomy support students experience, such that students who experience higher levels of teacher autonomy support show a more adaptive pattern of grade differences in autonomy, competence, relatedness, and engagement, suggesting that they maintain high levels of motivation, whereas students who experience lower levels of teacher autonomy support show patterns suggesting marked declines in motivation? 
To answer this question, a 3 X 3 factorial multivariate analysis of variance (MANOVA) was conducted, in which the two independent variables were grade of student (fifth, sixth, seventh) and level of teacher autonomy support in fall and the dependent variables were fall and spring averages of student autonomy, competence, relatedness, and engagement. Teacher autonomy support was entered into this model through a tertile split, in order to assess motivation for students receiving low, moderate, and high levels of autonomy support from their teachers. Grade was centered at fifth grade and teacher autonomy support was grand mean centered.

Main effects: grade differences. In the omnibus model, there was a significant effect of grade on student motivational outcomes, Pillai's trace $=.05, F(8,899)=6.24, p$ $<.001, \eta^{2}=.03$. Follow-up ANOVAs revealed that main effects of grade on outcomes was significant for student autonomy, competence, and engagement. Student relatedness did not differ significantly by grade when teacher autonomy support was included in the analysis. These follow-up results can be seen in Table 5.52. Levene's test of equality of error variances demonstrated that both student relatedness and engagement retained this assumption, whereas neither autonomy nor competence had equality of error variances across groups. Therefore, Tukey's test was used for post hoc analyses of relatedness and engagement and Dunnett's C was used for autonomy and competence. All post hoc analyses revealed that each motivational outcome differed significantly between each grade, such that fifth grade students reported the highest levels of motivation, followed by sixth graders, and finally seventh graders. 
Main effects: differences by Autonomy Support. There was also a significant effect of the level of teacher autonomy support on students' motivational outcomes, Pillai's Trace $=.40, F(8,899)=55.18, p<.001, \eta^{2}=.20$. Follow-up ANOVAs revealed that motivational outcomes differed significantly as a function of the level of autonomy support afforded to students. These results can be seen in Table 5.52. Post hoc analyses showed that levels of motivation were highest for students reporting the highest levels of autonomy support from teacher, significantly lower for students reporting moderate amounts of autonomy support, and lowest for the students reporting low levels of autonomy support.

Simple effects. The omnibus test for grade by level of autonomy support was nonsignificant, Pillai's Trace $=.02, F(16,891)=1.25, p=.22, \eta^{2}=.01$. Consistent with this omnibus test, the follow-up ANOVAs for student competence, relatedness, and engagement were all non-significant. The follow-up test for student autonomy, however, was trending toward significance. These follow-up results can be seen in Table 5.52. Due to this result, two additional ANOVAs were run for students with low support for their autonomy only and then for students with high support for their autonomy only. For students with low support for their autonomy, this ANOVA was significant, $F(2,300)=$ 4.57, $p<.05, \eta^{2}=.03$. Post hoc Dunnett's C showed a significant difference in student autonomy between sixth grade students and seventh grade students, such that seventh graders have lower levels. Fifth grade students' autonomy levels did not significantly differ with either sixth or seventh grade students. The ANOVA conducted only for students that reported high autonomy support was also significant, $F(2,306)=11.65, p<$ 
$.001, \eta^{2}=.07$. Dunnett's $\mathrm{C}$ post hoc analyses revealed that of the students receiving high levels of autonomy support reported, seventh grade students had significantly lower levels of autonomy than both fifth grade students and sixth grade students. Fifth and sixth grade students receiving high levels of autonomy support did not differ in their levels of autonomy. Figures 5.15-5.18 illustrate mean levels of all motivational outcomes for fifth, sixth, and seventh grade students experiencing low and high levels of teacher autonomy support. 
Table 5.52

Student Motivational Outcomes Across Fifth, Sixth, and Seventh Grades for Students with High, Moderate, and Low Levels of Teacher Autonomy Support

\begin{tabular}{|c|c|c|c|c|c|c|c|c|c|}
\hline & \multirow{2}{*}{$\begin{array}{l}\text { Fifth } \\
\text { Grade } \\
\text { M(SD) }\end{array}$} & \multirow{2}{*}{$\begin{array}{c}\text { Sixth } \\
\text { Grade } \\
\text { M(SD) }\end{array}$} & \multirow{2}{*}{$\begin{array}{l}\text { Seventh } \\
\text { Grade }\end{array}$} & \multicolumn{2}{|c|}{$\begin{array}{c}\text { Grade } \\
d f=2,899\end{array}$} & \multicolumn{2}{|c|}{$\begin{array}{c}\text { Autonomy } \\
\text { Support Level } \\
d f=2,899\end{array}$} & \multicolumn{2}{|c|}{$\begin{array}{c}\text { Grade*AS } \\
\text { Level } \\
d f=4,899\end{array}$} \\
\hline & & & & $\mathrm{F}$ & $\eta^{2}$ & $\mathrm{~F}$ & $\eta^{2}$ & $\mathrm{~F}$ & $\eta^{2}$ \\
\hline Autonomy & & & & $21.21 * * *$ & .05 & $77.86 * * *$ & .15 & 1.59 & .01 \\
\hline Low AS & $2.47(.60)$ & $2.53(.51)$ & $2.34(.41)$ & & & & & & \\
\hline Mod AS & $2.83(.54)$ & $2.67(.51)$ & $2.51(.40)$ & & & & & & \\
\hline High AS & $3.18(.58)$ & $3.03(.55)$ & $2.78(.54)$ & & & & & & \\
\hline Competence & & & & $4.33^{*}$ & .01 & $104.54 * * *$ & .19 & .85 & .00 \\
\hline Low AS & $3.08(.47)$ & $3.13(.52)$ & $3.04(.43)$ & & & & & & \\
\hline Mod AS & $3.41(.48)$ & $3.28(.47)$ & $3.22(46)$. & & & & & & \\
\hline High AS & $3.67(.34)$ & $3.65(.33)$ & $3.57(.36)$ & & & & & & \\
\hline Relatedness & & & & .91 & .00 & $186.87 * * *$ & .29 & 1.44 & .01 \\
\hline Low AS & $2.38(.54)$ & $2.47(.64)$ & $2.48(.52)$ & & & & & & \\
\hline Mod AS & $2.95(.64)$ & $2.81(.50)$ & $2.88(.53)$ & & & & & & \\
\hline High AS & $3.46(.50)$ & $3.32(.52)$ & $3.30(.50)$ & & & & & & \\
\hline Engagement & & & & $7.67 * * *$ & .02 & $165.16^{* * *}$ & .27 & .63 & .00 \\
\hline Low AS & $2.77(.43)$ & $2.73(.41)$ & $2.63(.36)$ & & & & & & \\
\hline Mod AS & $3.02(.41)$ & $2.92(.35)$ & $2.92(.38)$ & & & & & & \\
\hline High AS & $3.40(.39)$ & $3.32(.37)$ & $3.23(.39)$ & & & & & & \\
\hline
\end{tabular}

Note. ${ }^{\dagger} p<.10 * p<.05 * * p<.01 * * * p<.001$. Fall and spring motivational outcomes averaged. 
3.5

3

2.5

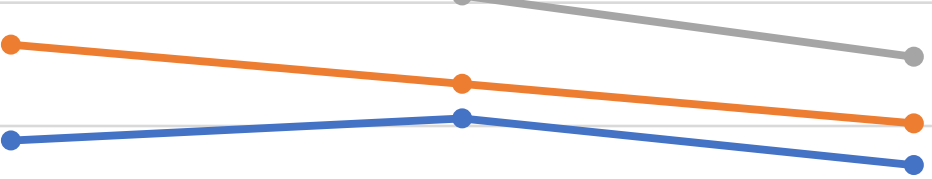

1.5

1

7th Grade

$\longrightarrow$ Low Autonomy Support $\quad \longrightarrow$ Moderate Autonomy Support $\quad-$ High Autonomy Support

Figure 5.15. Mean Levels of Student Autonomy in Fifth, Sixth, and Seventh Grades for Students with Low, Moderate, and High Teacher Autonomy Support

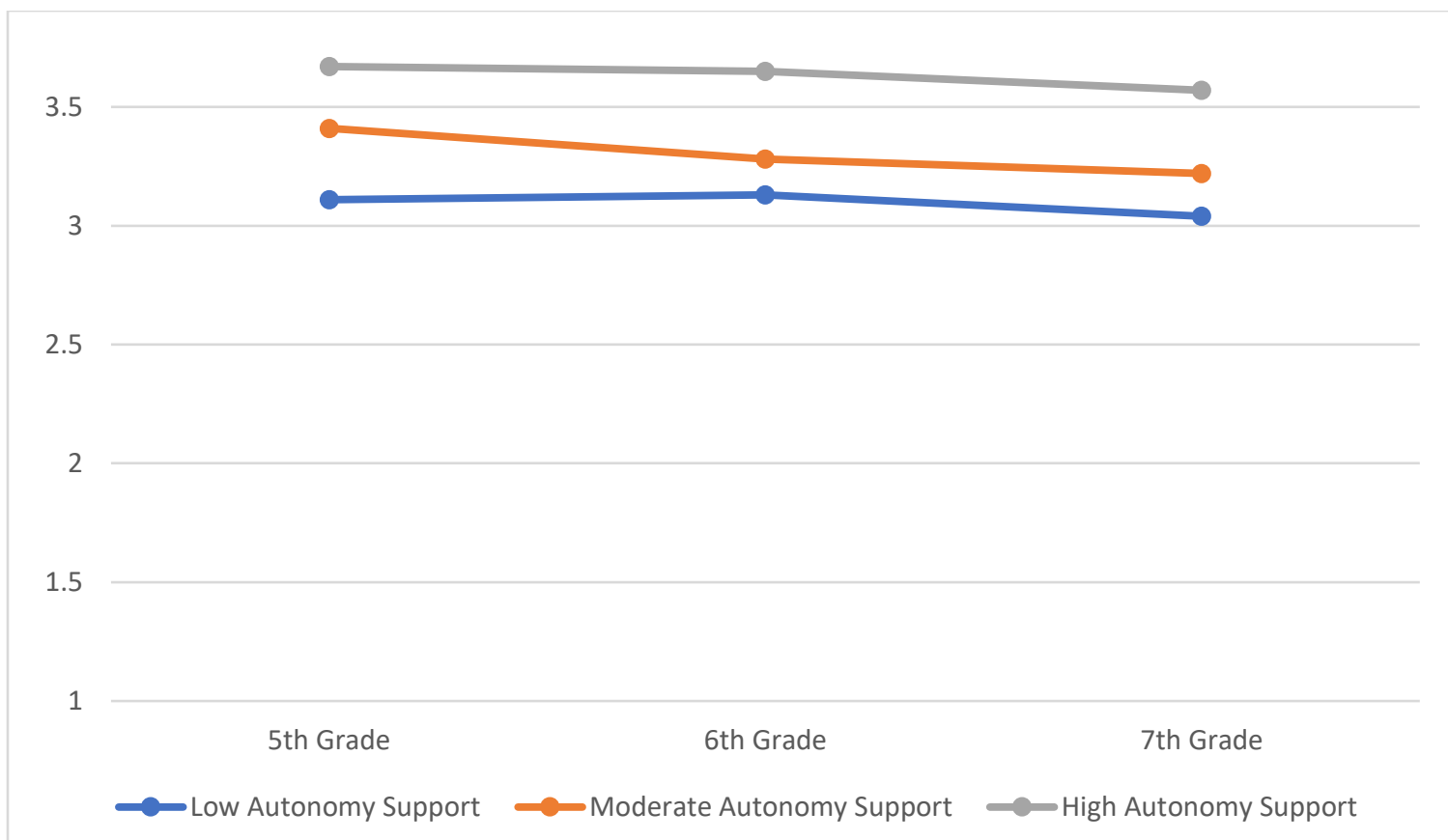

Figure 5.16. Mean Levels of Student Competence in Fifth, Sixth, and Seventh Grades for Students with Low, Moderate, and High Teacher Autonomy Support 


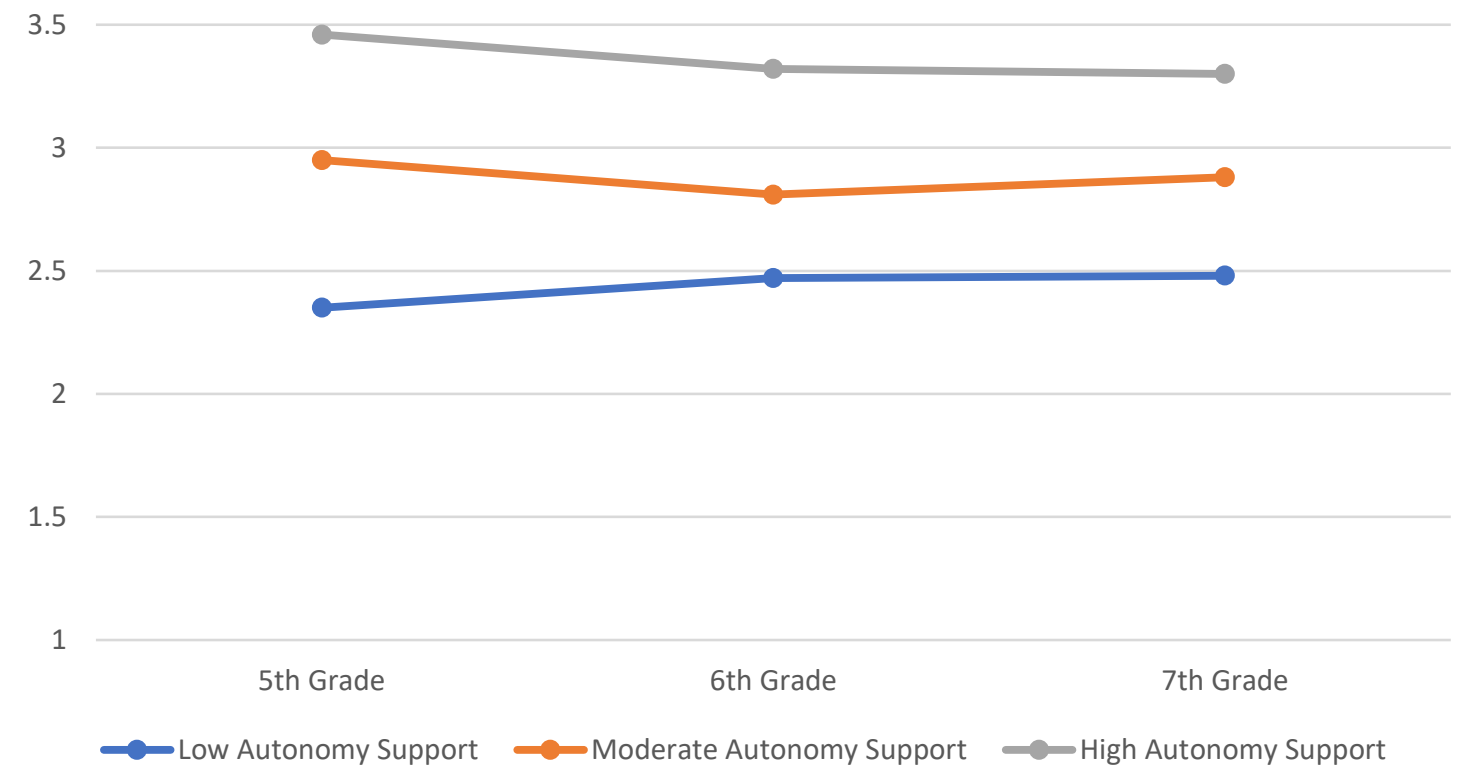

Figure 5.17. Mean Levels of Student Relatedness in Fifth, Sixth, and Seventh Grades for Students with Low, Moderate, and High Teacher Autonomy Support

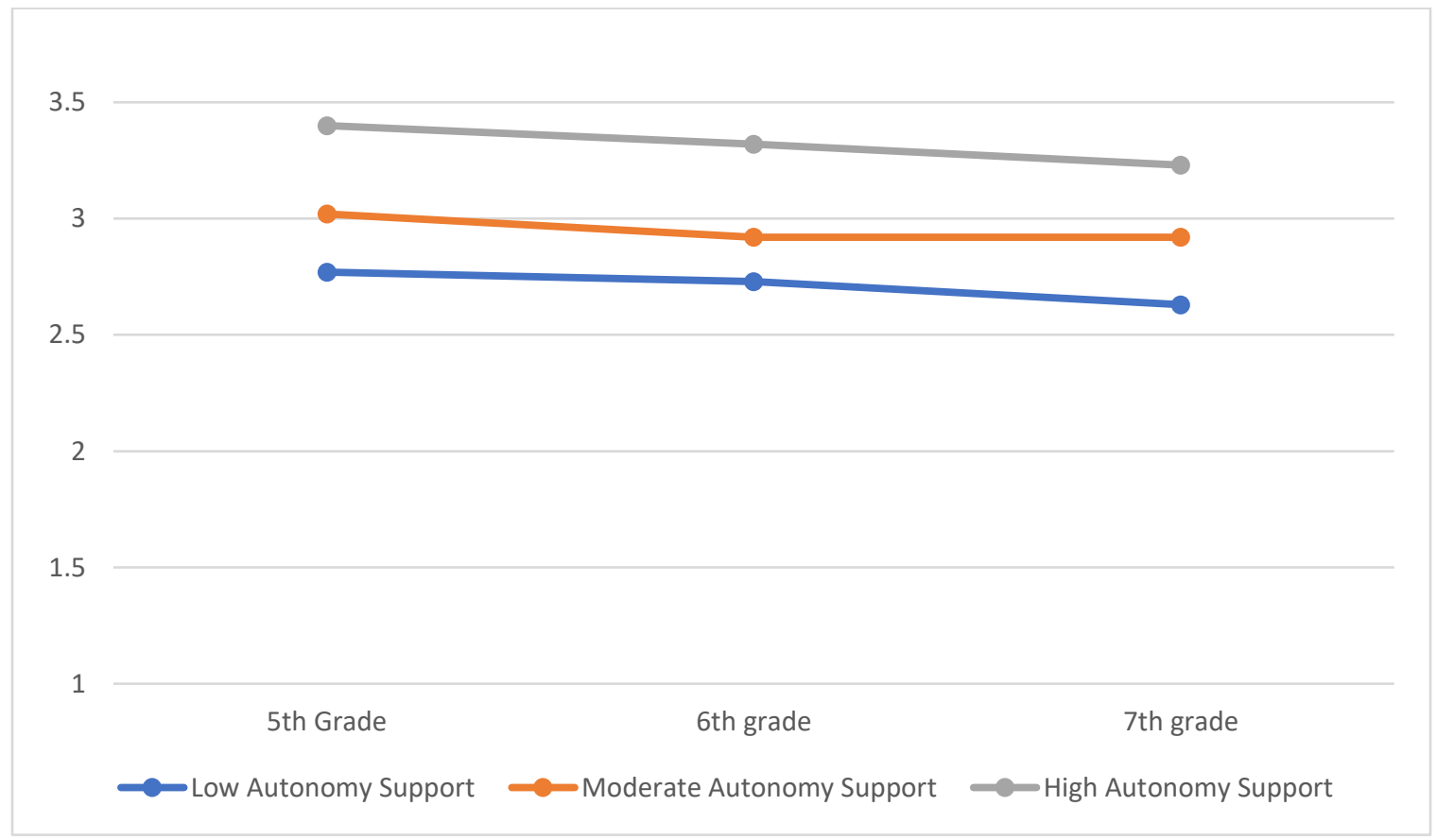

Figure 5.18. Mean Levels of Student Engagement in Fifth, Sixth, and Seventh Grades for Students with Low, Moderate, and High Teacher Autonomy Support 


\section{Chapter VI: Discussion}

This study attempted to provide a more differentiated and developmental picture of the role of teacher autonomy support during late elementary and early middle school by examining the effects of autonomy support on changes in a range of student motivational outcomes over the school year; dissecting its components and examining their differential and unique effects on student outcomes; and exploring whether differences in teacher autonomy support over the transition to middle school contributed to trends suggesting developmental declines in student motivational outcomes across grades. Unlike previous research, this study differentiated the construct of teacher autonomy support into its behavioral components of respect, choice, relevance, and coercion and investigated their contributions to four indicators of student motivation across fifth, sixth, and seventh grades. The following sections will include a summary of the study's findings, its strengths and limitations as well as its implications for educational practice and suggestions for future directions for research on this topic.

\section{Summary of Findings}

In the next sections, the results of this study are summarized for each motivational outcome. An overall summary of the research findings can be seen in Table 6.1. 


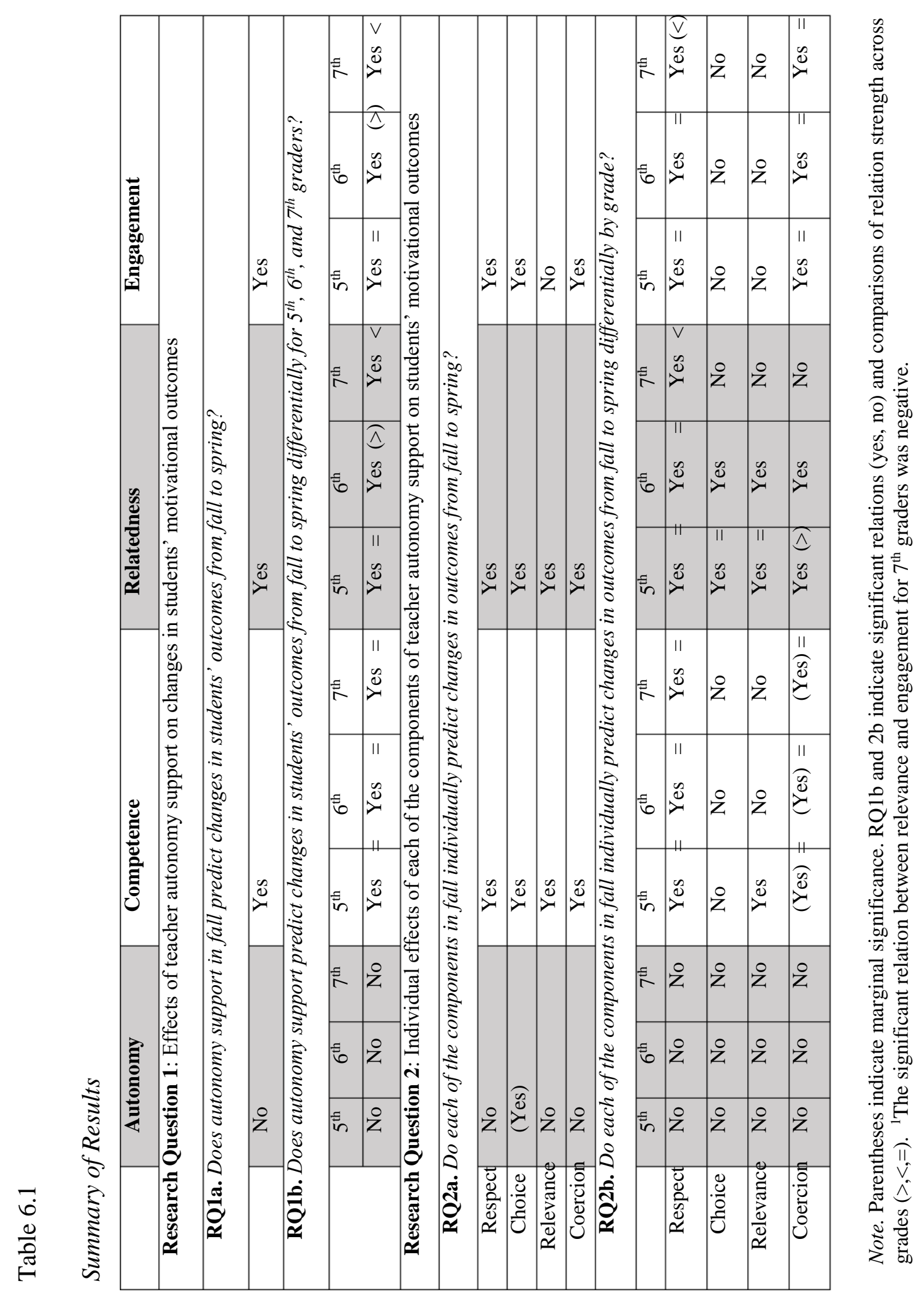




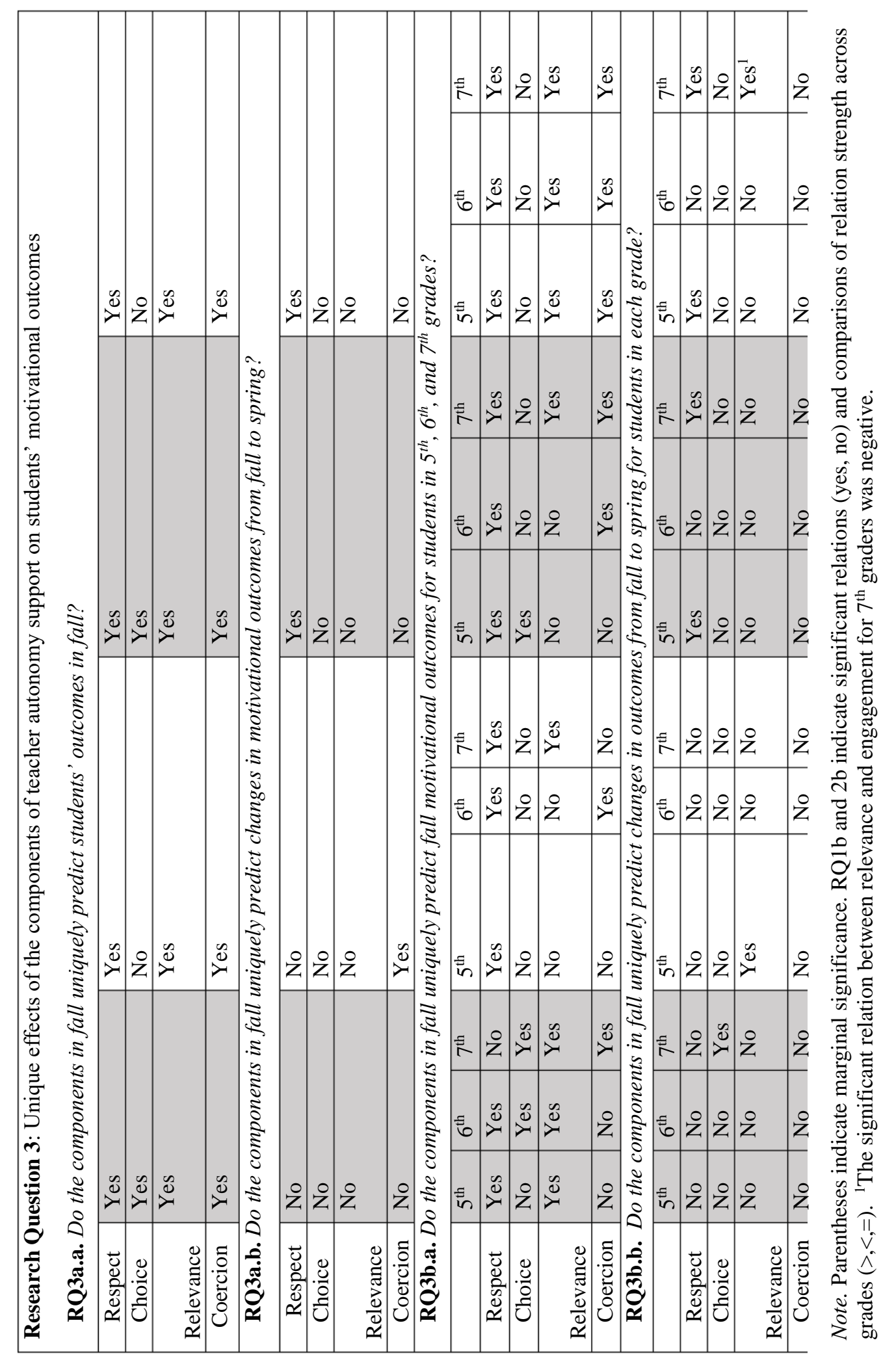




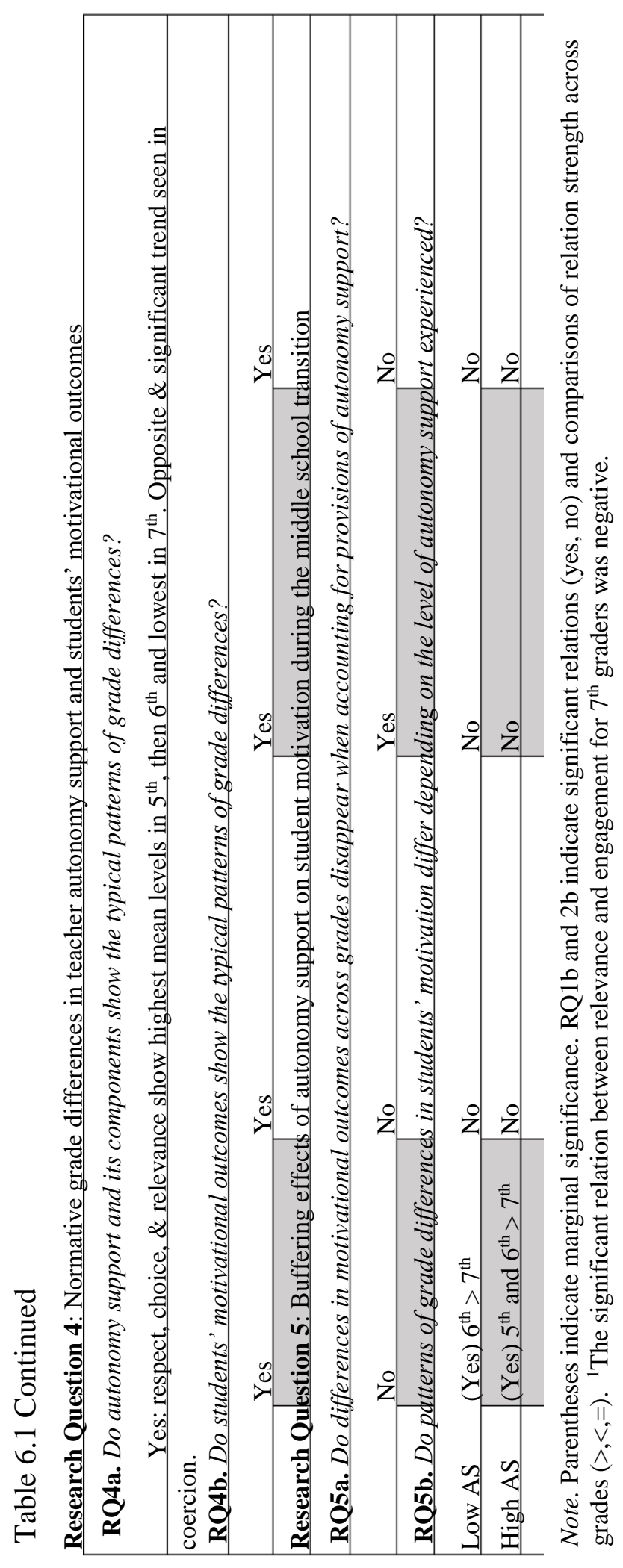


Autonomy. Teacher autonomy support was hypothesized to be a key predictor of student autonomy in this study. However, a nuanced picture emerged such that concurrent analyses revealed the expected pattern of relations, whereas findings involving change-over-time did not. Zero-order correlations indicated that teacher autonomy support in the fall was significantly correlated to both fall and spring reports of student autonomy. Moreover each component of autonomy support (i.e., respect, choice, relevance, coercion) showed the same pattern of zero-order correlations with autonomy; and in regressions, each was also found to be a unique concurrent predictor of student autonomy. In terms of grade differences in these unique effects, it is clear that, although the components did not seem to operate in the same way for students from different grades, more than one component made a unique contribution to student autonomy at every grade. Further, these concurrent unique effects by grade suggest that relevance might be the most central component to student autonomy because of its significance in every grade level, whereas the other three components were only significant in one or two grade levels.

The picture painted by analyses examining autonomy support as a predictor of changes in student autonomy from fall to spring was quite different. Autonomy support was not a significant predictor of changes in autonomy; and in individual analyses, of the four components of autonomy support, only choice marginally predicted changes in student autonomy across the school year. In analyses of unique effects, none of the components were significant predictors of changes in autonomy. When dissecting these change relations by grade, however, teacher provision of choice was a significant predictor of student autonomy for seventh grade students only. As discussed in more 
detail later, the largely non-significant results found in analyses examining changes in autonomy from fall to spring do not necessarily imply that autonomy support does not influence student autonomy, since concurrent analyses exhibit strong and significant relations between autonomy support and student autonomy. This unexpected pattern may instead be due to the high cross-time stability of students' feelings of autonomy from fall to spring $(r=.63, \mathrm{p}<.01)$.

Mean levels of student autonomy across grades showed a pattern that is consistent with the literature, namely, that, across the middle school transition, students' feelings of autonomy were significantly lower at each successive grade. It was expected that these mean level differences, suggesting declines, would disappear when accounting for levels of teacher autonomy support. Although these grade differences in autonomy did not disappear, the $F$-value did drop by more than half, suggesting that autonomy support might, at least in part, underlie some of the grade differences in autonomy. Finally, in analyses examining patterns of grade differences in autonomy for students who experienced different levels of teacher autonomy support, it was expected that students experiencing high levels of teacher autonomy support would show the same relatively high mean levels of autonomy across all grades; whereas students experiencing low levels of teacher autonomy support would exhibit the normative pattern of autonomy, such that, compared to students in the younger grades, students in the older grades would show lower levels of autonomy. Little evidence of this pattern could be found. Instead, at each grade students with high teacher autonomy support showed higher levels of autonomy than students with low teacher autonomy support, but changes in mean level differences across grade were marginal. For students experiencing high levels of 
autonomy support from teachers, differences between fifth and sixth graders' feelings of autonomy disappeared, but seventh graders still showed lower levels of autonomy than either fifth or sixth graders. For students experiencing low levels of autonomy support from their teachers, differences in fifth and sixth graders' levels of autonomy also disappeared. Additionally, differences between fifth and seventh grade levels of autonomy disappeared, although seventh graders showed lower levels of autonomy than did sixth graders.

Competence. As expected, teacher autonomy support was a significant predictor of student perceived competence concurrently, as well as over the school year, and remained a stable predictor across grades. In terms of concurrent connections, all zeroorder correlations between autonomy support and competence were significant, and three of the components of teacher autonomy support (i.e., respect, relevance, coercion) also uniquely predicted student perceived competence concurrently; only choice did not. When differentiating these relations by grade, few patterns emerged. First, at least one component of teacher autonomy support significantly and uniquely contributed to student competence at each grade level. Second, teacher provision of respect uniquely predicted student competence concurrently at every grade, whereas the other three components only predicted student competence in one grade level. Hence, respect seems to be the most central component of autonomy support for competence.

Analyses examining changes in student competence over the year told a somewhat different story. Although autonomy support was a significant predictor of changes in competence, in analyses of the four components individually, only coercion uniquely predicted changes in student competence. However, coercion was no longer a 
significant predictor of changes in student competence when the regressions were conducted separately by grade. These analyses indicated that only relevance uniquely contributed to changes in perceived competence for fifth graders. None of the components of autonomy support significantly predicted changes in competence for either sixth or seventh grade students. It is unlikely that these change-over-time analyses indicate that autonomy support does not influence competence, since concurrent analyses exhibit strong, significant relations among components of autonomy support and student competence. Instead, the high cross-time stability of competence over the school year might have prevented relations from reaching significance in the analyses of changeover-time $(r=.51, \mathrm{p}<.01)$.

Consistent with hypotheses, mean levels of student perceived competence were highest for fifth graders, followed by sixth graders, and lowest for seventh graders. Contrary to expectations, mean level differences in competence did not disappear when accounting for levels of teacher autonomy support. However, the $F$-value was reduced by a third, which suggests that provisions of autonomy support might contribute in some way to grade patterns seen. Finally, it appeared that patterns of grade differences in student competence did not differ for students experiencing different levels of teacher autonomy support. At the same time, mean levels of student perceived competence in all three grades were highest for students experiencing high levels of teacher autonomy support, lower for students experiencing moderate amounts of autonomy support, and lowest for students experiencing low levels of autonomy support.

Relatedness. Zero-order correlations and regressions demonstrated that teacher autonomy support was highly associated with student perceived relatedness both 
concurrently and over the school year, for all students together and in each grade separately. The connection between teacher autonomy support and changes in student relatedness over the school year was higher amongst fifth and sixth grade students than it was amongst seventh grade students. Additionally, regression analyses revealed that each component of autonomy support (i.e., respect, choice, relevance, coercion) uniquely predicted student relatedness concurrently. When grade differences among these concurrent relations were explored, a few patterns surfaced. First, similar to results with student competence, the provision of respect predicted student relatedness for all three grades, suggesting its comparative salience for student relatedness. Second, coercion significantly and negatively predicted relatedness only for students in middle school (i.e., $6^{\text {th }}$ and $7^{\text {th }}$ graders), but not for students in elementary school (i.e., $5^{\text {th }}$ graders). Third, it appeared that in each grade, at least two components of autonomy support predicted student relatedness. Regression analyses examining changes in relatedness over the school year indicated that respect was the only unique predictor and was significant in only fifth and seventh grade student samples.

Consistent with autonomy and competence, mean levels of relatedness showed the typical grade pattern, such that fifth graders experienced the highest levels of relatedness, followed by sixth and then seventh graders. When accounting for levels of autonomy support, these grade differences disappeared, suggesting that provisions of autonomy supportive behaviors may underlie grade differences in student relatedness. In analyses assessing grade patterns in relatedness for students experiencing different levels of teacher autonomy support, students receiving low levels of autonomy support did not exhibit a significantly different grade pattern of relatedness than students with high levels 
of autonomy support. Instead, at every grade students experiencing higher levels of autonomy support also experienced higher levels of relatedness. Paired with the results of the previous analysis, this non-significant difference in relatedness across levels of autonomy support likely occurred because the inclusion of level of autonomy support as an independent variable made it so the main effect for grade level was no longer significant. This group of findings suggest that autonomy support contributes to student relatedness in all grades.

Engagement. As expected, teacher autonomy support significantly correlated with student engagement concurrently and also predicted change in engagement over the school year. Concurrent unique analyses revealed that respect, relevance, and coercion each uniquely predicted student relatedness in the fall, but choice did not. In contrast to the other three motivational outcomes, the important components of autonomy support did not differ by grade. Namely, respect, relevance, and coercion remained significant, concurrent predictors for engagement for all three grades, suggesting their joint centrality for student engagement.

When examining the relative influence of teacher autonomy support on changes in engagement across grades, results indicated that autonomy support was a significant predictor of changes for all three grades, but more so for fifth and sixth grade students than for seventh grade students. Analyses examining the unique effects of the components of autonomy support on changes in engagement over the school year indicated that only respect was a unique predictor, whereas choice, relevance, and coercion were not. Further analyses by grade indicated that only respect predicted fifth grade student engagement; no components of autonomy support predicted sixth grade 
student engagement; and both respect and relevance predicted seventh grade student engagement, although relevance had an unexpected negative relation. No clear pattern could be discerned from these change-over-time findings, however, it is possible that the high cross-time stability of engagement $(r=.61, \mathrm{p}<.01)$ prevented other relations from reaching significance.

Levels of engagement followed the same grade trend as the other three motivational outcomes, suggesting declines in engagement from fifth to seventh grade. Although grade differences in engagement did not disappear when accounting for levels of teacher autonomy support, the new $F$-value was reduced to a quarter of its size before accounting for autonomy support. Thus, autonomy support cannot be stated to underlie grade differences in student engagement, but it may have some influence on grade patterns of student engagement. When examining these grade patterns of student engagement amongst students experiencing different levels of autonomy support, the patterns did not significantly differ amongst students experiencing low, moderate, and high levels of autonomy support. Across all grades, however, students with higher levels of autonomy support also experienced higher levels of engagement.

\section{Strengths and Limitations}

The current study built upon self-determination theory in three ways. First, it tested the predictive relations of teacher autonomy support on changes in several motivational outcomes for students. Second, it measured four components of teacher autonomy support, which may contribute to a more differentiated conceptualization, as well as improve teachers' understanding and provision of motivational support. And 
third, it examined SDT constructs at a particular developmental period in order to ascertain adolescents' unique motivational needs. Although this study offers researchers and practitioners insight into the reach of autonomy support within a motivational framework, the interpretation and application of the study's results must take its strengths and limitations into consideration. Hence, the following sections address the strengths and limitations in the study's conceptualization, measurement, design, and generalizability.

Conceptualization. A strength of the current study was its reliance on a welldocumented theoretical framework, namely self-determination theory (SDT; Ryan \& Deci, 2017), to guide the selection of the target construct — teacher autonomy support—as well as the four motivational outcomes. At the same time, however, the current study is also limited by the SDT framework in that, despite a focus on autonomy support over several decades, up to now no consensus has emerged as to its essential elements. Hence (as will be discussed in detail in later sections), it is difficult to know whether the four components targeted in this study are the most central, or whether the inclusion of additional components outside of the current measure of autonomy support, would strengthen the effects of autonomy support in predicting motivational outcomes.

The use of SDT as an overarching framework was also limiting in that it did not provide much guidance about whether researchers should expect developmental differences in the functioning of autonomy support or its components. As is, the theory posits autonomy, competence, and relatedness as universal needs both across all individuals, as well as at every age. 
Measurement. Given that this study examined ways to support student autonomy, it is fitting that constructs were measured from the student perspective. The utilization of student voice to inform autonomy research communicates to students that their opinions matter, thereby offering them respect. At the same time, reliance on student-reports alone can also be seen as a limitation. Exclusive use of measures that tapped only the student perspective (in assessing both teacher autonomy support and motivational outcomes) contributed to common-method bias, which tends to inflate covariation amongst variables. To enhance construct validity, future studies would benefit from the inclusion of additional sources of information about autonomy support. Teachers can provide information about the autonomy support they provide (e.g., Deci, Nezlek, \& Sheinman, 1981; Reeve, Bolt, \& Cai, 1999; Sosic-Vasic, Keis, Lau, Spitzer, \& Streb, 2015) and systems have been developed to collect third-person observations of teacher autonomy support (Reeve, Jang, Carrell, Jeon, \& Barch, 2004; Wallace, Sung, \& Williams, 2014; Rogat, Witham, \& Chinn, 2014). Teacher- and observer-reports of student engagement would also contribute a fuller picture of student motivational dynamics in the classroom. According to the representation model (e.g., Sameroff, 2010), it is students' evaluations of teacher behavior, and not teacher behavior alone, that provide a pathway that shapes subsequent student motivation and engagement. Future studies might examine these relations in a mediational model that measures the effects of teacher-reports or observations of teacher autonomy support on students' experiences of teacher autonomy support, which, in turn influence student motivation.

A major limitation of this study was the lack of direction student participants were given about which teacher to consider when answering questions about teacher behaviors. 
It is possible that some students answered questions related to one teacher, whereas other students aggregated their interactions with teachers in general, or even answered some questions with a certain teacher in mind and other questions with another in mind. This lack of information about who these students were answering questions about might have obfuscated the connections between teacher autonomy support and student motivation, especially for students in higher grades who had several different subject teachers. Future studies should be explicit, and either ask students to think about all their teachers together when answering questions (in which items should be changed to plural "teachers") or instruct students to consider one specific teacher (either their favorite teachers or one specified by the research team). This latter approach would also allow the use of hierarchical linear modeling, which would take into consideration effects at the level of the teacher or classroom, and thus produce more accurate estimates of individual level effects.

Design. One strength of the current study design is the use of two time points. Incorporating data from both fall and spring helped account for baseline levels of the outcome variables, and allowed for the examination of autonomy support as a predictor of changes in student motivation across the school year. At the same time, future research would benefit from an expanded timeframe. In addition to these two time points, future studies could conduct a longitudinal exploration of changes in teacher autonomy support and student motivation across the transition to middle school, rather than using crosssectional grade differences to infer them. Future studies might choose to implement this idea through individual growth curves across the middle school transition, and the 
examination of whether teacher autonomy support contributes to individual differences in the slopes of these growth curves.

In addition to a longitudinal design, this study would have benefitted from more frequent measurement points within the same year. Impacts of teacher support on student motivation are likely to occur in a matter of weeks, or even days — not lagged by nine months. Further, we know that student-teacher interactions are shaped by the mutual influence of teacher behaviors and student motivation (e.g., Skinner \& Belmont, 1993). The "launch" model utilized in this study did not account for these student-induced fluctuations in teacher behaviors over the course of the year, nor was it privy to how soon student motivation was impacted by teacher support. A shorter term design (i.e., one semester), with frequent points of measurement (perhaps every week) would better detect the nuances of student-teacher interactions.

Generalizability. Since the entire school district participated in data collection, an additional strength of this study is that the results are pertinent to the entire district and can also apply to other United States school districts that share a similar demography. Although, it is important to note that this study may not be generalizable to other U.S. populations, such as lower SES, ethnically diverse, or urban populations. Given the current political climate and burgeoning interest in rural education, however, it seems that studying this population is germane to advancing American society at large. Moreover, because these data were collected over twenty years ago, it is likely that the nature of this school district might have been very different than its current iteration. The ever-evolving technological sphere, as well as educational reform (i.e., No Child Left Behind, Common-Core), might have impacted student motivational resources that would be 
unaccounted for in this study's sample. Future studies would do well to replicate these findings in more recent and diverse samples.

The role of gender. Although preliminary analyses revealed gender differences in the mean levels of motivational outcomes, gender was not utilized as a covariate or moderator in subsequent analyses. This decision was based on the literature examining gender differences in motivation, which reveals that girls and boys differ on their mean levels of motivation, but do not differ in the correlational processes that describe motivational functioning. Additionally, the binary conceptualization of gender within these data makes it difficult to ascertain students' true gender identities, which compromises the validity of the construct in this sample. Finally, inserting a second moderating variable (along with grade) would unnecessarily complicate the analyses. Future studies without an existing moderator could assess the potential differences in motivational processes for different genders by incorporating the construct as a moderator.

\section{Implications and Future Directions}

The present study attempted to enrich our understanding of the role that teacher autonomy support plays in shaping the development of students' motivation in the years surrounding the transition to middle school in three main ways. First, this study explored the reach of teacher autonomy support beyond its well-documented links to autonomy and engagement and established its effects on competence and relatedness. Second, the current study made important contributions to the conceptualization of autonomy support by examining the differential importance of four of its components on these expanded 
motivational outcomes. Third, these findings shed light on possible developmental differences in both the provisions of teacher autonomy support and its connection to student motivation. Together, this study illuminates possible paths of intervention for educators. The following sections highlight each of these contributions through the discussion of the interpretations of the study results, their related implications, and the future directions for research and practice.

\section{Role of teacher autonomy support in shaping a range of student motivational}

outcomes. A primary goal of the current study was to examine the effects of teacher autonomy support not only on well-established outcomes (i.e., autonomy and engagement), but also on other related motivational outcomes within the selfdetermination theory framework (i.e., competence and relatedness). The following subsections describe how the results of this study add to the existing literature on teacher autonomy support as a predictor of student autonomy, competence, relatedness, and engagement.

Teacher autonomy support on student autonomy. Given that the construct teacher "autonomy support" derives its name based on its putative positive effects on student autonomy, some of the most surprising patterns of effects in this study were found for autonomy. As the summary of results indicated, teacher autonomy support had a clear connection to student autonomy in concurrent analyses, but not in analyses involving changes in student autonomy over the school year. These latter findings are inconsistent with hypotheses and with previous studies that have found that teacher autonomy support predicts changes in student autonomy over time, both correlationally and experimentally (e.g., deCharms, 1976; Chatzisarantis \& Hagger, 2009). Because 
autonomy support remained a significant predictor of changes over time, in the current study, for other motivational outcomes, it raises questions about the processes that link autonomy support to autonomy as well as the particular measure of autonomy utilized for this study.

The first possible explanation for why autonomy support did not predict changes over the year was the high cross-time stability of student autonomy in this sample. Unlike student perceived competence, which is likely to change with changing instructional topics, and student relatedness, which is likely to change as students become more familiar with their teachers, student autonomy might be calibrated earlier in the school year. Perhaps teacher autonomy support in this sample did not significantly predict changes in student autonomy over the year because students formed judgements about their autonomy in relation to teachers' supports early in the academic year (as seen in the moderately high correlations between autonomy support and autonomy at the first measurement point) and then maintained their autonomy throughout the year (as seen in the relatively stable autonomy in the sample).

A second possible reason why autonomy support did not predict changes in autonomy over the school year is based on the specific measure of autonomy used in this study. Only two of the four subscales of student autonomy in Ryan and Connell's (1989) Self-Regulatory Style Questionnaire were utilized. This questionnaire assesses four kinds of regulation: (1) intrinsic motivation, tapped via items relating to students' own personal interest and enjoyment (e.g., "Why do I work on classwork? Because it’s fun.”), (2) identified motivation, tapped using items, characterized by the desire to learn or attain a goal (e.g., "Why do I work on classwork? Because I think classwork is important for my 
learning.”), (3) introjected motivation items, consisting of internalized feelings of pressure as reasons for doing schoolwork (e.g., "Why do I work on my classwork? Because I'll be ashamed of myself if it doesn't get done.”), and (4) external motivation items, including anticipated rewards or punishments from teachers as motivation to do schoolwork (e.g., "Why do I work on my classwork? Because the teacher says we have to."). In much of the previous work on autonomy, students' responses to questions about their motivation were weighted by how strongly autonomous they were, such that intrinsic, identified, introjected, and external responses carried weights of $3,1,-1$, and -3 respectively, and those weighted scores were averaged in a summary score called the Relative Autonomy Index (RAI; adapted from Patrick, Skinner, \& Connell, 1993).

The current study utilized only intrinsic and identified motivation to capture student autonomy levels for two reasons: to increase precision and reduce complexity. Although Ryan and Connell (1989) describe these four sources of motivation as being on a "continuum of autonomy" (p. 750), this continuum is not linear, but rather includes qualitatively different regulations. Intrinsic and identified motivation can be characterized as autonomous in nature, whereas introjected and external motivation stems from external pressures. By utilizing the two subscales that characterize autonomous motivation only, an attempt was made to increase precision of measurement for autonomy. A second basis for this decision was the desire to reduce complexity by looking at a homogenous construct. In particular, introjected motivation was avoided because it is an internalized motivation, but is not autonomous. The complexity of this dimension suggests that it might not function in the same way, but instead assist different processes of motivation. 
Despite these goals, however, it is possible that excluding introjected and external motivation actually hindered the detection of real connections with autonomy support. We know that students in schools are frequently motivated by external factors (e.g., GPA, detention, various classroom rewards) and often introject those factors (e.g., reduced selfesteem from poor performance); and so by omitting those subscales, key motivational processes that are actually happening in the classroom might be missing. Perhaps intrinsic motivation, which is a task focused event, is shaped less by autonomy support and more by the material tasks they encounter in the classroom. In contrast, the other three dimensions (identified, introjected, external) might be impacted more by teacher autonomy support because the tasks that are not intrinsically fun or interesting to students gain meaning through interpersonal teacher supports, like providing rationales for otherwise boring tasks or offering choices on how to complete assignments. It is possible that if the two dimensions utilized in this study were separated, intrinsic motivation would remain a non-significant outcome of autonomy support, but that identified motivation by itself would reach significance. Future studies could separate the different dimensions of autonomy and examine whether identified, introjected, and external motivations are more likely to change based on provision of autonomy support than is intrinsic motivation.

Teacher autonomy support on student competence. A key goal of this study was to explore whether teacher autonomy support plays a role in other important motivational outcomes, such as student perceived competence. Self-determination theory posits that students' sense of competence is influenced by the structure that their teachers provide, which informs their capacity to succeed on academic tasks (Ryan \& Deci, 2000). 
Teachers' consistent help and guidance is internalized by students as confidence in their understanding of and ability to perform well on academic tasks. Within the competence literature, several researchers have demonstrated the positive relation between teacher autonomy support and student competence (e.g., Deci, Nezlek, \& Sheinman, 1981; Ryan \& Grolnick, 1986; Tucker et al., 2002; Vallerand, Fortier, \& Guay, 1997), suggesting that structure alone may be a necessary, but not sufficient support for competence. Following this idea, Jang, Reeve, and Deci (2010) found in their observational study of more than a hundred ninth and tenth grade classrooms that teacher structure and teacher autonomy support were positively correlated. They describe structure and autonomy support as being "complementary" teacher supports that engage students in learning activities (p. 596). Not only might these teacher supports work together to shape student engagement, but they may also have collective influence on student competence. Building off of these findings, it follows that teachers will be most effective in enhancing their students' sense of competence if they provide clear and consistent instructions on how to complete academic tasks in ways that support student autonomy. In contrast, structure provided to students in a coercive (rather than an autonomy-supportive) way might no longer be experienced as informational and instead be experienced primarily as coercive (Sierens, Vansteenkiste, Goossens, Soenens, \& Dochy, 2009). One explanation for this pattern is that students may not want to listen to teachers who give coercive instructions, and thus these students may not have the necessary information to feel competent about their ability to perform academic tasks successfully.

In addition to functioning in conjunction with structure, autonomy support may also influence student competence independently and directly. Students may interpret 
latitude from their teachers as the teacher's confidence in their abilities. Students might internalize this interpretation, thus bolstering their own perceived competence. In the same vein, students may interpret coercion from their teachers as evidence that their teachers view them as incompetent, and in turn students might internalize those feelings and come to view themselves as less able. Future studies could assess both the complementary and direct influences of teacher autonomy support on student competence by examining teachers who exhibit different combinations of high and low levels of autonomy support and structure, and examine whether certain combinations are more predictive of student competence.

Teacher autonomy support on student relatedness. Extant research has not, to date, examined the impact of autonomy support on relatedness within the school context. Thus, a key goal of this study was to explore this relation within this new setting. Results demonstrated that teacher autonomy support was a particularly strong and significant predictor of student relatedness both concurrently and in change over time analyses. In fact, it was the only outcome in this study whose grade differences over the transition to middle school could be completely accounted for by teacher autonomy support. Within the self-determination theory framework, researchers typically point to teacher involvement or warmth as central to students' feelings of relatedness. To interpret the relation between autonomy support and relatedness, it is helpful to consider work from the social relationships literature, which shows support for this relation in parent-child interactions, as well as dyadic partnerships. Relationship motivation theory (RMT; Deci \& Ryan, 2014) builds upon SDT by acknowledging the joint influence of involvement, autonomy support, and structure on high quality relationships, marked by strong feelings 
of relatedness. The empirical support for RMT (as reviewed in the purpose section) suggests that feelings of student relatedness might not be dependent solely upon teacher involvement, but are also shaped by other supports, including teacher autonomy support.

There is evidence to suggest that autonomy support shapes how involvement is perceived, similar to its coordination with structure. Deci and Ryan's (2014) review of literature on Parental Conditional Regard shows that parents who provide high warmth only when their children conform to parental expectations are often perceived by their children (correctly) as tacitly coercive, which in turn, has negative effects on child wellbeing and the child-parent relationship. These findings suggest that high levels of parental involvement are unlikely to predict high levels of relatedness unless they are accompanied by corresponding levels of autonomy support. Taking these concepts into the school context, if teachers' involvement and warmth is contingent upon student behavior, students may not believe that their teachers truly care about them, but rather that they only care about student conformity to teacher expectations and classroom norms.

Autonomy support might function not only as a qualifier of teachers' involvement in student endeavors, but also as an independent predictor of relatedness (e.g., Niemiec and Deci, 2014). Perhaps this relation exists through the process of trust-building. If a student experiences support for their autonomy, they may interpret this provision as trust from the teacher that their own trajectory is worthwhile and even that the teacher cares about them. If a student believes that their teacher trusts and cares about them, it naturally follows then that they will feel more connected to that teacher. Future studies would do 
well to examine potential mediators in the pathway from autonomy support to relatedness. A likely candidate for this mediating role is student trust from their teachers.

Teacher autonomy support on student engagement. The construct of student engagement was included in this study in part because of its association with a range of positive academic outcomes, including achievement, persistence, and graduation to name a few (for a review, see Fredricks, Blumenfeld, \& Paris, 2004). In agreement with previous research, the results of the present study illustrate the clear connection between teacher autonomy support and student academic engagement. This relation is best explained through the self-determination theory framework, which posits that student autonomy, competence, and relatedness act together as mediators between teacher autonomy support and student academic engagement (see empirical examples of this process: Yu, Li, \& Zhang, 2015; Yu, Li, Wang, \& Zhang, 2016; Zimmer-Gembeck, Chipuer, Hanisch, Creed, \& McGregor, 2006). In other words, if teachers meet students' psychological needs pertinent to motivation, students will then actively engage in the learning material. The strong connection between teacher autonomy support and student engagement in this study suggests that engagement accumulated all of the effects of teacher autonomy support on student autonomy, competence, and relatedness (together called self-system processes).

Due to the complexity of the current study, the mediated model illustrated above was not included in the analyses of this study. Because of this omission, the results communicate very little about how the self-system processes relate to engagement, above and beyond being additional motivational outcomes. Future studies that include this mediated model could clarify the mechanisms activating the relation between teacher 
autonomy support and student engagement. Further, given the results of this study, a structural equation model might be used to explore whether student competence or relatedness are better mediators of the effects of autonomy support on engagement than is autonomy.

Unique effects of components of autonomy support. This study contributes to a more differentiated and comprehensive understanding of teacher autonomy support by investigating its function using a measure that tapped the four most commonly-utilized and theoretically-sound components. Because autonomy support is an organizational construct, it is important to reach consensus on the key teacher behaviors that constitute its essential elements. Such consensus allows the kind of comparison and aggregation of research findings that will build the field. The results of this study alert researchers that each component may have a different effect on student motivation and further, may help explain why previous findings with different measures may be inconsistent; namely, because they were tapping different components of autonomy support.

A key goal of this study was to gauge the relative contributions of different components of teacher autonomy support on multiple motivational outcomes for students. The following subsections interpret the concurrent unique effects of each component of autonomy support. The concurrent, rather than the change-over-time, results are the focal point here because the highly-sensitive change-over-time analyses likely missed many connections present in the classroom, whereas the concurrent analyses seemed to more so detect the real connections.

Unique effects of autonomy support on autonomy. It was hypothesized that all components of teacher autonomy support would uniquely predict student autonomy, 
given that the construct is defined by its contribution to autonomy. While this hypothesis was confirmed concurrently, results also suggest that relevance might be the most central component to student autonomy. These findings are consistent with some studies, but not others. On the one hand, Assor and Kaplan (2001) documented relevance (labeled as fostering understanding and interest) as the key contributor to student autonomy (labeled academic enjoyment), in comparison to respect (labeled as allowing criticism and encouraging independent thinking) and choice. On the other hand, Patall and Colleagues (2013) found choice as the central contributor to student autonomy, in comparison to relevance (labeled as rationale provision) and respect (labeled as and separated into student perspective-taking and consideration of student preferences).

One explanation for the inconsistency in these findings is the difference in ages of the different study samples. Whereas this study's sample and Assor and Kaplan's (2001) sample were composed of elementary and middle school-aged students, Patall and colleagues' (2013) sample was comprised exclusively of high school students. Perhaps there is a developmental progression as to which teacher behaviors are more central at different moments in students' school careers. Another possible explanation is the difference in measures of autonomy that were utilized in each study. As mentioned previously, the present study used measures only of autonomous motivation to capture student autonomy (i.e., intrinsic and identified motivation). Similarly, Assor and Kaplan's (2001) outcome variable was labeled academic enjoyment, which seems to capture only the intrinsic motivation part of the autonomy measure. In contrast, Patall and colleagues (2013) utilized Reeve, Nix, and Hamm's (2003) measure of autonomy, which includes perceived locus of causality and volition. This measure incorporates items 
related to intrinsic, identified, and external motivation. In fact, one item tapping external motivation (i.e., "I felt I was doing only what the teacher wanted me to do," reversecoded) implies a lack of choice, which might be driving the stronger relation between constructs found in that study. Further, it makes theoretical sense that the provision of content relevance and a rationale for classwork highly predicts the two autonomy scales that hone in on enjoyment of academic material and identified academic goals as motivators. Finally, the present study and Assor and Kaplan's (2001) study both examined these relations using unique effect analyses, whereas Patall and colleagues (2013) used profiles of teacher behavior for their investigation. The former holds other components constant while examining the unique effects of the target component, whereas the latter examines real combinations of autonomy support levels that exist in the study's sample. When utilizing multiple regression, multicollinearity of overlapping components might attenuate relations that Patall and colleagues (2013) were able to detect in their profile analyses. Taken together, inconsistency of prior findings regarding the most salient component of autonomy support in predicting autonomy are likely due to the combination of differing samples, measurement, and analyses. Future studies could test whether different components of teacher autonomy support are most important in predicting multiple facets derived from various conceptualizations of student autonomy at different ages.

Unique effects of autonomy support on competence. Unlike results from autonomy, only teacher respect, relevance, and coercion significantly and uniquely predicted student perceived competence; choice did not. Further analyses revealed that respect seems to be the most central component of autonomy support for competence, 
despite the hypothesis that provision of choice and relevance would be most central. Building on the discussion above relating to autonomy support and competence, it seems likely that the respect construct communicated the most faith in students' academic abilities as compared to the other components of autonomy support. For example, one respect item, "My teacher listens to my ideas", implies that the teacher thinks that the student's ideas are worthwhile. Thus, the teacher's trust in the student's capabilities might foster that student's own perceived competence.

Unique effects of autonomy support on relatedness. In this study, all four components of teacher autonomy support made concurrent contributions to student relatedness. It was hypothesized that respect and coercion would be the two most central components of autonomy support shaping student relatedness. This hypothesis was partially confirmed in that teacher respect surfaced as the most central component. Teacher respect and student relatedness seem to be a natural fit due to the relational nature of both. The teacher respect subscale underscores teacher listening, which may nurture students' feeling of acceptance, an emphasis of the student relatedness scale. By listening to students' ideas, opinions, and points of view, teachers communicate not only that they care about their students, but also that they trust them - this trust may, in turn, strengthen the emotional connection that students feel with their teachers.

Unique effects of autonomy support on engagement. Similar to the results for student perceived competence, engagement was uniquely predicted by teacher respect, relevance, and coercion, but not by choice. It was hypothesized that teacher coercion would be the only central component for student engagement because the highly negative experience it produces for students - in comparison to the absence of other supports- 
was thought to be the most emotionally salient for participating in learning activities. Results indicated that in addition to the hypothesized effect of teacher coercion, respect and relevance were also central unique components of autonomy support for student engagement.

In a similar study, Assor, Kaplan, and Roth (2002) examined several dimensions of autonomy support, including: respect (labeled as allowing criticism and encouraging independent thinking), choice, relevance (labeled as fostering understanding and interest), and coercion (labeled as intruding) and their relation to academic engagement. Like the present study, their regression results revealed that teacher relevance was significantly and uniquely related to engagement and that choice was not. Contrary to the results of the present study, however, Assor, Kaplan and Roth (2002) found that neither respect nor coercion were significant unique predictors of engagement. It is important to note that their coercion measurement included items that appear to be theoretically closer to choice (e.g., "When I choose a topic for a paper, [my teacher] tries to influence my choice too much.”). Perhaps teacher coercion in Assor and Colleagues' (2002) study was not a significant predictor of engagement because of its construct proximity to choice, which was not significant in either study. Another possible reason for the discrepancy in findings is the different conceptualizations of student engagement. While Assor and colleagues (2002) included behavioral and cognitive aspects of engagement, the present study captured behavioral and emotional aspects of engagement. Perhaps teacher respect and coercion specifically shape the emotional aspect of engagement for students. Future studies could examine each aspect of engagement to clarify which of the components of teacher autonomy support predict each dimension. Additionally, the present study 
reverse-coded and integrated the disaffection items (e.g., "When I'm doing my work in class, I feel bored.") into the engagement scale. Future studies should distinguish between engagement and disaffection items to assess whether the components of teacher autonomy support function differently with student engagement than they do with disaffection.

Strategies to study components of autonomy support. In this study, the analytic strategy used to investigate the effects of the four components of autonomy support involved multiple regressions that examined their simultaneous effects. By including all four components in a single regression analysis, the goal was to differentiate contributions of the four components of autonomy support, by accounting for each component simultaneously. In the classroom, however, certain autonomy-supportive behaviors are not held constant, but rather likely work in tandem to shape student motivation. Future studies should capture student experiences of all teacher provisions of autonomy support together and examine how those different combinations of teacher autonomy support influence various motivational outcomes. One strategy is to conduct a factorial analysis of variance (factorial ANOVA) that compares autonomy support profiles comprised of high and low levels of the components on student motivation (e.g., Patall et al., 2013). Another issue with the present analysis decisions is that they do not fully capture process, which is important for theory-building within the SDT framework. Future researchers might conduct mediational analyses that clarify pathways from specific components of autonomy support to student engagement, through the motivational self-perceptions of autonomy, competence, and relatedness to further uncover motivational processes within SDT. 
Conceptualization of autonomy support and its essential elements. This study addressed a gap in the literature by attempting to identify specific teacher behaviors that might help shape a variety of important motivational outcomes for students. Although the results of this study were not always consistent, overall, several patterns emerged that may have meaning for researchers and educators interested in understanding autonomysupportive instruction. The following sections discuss conceptualizations of the components of autonomy support that future studies might learn from and build upon, as well as the general issues related to the autonomy support construct.

Conceptualization of components of autonomy support. This study makes an important contribution by identifying and examining the most prominent components of teacher autonomy support in the literature (i.e., respect, choice, relevance, coercion). Despite the wide-spread usage of these components of autonomy support, however, the current study uncovered some conceptual and operational problems that may be partially responsible for unclear results, and thus, are important to address.

Choice. Among the various components of autonomy support cited in the literature, choice is the most commonly referred to component said to influence student motivation. Despite its attention in the field, empirically, choice did not predict student motivation in this study to the same extent as did the other components of autonomy support. Perhaps the present study's operationalization of choice was responsible for the failure to find that teacher provision of choice made a unique contribution to student competence and engagement, rather than an actual lack of connection amongst these factors in the classroom. In the scale used in the present study, items intended to mark a higher level of autonomy support from the teacher referred to the presence of options or 
choices, but the quality of these choices was not specified (e.g., "My teacher gives me a lot of choices about how I do my schoolwork."; "When it comes to assignments, my teacher gives me all kinds of things to choose from."). It is important to note, however, that some choices may be meaningless (e.g., "You can give your presentation in the front or the back of the room."), or they might even mask coercion (e.g., "You can either stop talking or you can get a detention.”) (Deci \& Ryan, 2016). In using choice as a component in this way, assumptions were made that students answered these items by considering the meaningful choices they were provided exclusively and disregarding the meaningless and coercive choices they were given. Future research should ensure that the quality of choices provided by teachers is captured in items, in addition to the typical operationalization of quantity of choice to parse apart true relations (e.g., "The teacher allows me to choose to study topics that interest me"; Assor \& Kaplan, 2001; Assor, Kaplan, \& Roth, 2002).

Coercion. Although the coercion component of autonomy support had significant and unique effects on all four motivational outcomes in this study, its conceptualization, both in the combined measure of autonomy support and as a unique predictor of motivation, has room for improvement. Within the combined measure of teacher autonomy support, this construct functioned as lack-of-coercion because it was reversecoded. A lack of coercive behaviors may not actually support student autonomy, unless it is combined with other behaviors like respect. By treating coercion (reverse-coded) in the same manner as respect, choice, and relevance, assumptions were made that the absence of a negative behavior influences motivation in the same way that positively-valanced teacher behaviors do. Assor and Kaplan (2001) addressed this point directly when they 
argued that two types of autonomy-affecting teacher behaviors can be distinguished: autonomy-enhancing behaviors and autonomy-suppressing behaviors; the first of which shape student autonomy by evoking positive emotions and the second by generating negative feelings. These authors operationalized autonomy-enhancing and autonomysuppressing behaviors on separate scales that independently predicted academic outcomes and well-being of students. In contrast, the present study conceptualized teacher behaviors that exert control over students in a unipolar component (i.e., coercion) and distinguished it from the other components of autonomy support that were comprised of both positively- and negatively-valanced aspects related to their nature (e.g., respect: "My teacher listens to my opinion." and "My teacher doesn't listen to my opinion." reverse-coded). Because autonomy-enhancing and autonomy-suppressing behaviors were combined to create the component measures of respect, choice, and relevance in this study, the conceptual precision of teacher coercion may be limited. Future studies might separate the aspects of components that support and thwart student autonomy, as Assor and Kaplan (2001) did, in order to assess if and how they function differently. Additionally, confirmatory factor analyses (CFAs) could help clarify whether teacher coercion is conceptually different from not providing other autonomy-supportive behaviors to students (e.g., not listening to student opinions; offering few choices; omitting rationales for assignments).

Additional components. Although respect, choice, relevance, and coercion are prominent, well-defined features of autonomy support, these components do not exhaust all possible elements of the construct. Five of the 15 measures that were reviewed identified elements of autonomy support that did not fit into any of the four components 
highlighted in the current study (e.g., promoting independent thinking, Wallace, Sung, \& Williams, 2014) and two other autonomy support measures included undifferentiated items that were also not captured in this study (e.g., "The teacher gets angry when students try to help each other", Origin Climate Questionnaire, 1976). Although the four components used in this proposed study were drawn from several sources (i.e., Connell, 1990; Patrick, Skinner, \& Connell, 1993; Skinner \& Belmont, 1993), it is possible, for example, that Reeve's (2006) component pertaining to the use of noncoercive language and communication styles might be critical to supporting student autonomy. By adding components like the ones listed above, we could develop a fuller picture of key teacher behaviors that shape student motivation. Moreover, critical aspects of the construct of autonomy support and important levers for intervention may be identified. Future studies that include additional components of autonomy support might explore whether the unused components are distinguishable from the four utilized in this study or if they are simply redundant. Alternatively, researchers could ask middle school students which behaviors they experience as the most autonomy-supportive and then further investigate the key behaviors cited by the students.

Re-considering the construct of autonomy support. By investigating the function of teacher autonomy support on students' motivation and mapping these relations using multiple components of autonomy support, this study sought to enrich theoretical discourse on the autonomy support construct. Despite the steps taken to clarify the form and function of autonomy support, the results from this study suggest that the construct name "autonomy support" may be a barrier to unified understanding, in itself. The term lacks a conceptual fence to keep out related, but distinct ideas. For example, Maulana and 
colleagues (2011) reported a significant relation between teacher involvement and autonomous motivation in Indonesian students. Here, involvement technically predicts autonomy and although the construct of involvement is theoretically distinct from most measures of autonomy support, one could argue that as a support for autonomy, it belongs within the construct. By referring to this construct by what it influences, researchers undermine its precision and increase the likelihood of the "jingle-jangle" problem. Furthermore, the results of the present study demonstrate that "autonomy support" not only supports student autonomy, but it also supports student competence and relatedness, which further calls its label into question. Although a radical implication of the study, it appears that a renaming may be in order. By changing the name of "autonomy support" to capture what it is, rather than what it does, researchers may have an easier time converging on its components. Additionally, by stepping away from a functional label, researchers would not have to question the name each time a new outcome is discovered that can be predicted by this construct.

Developmental patterns. One goal of the present study was to add a developmental framework by examining the function of teacher autonomy support on student motivation during a particularly vulnerable motivational moment, namely, the transition to middle school. As mentioned earlier, self-determination theory assumes that the specified teacher supports are important for student motivation across all age groups. Consistent with that general framework, teacher autonomy support was closely linked with student autonomy, competence, relatedness, and engagement at every grade, as was seen in the zero-order correlations among these variables in both fall and spring. Because SDT does not provide an explicit rationale for why grade differences might exist in the 
effects of autonomy support, the findings in this study that included grade differences are interpreted through a lens that enriches SDT with the developmental perspective of stageenvironment fit theory (Eccles \& Midgley, 1989).

Not only does stage-environment fit theory account for the context within which students are embedded to explain student motivation (i.e., environment), as SDT does, but it also adds the element of students' developmental period (i.e., stage), as well as the interplay between their stage of development and the environments to which they are asked to adapt, to further explain student motivational development. Stage-environment fit theory explains the well-documented declines in student motivation over the transition to middle school based on the growing needs of adolescents to feel agentic in their learning, combined with the tendency for middle school contexts to be more coercive than elementary schools. Guided by the complementary frameworks of self-determination theory and stage-environment fit theory, the following sections interpret findings from the present study pertaining to both mean-level differences in autonomy support and motivational outcomes, as well as the differential contributions of autonomy support to student motivation over fifth, sixth, and seventh grades.

Mean-level differences in study constructs. Results from this study indicated that students experience lower levels of respect, choice, and relevance from their teachers at each successive grade from elementary to middle school, suggesting declines in teacher support surrounding the transition. These findings might explain the weakening relationship between students and teachers from elementary to middle school documented in the literature (Wigfield et al., 2015). Conversely, results showed that higher levels of teacher coercion emerged in older grades. Pressure exerted on teachers has been 
documented as a major factor contributing to the adoption of a coercive, rather than autonomy-supportive motivating style (Reeve, 2009). These results conform to that idea, given that middle school teachers experience heightened external pressures with the addition of standardized tests and increased expectations of rigor.

Results also indicated that students exhibited lower levels of all four motivational outcomes studied (i.e., autonomy, competence, relatedness, engagement) in each successive grade, a finding that is well-documented in the literature (for a review, see Mahatmya, Lohman, Matjasko, \& Feldman Farb, 2012). In conjunction with the loss of autonomy support and heightened coercion from teachers, these findings provide evidence consistent with stage-environment fit theory (Eccles \& Midgley, 1989), namely, that the loss of positive student-teacher interactions that typically occurs across the middle school transition is associated with lower levels of student motivation because the particular motivational needs students have in adolescence are not being met.

Although it was expected that students' experience of their teachers' autonomy support would completely account for grade differences in all four motivational outcomes studied, this was not the case. Instead, for three of the four outcomes studied, levels of autonomy support seemed to only partially explain the developmental differences in student motivation, indicating that students need other teacher supports, in addition to autonomy support. Although unexpected, this finding is consistent with SDT, which posits that autonomy support, involvement, and structure together influence student motivation (Deci \& Ryan, 2000). Teacher autonomy support was the focal point of this study, but future researchers could investigate the combined impact of teacher autonomy support, involvement, and structure on student motivation across the middle school 
transition in order to understand more fully why these motivational differences exist across grades.

Differential contributions of autonomy support. The results examining differential contributions of teacher autonomy support on motivational outcomes across fifth, sixth, and seventh grade students were less clear. Despite the largely inconsistent results, a few patterns did emerge from the data. The first of these arose from the changeover-time analyses and indicated that the influence of teacher autonomy support on student autonomy and competence remained stable across fifth, sixth, and seventh grade students, whereas its influence on student relatedness and engagement was weaker in seventh graders than it was in either fifth or sixth graders. Consistent with stageenvironment fit theory, it is possible that some aspects of motivation are more salient for students at different developmental periods. Previous work has established that teachers provide lower levels of support for student autonomy, as compared to competence or relatedness, during the middle school transition (e.g., Eccles \& Midgley, 1989), suggesting that the need for supporting student autonomy may increase in importance for students over that transition. Taken together with the lower levels of autonomy support provisions from fifth to seventh grade found in this study, perhaps the amount of certain autonomy support behaviors that teachers provide to students in later grades (e.g., shift from many to few choices) is not enough to have an impact on some dimensions of student motivation. If that were the case, then that could explain why the association between teacher autonomy support and some student motivational outcomes would become weaker in the later grades, as we saw with student relatedness and engagement. 
Alternatively, these results may also be interpreted explicitly within the frame of SDT by considering the relative impact of each teacher. It makes sense that an elementary school teacher, who interacts with students for the majority of the day, would make a larger impression on students' motivation than would a teacher in middle school who only spends approximately 45 minutes a day with any given student. The difference in the strength of relation between teacher autonomy support and student relatedness and engagement between fifth and seventh grade students could be explained by the sheer amount of time each teacher has to influence their students. Given that this study asks participants to consider a teacher (singular), answers from students with more than one teacher, who considered only their English teacher for example, may not fully account for their motivational context. Interpreting the results that indicate no difference in the contributions of teacher autonomy support on student relatedness and engagement between fifth and sixth graders is then more complicated. It could be that students just transitioning to middle school, namely sixth grade students, are used to closer bonds with their teachers based on their elementary school experiences, and intentionally seek out those relationships with their teachers in the beginning of middle school. From this perspective, it is possible that sixth grade students maintain closer bonds with some teachers than do seventh and eighth grade students and are thus influenced by their teachers to a similar extent as fifth grade students. The context, in combination with socialization from other students in middle school, might yield the most distanced and strained student-teacher relationships in later middle school, hence the weakening connection between teacher autonomy support and certain elements of student motivation. 


\section{Grade differences in the unique effects of the components of autonomy support.}

Another possible explanation for the difference in findings across grades that falls within the scope of self-determination theory is that, while the need for teacher autonomy support does not change, the expression of that support needs to be developmentallycalibrated, and thus looks different from one grade to the next. One pattern that emerged from the concurrent unique effect analyses is consistent with this explanation. When considering the most important components of autonomy support at each grade, that is, the components that predicted at least three of the four outcomes, there were more important components for older students than there were for younger students. For fifthgrade students, teacher respect emerged as the most important component: it predicted all four outcomes, whereas the other components only predicted one or two outcomes. For sixth-grade students, teacher respect remained important (predicting all four outcomes), and coercion became important as well (predicting three outcomes). For seventh graders, respect and coercion remained important (each predicting three outcomes) and relevance emerged as a new central component (predicting all four outcomes). Thus, not only did the number of important components perceived by the students increase from fifth to seventh grade, but also each older sample of students maintained the same vital component. Thus, these findings imply that as students get older, different components of autonomy support become more important to their motivation, which supports the idea that the context must be developmentally-calibrated to the motivational needs of the student.

There are several developmental possibilities for why different components of autonomy support seemed to be more important in some grades over others. When 
considering the fifth grade students, who in this sample were the oldest students in their school and on the precipice of a school transition, it makes sense that they would expect and be particularly sensitive to high levels of respect. With a specific focus on the provision of respect from teachers, students' emotional affect is likely to be influenced by this component; and as Assor and Kaplan (2001) demonstrated in their study, positive and negative emotions of students often act as a mediating factor between teacher autonomy support and student motivation. Hence, it seems reasonable that teacher respect would be salient for fifth graders' academic motivation. Perhaps the introduction of teacher coercion in middle school as a significant influencer of student motivation occurred because of the heightened demands and accountability of middle school teachers mentioned earlier. With the higher levels of coercion experienced by students, their motivation may be more strongly threatened than it is for elementary school students. Finally, it seems possible that as curricula increasingly teach to the test in older grades in preparation for nation-wide standardized exams, the relevance of instruction to students' interests and identified goals may become less and less obvious to students. Therefore, seventh-grade students may respond more strongly, motivationally, to teachers who provide rationales.

Future research that investigates student motivation at different developmental moments should incorporate structural equation modeling (SEM) analyses, which can examine multiple processes simultaneously, while mitigating issues of multicollinearity present in regression analyses. In the future, developmental nuances in motivation might also be uncovered by asking students of different ages, in their own words, what kinds of interactions with their teachers nurture or undermine their academic motivation. If 
students are given the opportunity to articulate their motivational needs-rather than select from options in researcher-written surveys - then researchers might more easily be able to distinguish between the needs of elementary school and middle school students.

Summary. This study addressed a gap in the literature in that it investigated the functioning of autonomy support and its components across different developmental moments. In sum, there is initial evidence to suggest that the association between teacher autonomy support and some aspects of student motivation weakens for students in older grades, but that the number of influential components of teacher autonomy support increases. Despite these initial findings, it is important to note that several results from the present analyses did not show clear patterns and so warrant more sophisticated statistical analyses that are able to model the complexity of inter-relationships between students and teachers across time (e.g., structural equation modeling). Additionally, including student voice (e.g., interviews or focus groups) in future developmental research might contribute to a more nuanced understanding of student needs at different periods of development. This study is merely one step and continued efforts to understand teacher provision of support surrounding the middle school transition, utilizing a developmental frame, will begin to open up possible avenues of intervention.

\section{Implications for Educators and Interventionists}

This study has implications for advancing classroom instruction by expanding knowledge that can inform teachers' motivating styles and by illuminating paths of intervention appropriate for students in different grades. The first educational implication, backed by decades of research, is that autonomy-supportive instruction matters 
(deCharms, 1976; Deci \& Ryan 1987; Vallerand, Fortier, and Guay, 1997; Reeve, 2006;

Wallace, Sung, \& Williams, 2014). This study's results suggest that teacher autonomy support plays a salient role in cultivating student perceived competence and relatedness, in addition to its already-established role in promoting student autonomy and engagement. Reeve (1998) notes that a major barrier preventing autonomy-supportive practices in the classroom is teachers' lack of awareness of its importance for many aspects of student motivation. It is possible that teachers might not be persuaded to utilize autonomy-supportive instructional practices if the only outcome that they know it benefits is autonomy. However, informing teachers that it also promotes several other important features of student motivation, as was established in this study, will likely encourage teachers to adopt this style. Future preservice training as well as professional development for in-service teachers should communicate the many benefits of providing students autonomy support.

Another barrier teachers face is the lack of knowledge about how to support student autonomy, and imagining that it is not worth all the effort (Reeve, 1998; Reeve et al., 2004). This study offers guidance on the specific teacher behaviors that comprise autonomy support and further, on the motivational outcomes that these behaviors are most likely to foster. Practitioners might utilize these findings to inform their own practices in the classroom. With specific information about the facets of autonomy support, teachers can be more adept at supporting their students' motivational needs through developmentally appropriate behaviors (Reeve et al., 2004). Interventions designed to help preservice teachers learn how to provide autonomy support can utilize these and other findings to increase the specificity of the strategies they suggest. 
As mentioned earlier, changing the construct name of autonomy support might be a step in that direction. Unlike self-determination theory's prescription for teachers to follow in fostering students' sense of relatedness in the classroom (i.e., provide more warm involvement) or enhancing students' perceived competence (i.e., provide more structure), teachers currently must rely on "provide more autonomy support" as the vague guiding principle to support student autonomy. It seems that using a more informative construct name in theoretical and educational discourse would be helpful to increase clarity and encourage its use. Teachers and researchers would benefit from converging on a term that captures the entirety of the construct, makes theoretical sense, and feels relevant for instruction. Until such time as this label emerges, it would be even more important for theorists and researchers to be specific about the lower order subconstructs it contains.

Finally, this study's use of fifth, sixth, and seventh grade samples provides a picture of the role of autonomy support during the particularly vulnerable moment that is adolescence and the transition to middle school. Although this study was unable to fully portray the differing motivational needs across these grades, the findings from this exploration still have a few developmental implications. If it is true that teachers of older grades currently have a weaker influence on certain aspects of student motivation, as demonstrated in this study, schools might work to encourage the strengthening of the student-teacher relationship in those grades, in addition to enhancing the use of autonomy-supportive instruction. Student-teacher relationships might be enhanced if students take more than one class taught by the same teacher (language classes generally do this) or by encouraging teachers to participate in after school activities with students. 
Operating under the assumption that students are more affected by teachers whom they care about, these and other strategies for strengthening relationships may augment the influence that teachers' autonomy support has on their students.

The preliminary finding that students in older grades may be more sensitive to multiple autonomy-supportive behaviors implies that it is particularly important for middle school teachers to intentionally provide several types of behaviors to support student autonomy. Assor and Kaplan (2001) also found that many aspects of autonomysupportive instruction, and not just one or two, uniquely predicted levels of interest and enjoyment for students in sixth, seventh, and eighth grades. Together, these findings suggest that trainings provided to middle school teachers should incorporate multiple avenues for teachers to support their students' autonomy. Teaching educators a variety of autonomy-supportive practices alone is not enough to promote teacher autonomy support in middle school. Reeve (2009) notes that "pressures from above" (i.e., administrators, national standards), "pressures from below" (i.e., student amotivation, behavior problems), and "pressures from within" (i.e., teacher's own self-concept and selfefficacy) often trigger teachers to adopt coercive, rather than autonomy-supportive motivating styles. Given that middle school teachers have increased pressures in all three facets, it is critical that intervention also occur on the school level, so that the larger middle school context allows for and encourages teachers to provide autonomysupportive instruction. 


\section{Conclusion}

This study investigated the role of teacher autonomy support across the transition to middle school, including its components, reach, and developmental effects. These findings contribute to theory by creating a more differentiated and comprehensive foundation upon which to build conceptualizations of the construct of autonomy support. Additionally, these findings may not only help teachers to better identify specific behaviors to incorporate in their repertoire to support student motivational outcomes, but also inform them about how to better calibrate components of autonomy support to students' development. Taken with its limitations, the current study has potential to contribute to the field, in its ongoing investigation of the importance of teacher autonomy support during the middle school transition. 


\section{References}

Anderman, E. M., \& Mueller, C. E. (2010). Middle school transitions and adolescent development. In J. L. Meece, \& J. S. Eccles (Eds.), Handbook of research on schools, schooling and human development (pp. 198-215). New York, NY: Routledge.

Appleton, J. J., Christenson, S. L., \& Furlong, M. J. (2008). Student engagement with school: Critical conceptual and methodological issues of the construct. Psychology in the Schools, 45(5), 369-386.

Assor, A., \& Kaplan, H. (2001). Mapping the domain of autonomy support: Five important ways to enhance or undermine students' experience of autonomy in learning. In A. Efklides, J. Kuhl \& R. M. Sorrentino (Eds.), Trends and prospects in motivation research. (pp. 101-120) Kluwer Academic Publishers, Dordrecht.

Assor, A., Kaplan, H., \& Roth, G. (2002). Choice is good, but relevance is excellent: autonomy-enhancing and suppressing teacher behaviours predicting students' engagement in schoolwork. British Journal of Educational Psychology, 72(2), $261 \mathrm{e} 278$.

Bandura, A., Barbaranelli, C., Caprara, G. V., \& Pastorelli, C. (1996). Multifaceted impact of self-efficacy beliefs on academic functioning. Child Development, 67(3), 1206-1222.

Baumeister, R. F., \& Leary, M. R. (1995). The need to belong: desire for interpersonal attachments as a fundamental human motivation. Psychological Bulletin, 117(3), 497-529. 
Benware, C. A., \& Deci, E. L. (1984). Quality of learning with an active versus passive motivational set. American Educational Research Journal, 21(4), 755-765.

Birch, S. H., \& Ladd, G. W. (1997). The student-teacher relationship and children's early school adjustment. Journal of School Psychology, 35, 61-79.

Boggiano, A. K., Flink, C., Shields, A., Seelbach, A., \& Barrett, M. (1993). Use of techniques promoting students' self-determination: Effects on students' analytic problem-solving skills. Motivation and Emotion, 17(4), 319-336.

Brophy, J. (1986). Teacher influences on student achievement. American Psychologist, 41 (10), 1069-1077.

Chatzisarantis, N. \& Hagger, M. (2009) Effects of an intervention based on selfdetermination theory on self-reported leisure-time physical activity participation, Psychology \& Health, 24:1, 29-48.

Cohen, J., Cohen, P., West, S. G., \& Aiken, L. S. (2003). Applied multiple regression/correlation analysis for the behavioral sciences (3rd ed. ed.) Lawrence Erlbaum Associates Publishers, Mahwah, NJ.

Connell, J. P. (1990). Context, self, and action: A motivational analysis of self-system processes across the life span. In D. Cicchetti, \& M. Beeghly (Eds.), The self in transition: Infancy to childhood; the self in transition: Infancy to childhood (pp. 61-97, Chapter viii, 399 Pages) University of Chicago Press, Chicago, IL.

Connell, J. P., \& Wellborn, J. G. (1991). Competence, autonomy, and relatedness: A motivational analysis of self-system processes. Self-processes and development. (pp. 43-77) Lawrence Erlbaum Associates, Inc, Hillsdale, NJ. 
Damon, W., \& Hart, D. (1982). The development of self-understanding from infancy through adolescence. Child Development, 53, 841-864.

deCharms, R. (1976). Enhancing motivation: Change in the classroom Irvington, Oxford. Deci, E. L., \& Ryan, R. M. (1985). Intrinsic motivation and self-determination in human behavior. New York, NY: Plenum Press.

Deci, E. L., \& Ryan, R. M. (1987). The support of autonomy and the control of behavior. Journal of Personality and Social Psychology, 53, 1024-1037.

Deci, E. L., \& Ryan, R. M. (2000). The "what" and "why" of goal pursuits: Human needs and the self-determination of behavior. Psychological Inquiry, 11, 227-268.

Deci E. L., Schwartz A. J., Sheinman L., Ryan R. M. (1981). An instrument to assess adults' orientations toward control versus autonomy with children: reflections on intrinsic motivation and perceived competence. J. Educ. Psychol. 73 642-650

Deci, E. L., Vallerand, R. J., Pelletier, L. G., \& Ryan, R. M. (1991). Motivation and education: The self-determination perspective. Educational Psychologist, 26(3-4), 325-346.

Eccles, J. S., \& Midgley, C. (1989). Stage/environment fit: Developmentally appropriate classrooms for early adolescents. In R. E. Ames \& C. Ames (Eds.), Research on motivation in education (Vol. 3, pp. 139-186). San Diego, CA: Academic Press.

Fredricks, J. A., Blumenfeld, P. C., \& Paris, A. H. (2004). School engagement: Potential of the concept, state of the evidence. Review of Educational Research, 74(1), 59109. 
Furrer, C., \& Skinner, E. (2003). Sense of relatedness as a factor in children's academic engagement and performance. Journal of Educational Psychology, 95(1), 148162.

Gottfried, A. E., Fleming, J. S., \& Gottfried, A. W. (2001). Continuity of academic intrinsic motivation from childhood through late adolescence: A longitudinal study. Journal of Educational Psychology, 93(1), 3.

Grolnick, W. S., \& Ryan, R. M. (1987). Autonomy in children's learning: An experimental and individual difference investigation. Journal of Personality and Social Psychology, 52, 890-898.

Harter, S. (1981). A new self-report scale of intrinsic versus extrinsic orientation in the classroom: Motivational and informational components. Developmental Psychology, 17, 300-312.

Jang, H., Reeve, J., \& Deci, E. L. (2010). Engaging students in learning activities: it is not autonomy support or structure but autonomy support and structure. Journal of Educational Psychology, 102(3), 588e600.

Janosz, M., Archambault, I., Morizot, J., \& Pagani, L. S. (2008). School engagement trajectories and their differential predictive relations to dropout. Journal of Social Issues, 64(1), 21-40. 
Koestner, R., Ryan, R. M., Bernieri, F., \& Holt, K. (1984). Setting limits on children's behavior: The differential effects of controlling vs. informational styles on intrinsic motivation and creativity. Journal of Personality, 52(3), 233-248.

Ladd, G. W., \& Dinella, L. M. (2009). Continuity and change in early school engagement: Predictive of children's achievement trajectories from first to eighth grade? Journal of Educational Psychology, 101, 190-206.

Lewis, C. C. (1981). How adolescents approach decisions: Changes over grades seven to twelve and policy implications. Child Development, 538-544.

Mahatmya, D., Lohman, B. J., Matjasko, J. L., \& Farb, A. F. (2012). Engagement across developmental periods. In S. L. Christenson, A. L. Reschly \& C. Wylie (Eds.), Handbook of research on student engagement; handbook of research on student engagement (pp. 45-63, Chapter xxvii, 840 Pages) Springer Science + Business Media, New York, NY.

Marsh, H. W. (1990). Causal ordering of academic self-concept and academic achievement: A multiwave, longitudinal panel analysis. Journal of Educational Psychology, 82(4), 646-656.

Martin, A. J., \& Dowson, M. (2009). Interpersonal relationships, motivation, engagement and achievement: Yields for theory, current issues, and educational practice. Review of Educational Research, 79, 327-365. 
Maulana, R., Opdenakker, M.-C., den Brok, P., \& Bosker, R. (2011). Teacher-student interpersonal relationships in Indonesia: Profiles and importance to student motivation. Asia Pacific Journal of Education, 31(1), 33-49.

Murdock, T. B., Anderman, L. H., \& Hodge, S. A. (2000). Middle-grade predictors of students' motivation and behavior in high school. Journal of Adolescent Research, 15(3), 327-351.

Osterman, K. F. (2000). Students' need for belonging in the school community. Review of Educational Research, 70(3), 323-367.

Patall, E. A., Dent, A. L., Oyer, M., \& Wynn, S. R. (2013). Student autonomy and course value: The unique and cumulative roles of various teacher practices. Motivation and Emotions, 37(1), 14-32.

Pianta, R. C., Hamre, B. K., \& Allen, J. P. (2012). Teacher-student relationships and engagement: Conceptualizing, measuring, and improving the capacity of classroom interactions. In S. L. Christenson, A. L. Reschly \& C. Wylie (Eds.), Handbook of research on student engagement (pp. 365-386, Chapter xxvii, 840 Pages) Springer Science + Business Media, New York, NY.

Reeve, J., Jang, H., Carrell, D., Jeon, S., \& Barch, J. (2004). Enhancing students' engagement by increasing teachers' autonomy support ${ }^{1}$. Motivation and Emotion, 28(2), 147-169. 
Reeve, J. (2006). Teachers as facilitators: What autonomy-supportive teachers do and why their students benefit. The Elementary School Journal, 106(3), 225-236.

Reeve, J., \& Jang, H. (2006). What teachers say and do to support students' autonomy during a learning activity. Journal of Educational Psychology, 98(1), 209-218.

Reeve, J. (2009). Why teachers adopt a controlling motivation style toward students and how they can become more autonomy-supportive. Educational Psychologist, 43(3), 159-175.

Reeve, J., Nix, G., \& Hamm, D. (2003). Testing models of the experience of selfdetermination in intrinsic motivation and the conundrum of choice. Journal of Educational Psychology, 95, 375-392.

Reschly, A. L., \& Christenson, S. L. (2012). Jingle, jangle, and conceptual haziness: Evolution and future directions of the engagement construct. In S. L. Christenson, A. L. Reschly \& C. Wylie (Eds.), Handbook of research on student engagement; (pp. 3-19, Chapter xxvii, 840 Pages) Springer Science + Business Media, New York, NY.

Roeser, R. W., Eccles, J. S., \& Sameroff, A. J. (1998). Academic and emotional functioning in early adolescence: Longitudinal relations, patterns, and prediction by experience in middle school. Development and Psychopathology, 10(2), 321352. 
Roeser, R. W., Eccles, J. S., \& Sameroff, A. J. (2000). School as a context of early adolescents' academic and social-emotional development: A summary of research findings. The elementary school journal, 100(5), 443-471.

Roeser, R. W., Midgley, C., \& Urdan, T. C. (1996). Perceptions of the school psychological environment and early adolescents' psychological and behavioral functioning in school: The mediating role of goals and belonging. Journal of Educational Psychology, 88(3), 408-422.

Rogat, T. M., Witham, S. A., \& Chinn, C. (2014). Teachers' autonomy-relevant practices within an inquiry-based science curricular context: Extending the range of academically significant autonomy-supportive practices. Teachers College Record, 116, 1-46.

Ryan, R. M., \& Deci, E. L. (2016). Facilitating and hindering motivation, learning, and well-being in schools: Research and observations from self-determination theory. In K. R. Wentzel \& D. B. Miele (Eds.), Handbook on motivation at schools (pp. 96-119). New York, NY: Routledge.

Ryan, R. M., \& Grolnick, W. S. (1986). Origins and pawns in the classroom: Self-report and projective assessments of individual differences in children's perceptions. Journal of Personality and Social Psychology, 50(3), 550-558.

Selman, R. L. (1980). The growth of interpersonal understanding: Developmental and clinical analyses. San Diego, CA: Academic Press. 
Simmons, R. G., \& Blyth, D. A. (1987). Moving into adolescence: The impact of pubertal change and school context. Hawthorne, NY: Aldine de Gruyter.

Simmons, R. G., Rosenberg, F., \& Rosenberg, M. (1973). Disturbance in the self-image at adolescence. American Sociological Review, 553-568.

Skinner, E. A., Chapman, M., \& Baltes, P. B. (1988). Control, means-ends, and agency beliefs: A new conceptualization and its measurement during childhood. Journal of Personality and Social Psychology, 54, 117-133.

Skinner, E. A., \& Belmont, M. J. (1993). Motivation in the classroom: Reciprocal effects of teacher behavior and student engagement across the school year. Journal of Educational Psychology, 85(4), 571-581.

Skinner, E., Furrer, C., Marchand, G., \& Kindermann, T. (2008). Engagement and disaffection inthe classroom: Part of a larger motivational dynamic? Journal of Educational

Psychology, 100(4), 765-781.

Skinner, E. A., Kindermann, T. A., Connell, J. P., \& Wellborn, J. G. (2009). Engagement and disaffection as organizational constructs in the dynamics of motivational development. In K. R. Wenzel, \& A. Wigfield (Eds.), Handbook of motivation at school; handbook of motivation at school (pp. 223-245, Chapter xiii, 686 Pages) Routledge/Taylor \& Francis Group, New York, NY.

Skinner, E. A., Kindermann, T. A., \& Furrer, C. J. (2009). A motivational perspective on engagement and disaffection: Conceptualization and assessment of children's 
behavioral and emotional participation in academic activities in the classroom. Educational and Psychological Measurement, 69(3), 493-525.

Skinner, E. A., \& Wellborn, J. G. (1994). Coping during childhood and adolescence: A motivational perspective. In D. L. Featherman, R. M. Lerner (Eds.), Life-span development and behavior (pp. 91-133). Hillsdale, NJ: Erlbaum.

Skinner, E. A., Wellborn, J. G., \& Connell, J. P. (1990). What it takes to do well in school and whether I've got it: A process model of perceived control and children's engagement and achievement in school. Journal of Educational Psychology, 82(1), 22-32.

Skinner, E. A., Zimmer-Gembeck, M., \& Connell, J. P. (1998). Individual differences and the development of perceived control. Monographs of the Society for Research in Child Development, 63(2-3), v-220.

Sosic-Vasic, Z., Keis, O., Lau, M., Spitzer, M., \& Streb, J. (2015). The impact of motivation and teachers' autonomy support on children's executive functions. Frontiers in Psychology, 6, 12.

Stipek, D. J., \& Weisz, J. R. (1981). Perceived personal control and academic achievement. Review of Educational Research, 51(1), 101-137

Stroet K., Opdenakker M.-C., Minnaert A. (2013). Effects of need supportive teaching on early adolescents' motivation and engagement: a review of the literature. Educ. Res. Rev. 9 65-87 
Tucker, C. M., Zayco, R. A., Herman, K. C., Reinke, W. M., Trujillo, M., Carraway, K.,...Ivery, P. D. (2002). Teacher and child variables as predictors of academic engagement among low-income african american children. Psychology in the Schools, 39(4), 477-488.

Ullah, H., \& Wilson, M. A. (2007). Students' academic success and its association to student involvement with learning and relationships with faculty and peers. College Student Journal, 41(4), 1192-1203.

Wallace, T. L., Sung, H. C., \& Williams, J. D. (2014).The defining features of teacher talk within autonomy-supportive classroom management. Teaching and Teacher Education, 42, 34-46.

Wang, M. T., \& Eccles, J. S. (2013). School context, achievement motivation, and academic engagement: A longitudinal study of school engagement using a multidimensional perspective. Learning and Instruction, 28, 12-23.

Way, N., Reddy, R. and Rhodes, J. (2007), Students' Perceptions of School Climate During the Middle School Years: Associations with Trajectories of Psychological and Behavioral Adjustment. American Journal of Community Psychology, 40: 194-213.

Wentzel, K. R. (2010). Students' relationships with teachers. In J. L. Meece, \& J. S. Eccles (Eds.), Handbook of research on schools, schooling and human development (pp. 75-91). New York, NY: Routledge. 
Wentzel, K. (2016). Teacher-student relationships. In K. Wentzel \& D. Miele (Eds.), Handbook of Motivation at School, 2nd ed (pp. 211-230). Malwah, NJ: Erlbaum.

Wentzel, K., Muenks, K., McNeish, D., \& Russell, S. (2016) Peer and teacher supports in relation to motivation and effort: a multi-level study. Contemporary Educational Psychology, 49, 32-45.

Yu, C., Li, X., Wang, S., \& Zhang, W. (2016). Teacher autonomy support reduces adolescent anxiety and depression: An 18-month longitudinal study. Journal of Adolescence, 49, 115-123.

Yu, C., Li, X., \& Zhang, W. (2015). Predicting adolescent problematic online game use from teacher autonomy support, basic psychological needs satisfaction and school engagement: a two-year longitudinal study. Cyberpsychology, Behavior, and Social Networking, 18, 228e233.

Zimmer-Gembeck, M. J., Chipuer, H. M., Hanisch, M., Creed, P. A., \& McGregor, L. (2006). Relationships at school and stage-environment fit as resources for adolescent engagement and achievement. Journal of Adolescence, 29, 911—933. 


\section{Appendix: Measures}

\section{Autonomy-Support.}

\section{Respect.}

1. My teacher listens to my ideas.

2. My teacher listens to my opinion.

3. My teacher interrupts me when I have something to say. (-)

4. My teacher doesn't listen to my opinion. (-)

5. My teacher never listens to my side. (-)

\section{Choice.}

1. My teacher gives me a lot of choices about how I do my schoolwork.

2. When it comes to assignments, my teacher gives me all kinds of things to choose from.

3. My teacher doesn't give me much choice about how I do my schoolwork. (-)

4. My teacher doesn't give me a chance to choose anything about my classwork. (-)

5. My teacher doesn't give me many choices when it comes to doing assignments. (-)

\section{Relevance.}

1. My teacher talks about how I can use the things we learn in school.

2. My teacher encourages me to find out how schoolwork could be useful to me.

3. My teacher doesn't explain why what I do in school is important to me. (-)

4. My teacher doesn't explain why we have to learn certain things in school. (-)

5. My teacher never talks about how I can use the things we learn in school. (-)

\section{Coercion.}

1. My teacher is always getting on my case about schoolwork. (-) 
2. My teacher tries to control everything I do. (-)

3. It seems like my teacher is always telling me what to do. (-)

\section{Autonomy.}

\section{Intrinsic Self-Regulation.}

1. Why do I do my homework? Because it's fun.

2. Why do I do my homework? Because I enjoy doing my homework.

3. Why do I work on my classwork? Because it's fun.

4. Why do I work on my classwork? Because I enjoy doing my classwork.

\section{Identified Self-Regulation.}

5. Why do I do my homework? Because I want to understand the subject.

6. Why do I do my classwork? Because I want to learn new things.

7. Why do I work on my classwork? Because I think classwork is important for my learning.

8. Why do I try to do well in school? Because I enjoy doing schoolwork well.

9. Why do I try to do well in school? Because doing well in school is important to me.

\section{Competence.}

1. If I decide to learn something hard, I can.

2. I can do well in school if I want to.

3. I can get good grades in school.

4. I can't get good grades no matter what I do. (-) 
5. I can't stop myself from doing poorly in school. (-)

6. I can't do well in school, even if I want to. (-)

\section{Relatedness.}

\section{Emotional Security with Teacher.}

1. When I'm with my teacher, I feel accepted.

2. When I'm with my teacher, I feel like someone special.

3. When I'm with my teacher, I feel ignored. (-)

4. When I'm with my teacher, I feel unimportant. (-)

\section{Engagement.}

\section{Emotional Engagement.}

1. When I'm working on my classwork, I feel relaxed.

2. When I'm working on my classwork, I feel involved.

3. When I'm working on my classwork, I feel nervous. (-)

4. When I'm working on my classwork, I feel mad. (-)

5. When I'm doing my work in class, I feel worried. (-)

6. When I'm doing my work in class, I feel bored. (-)

\section{Behavioral Engagement.}

7. I try very hard in school.

8. I participate in class discussions.

9. In class, I try to do just enough to get by. (-) 